\title{
Trace element inventory of meteoritic Ca-phosphates
}

\author{
Dustin Ward ${ }^{1}$, Addi Bischoff ${ }^{1}$, Julia Roszjar ${ }^{2}$, Jasper Berndt ${ }^{3}$ and Martin J. Whitehouse ${ }^{4}$
}

${ }^{1}$ Institut für Planetologie, Westfälische Wilhelms-Universität Münster, Wilhelm-Klemm-Str. 10, 48149 Münster, Germany

2Department of Mineralogy and Petrography, Natural History Museum Vienna, Burgring 7, 1010 Vienna, Austria

${ }^{3}$ Institut für Mineralogie, Westfälische Wilhelms-Universität Münster, Corrensstraße 24, 48149 Münster, Germany

${ }^{4}$ Department of Geosciences, Swedish Museum of Natural History, Box 50007, 10405 Stockholm, Sweden

\begin{abstract}
Most extraterrestrial samples feature the two accessory Ca-phosphates - apatite-group minerals and merrillite, which are the dominating carrier phases of the rare earth elements (REE). The trace element concentrations (REE, Sc, Ti, V, Cr, Mn, Co, As, Rb, Sr, Y, Zr, Nb, Ba, Hf, Ta, Pb, Th and U) of selected grains were analyzed by LA-ICP-MS and/or SIMS (REE only). This systematic investigation includes 99 apatite and 149 merrillite analyses from meteorites deriving from various asteroidal bodies including one carbonaceous chondrite, eight ordinary chondrites, three acapulcoites, one winonaite, two eucrites, five shergottites, one ureilitic trachyandesite, two mesosiderites and one silicated IAB iron meteorite.

Although Ca-phosphates predominantly form in metamorphic and/or metasomatic reactions, some are of igneous origin. As late-stage phases that often incorporate a vast majority of their host's bulk REE budget, the investigated Ca-phosphates have REE enrichments of up to two orders of magnitude compared to the host rocks bulk concentrations. Within a single sample, each phosphate species displays a uniform REE-pattern, and variations are mainly restricted to their enrichment, therefore indicating similar formation conditions. Exceptions are brecciated samples, i.e., the AdzhiBogdo (LL3-6) ordinary chondrite. Despite this uniformity within single samples, distinct meteorite groups do not necessarily have unique REE-patterns. Four basic shapes dominate the REE patterns of meteoritic Ca-phosphates: (1) Flat patterns, smoothly decreasing from La-Lu with prominent
\end{abstract}


negative $\mathrm{Eu}$ anomalies (acapulcoites, eucrites, apatite from the winonaite and the ureilitic trachyandesite, merrillite from ordinary chondrites); (2) unfractionated patterns, with only minor or no anomalies (mesosiderites, enriched shergottites, IAB-iron meteorite); (3) LREE-enriched patterns, with either positive or slightly negative Eu anomalies (chondritic apatite); and (4) strongly LREEdepleted patterns, with negative Eu anomalies (depleted shergottites). Although patterns do not correlate with the grade of metamorphism (petrologic type), adjacent mineral assemblages or with Ca-phosphate grain size. Neither the proportions of different REE, nor particular REE patterns themselves are universally correlated to a specific formation mechanism yet Eu (i.e., magnitude of the Eu anomaly) is a sensitive indicator to evaluate the timing of plagioclase and phosphate crystallization. Based on our data $\mathrm{U}$ and Th abundances in apatite, increase (almost linearly) with the grade of metamorphism, as well as with the differentiation of their host rock.

\section{Keywords}

Meteorites, apatite, merrillite, La-ICP MS, SIMS, trace elements, REE 


\section{Introduction}

Although Ca-phosphates are only accessory phases in numerous meteorite classes, they are ubiquitous and represent the predominant phosphorous $(\mathrm{P})$ reservoir in meteorites. The most common meteoritic Ca-phosphate species are apatite-group minerals $\left[\mathrm{Ca}_{5}\left(\mathrm{PO}_{4}\right)_{3}(\mathrm{~F}, \mathrm{Cl}, \mathrm{OH})\right]$ (later referred to as apatite) and merrillite $\left[\mathrm{Ca}_{9} \mathrm{NaMg}\left(\mathrm{PO}_{4}\right)_{7}\right]$, with the latter being devoid of hydrogen with respect to the predominantly terrestrial whitlockite $\left[\mathrm{Ca}_{9} \mathrm{Mg}\left(\mathrm{PO}_{4}\right)_{6}\left(\mathrm{PO}_{3} \mathrm{OH}\right)\right]$ (e.g., Hughes et al. 2008). Although both terms, whitlockite and merrillite, are still often used interchangeably in descriptions of extraterrestrial material, we concur with Rubin (1997) and Jones et al. (2014) and refer to the anhydrous, $\mathrm{Na}$ - and $\mathrm{Mg}$-bearing $\mathrm{Ca}$-phosphate phase within our sample suite as merrillite. However, a (hydrated) whitlockite component, especially in Martian meteorites, can not be excluded (Shearer et al. 2015). Detailed chemical and structural information on merrillite is given i.e. by Jolliff et al. (1993, 2006), Hughes et al. (2008), and Xie et al. (2015).

This study focusses on meteoritic apatite and merrillite deriving from diverse asteroidal bodies in the inner Solar System. Both species occur in varying abundances and their grain sizes range from a few micrometers to millimeters. They usually coexist, but one or the other may be absent in some samples. While both species are considered to be of metamorphic origin in (most) chondrites (Brearley and Jones 1998; Jones et al. 2014) and many differentiated meteorites (e.g. Crozaz et al. 1985; Davis and Olsen 1991), an igneous origin has been inferred for Ca-phosphates from some meteorite groups or individual samples, e.g. eucrites (Delaney 1982, 1984a, 1984b), shergottites (McCubbin et al. 2012; Sarafian et al. 2013, 2017; Shearer et al. 2015), the ureilitic trachyandesite ALM-A (Bischoff et al. 2014), as well as (at least) some of the phosphates in pallasites (Davis and Olsen 1991) and lunar rocks (Delaney 1984b). Ca-phosphates are abundant accessory phases in lunar meteorites and a major source of volatiles in these rocks (e.g., Joy et al. 2014; Boyce et al. 2014, and refs therein). However, the severe brecciation and overprint by shock, igneous activity and/or even 
aqueus alteration in lunar meteorites and rocks might obscure primary mineral parageneses and prevents the exact assignment of phosphates to their original source lithologies in many cases.

The formation of metamorphic Ca-phosphates in chondrites is assumed to be initiated with the oxidation of phosphorous initially located in chondrules or dissolved in Fe,Ni-metal, which then reacts with surrounding silicates (olivine, pyroxene, etc.) to form the phosphates (Brearley and Jones 1998; Jones et al. 2014). Moreover, a metasomatic contribution to Ca-phosphate fomation during metamorphism is discussed for some ordinary chondrites (Jones et al. 2014, 2016; Lewis and Jones 2016). Since igneous phosphates are formed late within the crystallization sequence of their parent melt (Delaney 1984b; Davis and Olsen 1991; Shearer et al. 2015), they may incorporate high amounts of incompatible trace elements, especially the rare earth elements (REEs), $\mathrm{U}$ and Th.

Although Ca-phosphates occur only as accessory phases (most meteorites do not exceed $1 \mathrm{vol} \%$ of both phosphate species combined), they are, if present, the dominant carrier phases for the REEs, as well as for halogens (F, Cl, Br, I) and hydrogen. Halogens are predominately incorporated in apatite, although merrillite is also capable to incorporate minor amounts of $\mathrm{F}$ and $\mathrm{Cl}$ (e.g., McCubbin et al. 2014). If apatite occurs, its halogen content usually reflects that of the bulk host sample (e.g., Roszjar et al. 2013) and therefore igneous apatite is frequently examined to gain insight into the volatile evolution of planetary bodies; e.g. Mars (Bellucci et al. 2016), the Moon (Boyce et al. 2014) or the parent body of the howardite-eucrite-diogenite (HED) suite of meteorites (Sarafian et al. 2013, 2017). Furthermore, it is also often used to establish constraints on the composition and evolution of the magma from which it has crystallized (e.g., Jolliff et al. 1993, Patiño-Douce and Roden 2006; Patiño-Douce et al. 2011; McCubbin et al. 2010, 2011, 2014; Gross et al. 2013; Sarafian et al. 2013, 2017). Since chondrites have not been melted since their accretion (despite heating to varying degrees), their REE budget is not altered by secondary fractionation which enables their use for constraining processes in the early Solar System. In differentiated 
meteorites the REE provide clues for igneous fractionation processes affecting the parent body and enable constraints on its magmatic evolution.

Numerous investigations have examined the extremely high concentrations of REE in meteoritic phosphates - in eucrites they exhibit enrichments of up to 30,000 $\times$ CI (Delaney et al. 1984b). These investigations have covered both chondritic (e.g., Van Schmus and Ribbe 1969; Ebihara and Honda 1983; Reed et al. 1983; Reed and Smith 1984; Crozaz and Zinner 1985; Crozaz et al. 1989) and achondritic samples (Delaney 1982; Delaney et al. 1984a, 1984b; Laul and Smith 1986; Davis et al. 1993; Zipfel et al. 1995; Hsu and Crozaz 1996; Shearer et al. 2015). Overall, Caphosphates provide valuable insight into the genesis and evolution of their host rocks. Nevertheless, their abundances, distribution and formation mechanisms remain poorly constrained. Therefore, we present a survey of occurrences, phase associations, mineralogy, and trace element chemistry of apatite and merrillite in a comprehensive dataset extending over twelve asteroidal meteorite (sub)groups. Preliminary data on the sample suite discussed here has been published in Ward et al. $(2014,2015,2016)$.

\section{Material and Analytical Methods}

The analysed thin sections are part of the meteorite collection at the Institut für Planetologie of the Westfälische Wilhelms-Universität (WWU) Münster, Germany; the meteorites and thin section numbers are given in Table 1. Despite their rarity in some meteorite groups, over 600 Ca-phosphate grains within twelve different meteorite (sub)groups were documented chemically and petrographically. The trace element concentration - with particular emphasis on the REEs - of

selected grains was analyzed by laser ablation inductively coupled plasma mass spectrometry (LAICP-MS) at the University of Münster (Germany) and/or secondary ion mass spectrometry (SIMS) at the NordSIMS Laboratory in Stockholm (Sweden). This dataset covers ordinary chondrites, a 
carbonaceous chondrite, acapulcoites, eucrites, shergottites, winonaites, mesosiderites, as well as from one IAB iron meteorite and an ureilitic trachyandesite (Table 1).

\section{Scanning Electron Microscopy}

A JEOL 6610-LV electron microscope (SEM) at the WWU Münster was used to locate, identify and document the Ca-phosphates and the parageneses in which they are assembled. The chemical characterizations of the different mineral constituents were obtained by an attached EDS system (INCA; Oxford Instruments) operating at $20 \mathrm{kV}$, while the beam current was controlled by a Faraday cup. The different P-bearing phases were identified by multiple element mappings, each conducted with three frames with a dwell time of $250-950 \mu \mathrm{s}$. The reference materials used for semiquantitative analysis were (Astimex) apatite $(\mathrm{P}, \mathrm{Ca}, \mathrm{F})$, tugtupite $(\mathrm{Cl})$, olivine $(\mathrm{Mg}, \mathrm{Fe}, \mathrm{Si})$, jadeite $(\mathrm{Na})$, plagioclase $(\mathrm{Al})$, sanidine $(\mathrm{K})$, rutile $(\mathrm{Ti})$, rhodonite $(\mathrm{Mn})$, chromium oxide $(\mathrm{Cr})$ and pentlandite $(\mathrm{Ni})$.

\section{Electron Microprobe Analysis}

Quantitative analyses of the Ca-phosphates were conducted with a JEOL JXA 8900 Superprobe electron microprobe. It was operated at $15 \mathrm{keV}$ accelerating voltage with a defocused beam of $5 \mu \mathrm{m}$ at a beam current of $10 \mathrm{nA}$. In total, 15 elements were measured using the following standards: Astimex fluorite (Ca, F), Astimex apatite (P), USNM Rockport fayalite (Fe), USNM San Carlos olivine $(\mathrm{Mg})$, rhodonite $(\mathrm{Mn})$, celestine $(\mathrm{Sr}, \mathrm{S})$, jadeite $(\mathrm{Na})$, sanidine $(\mathrm{K})$, hypersthene (Si), Astimex rutile (Ti), kyanite (Al), Astimex chromium oxide (Cr) and Astimex tugtupite (Cl). For apatite, $\mathrm{F}$ and $\mathrm{Cl}$ concentrations were measured first and exposed to a lower beam current of $5 \mathrm{nA}$ to prevent migration or loss of volatiles. Counting times were $10 \mathrm{~s}$ on peak and $5 \mathrm{~s}$ on background, except for $\mathrm{Cl}, \mathrm{F}, \mathrm{Na}$ and $\mathrm{K}$, which were $7 \mathrm{~s}$ on peak and $3.5 \mathrm{~s}$ on background. The matrix corrections were made according to the $\Phi \varrho(z)$ procedure outlined by Armstrong (1991).

The hydroxyl component in apatite had to be calculated by difference according to atomic 
proportions based on the number of oxygens and assuming an occupancy of the X-site with two anions, giving a total of $\mathrm{X}_{\mathrm{Cl}}+\mathrm{X}_{\mathrm{F}}+\mathrm{X}_{\mathrm{OH}}=2$. The calculated $\mathrm{OH}$-fraction of the apatite $\mathrm{X}$-site may therefore also include other anions besides $\mathrm{F}$ and $\mathrm{Cl}$ (e.g., $\mathrm{Br}$ or $\mathrm{I}$ ) and/or also possible vacancies in the apatite crystal structure.

\section{Laser Ablation Inductively Coupled Plasma Mass Spectrometry}

The abundances of 32 trace elements (supplemental table S1) for Ca-phosphate grains larger than $25 \mu \mathrm{m}$ were analyzed at the Institut für Mineralogie (WWU Münster) by a Finnigan Element 2 single collector ICP-MS coupled with Excimer laser ablation system (Analyte G2, Photon Machines). The latter provided an output wavelength of $193 \mathrm{~nm}$ and was operated with a fluence of $3 \mathrm{~J} / \mathrm{cm}^{2}$ and a repetition rate of $5 \mathrm{~Hz}$. Counting times were $40 \mathrm{~s}$ on peak signals and $20 \mathrm{~s}$ on background respectively. The spot-size was adjusted for each grain depending on its size and condition (e.g., cracks, inclusions, etc.) and varied from 25-65 $\mu \mathrm{m}$. Reference material was NIST-SRM 612 glass. For quantification ${ }^{43} \mathrm{Ca}$ was used as internal standard. To keep track of precision and accuracy basaltic BIR-1G (Gladney and Roelandts 1988) and phosphatic STDP5 (Klemme et al. 2008) reference glasses were measured as unknowns over the course of this study. Results are given in supplemental Table S2.

\section{Secondary Ion Mass Spectrometry}

The REE concentrations of Ca-phosphates smaller than $25 \mu \mathrm{m}$ were analyzed by a Cameca IMS 1280 large geometry ion microprobe at the Swedish Museum of Natural History, Stockholm (NordSIMS laboratory). The analytical protocol corresponds tothat described by Lepland and Whitehouse (2011): The ellipsoidal (long axis: $\sim 20 \mu \mathrm{m}) \mathrm{O}_{2}{ }^{-}$primary beam operated with an incident energy of $23 \mathrm{kV}$. Spot sizes of $5 \mu \mathrm{m}, 7 \mu \mathrm{m}$ or $20 \mu \mathrm{m}$ (corresponding beam currents of $0.5 \mathrm{nA}, 1 \mathrm{nA}$ and $13 \mathrm{nA}$ ) were chosen according to the shape and size of the grains, using Köhler illuminated apertures in the primary column. 
The REE species were determined as $\mathrm{M}^{+}$ions on an ion-counting electron multiplier by a peakhopping routine comprising the REE and two apatite matrix peaks, ${ }^{40} \mathrm{Ca}_{2}{ }^{31} \mathrm{P}^{16} \mathrm{O}_{3}$ and ${ }^{40} \mathrm{Ca}_{2}{ }^{31} \mathrm{P}^{16} \mathrm{O}_{4}$. Following a 60 second pre-sputter over a rastered area of $25 \times 25 \mu \mathrm{m}$ to remove the Au coating, the beam was centered in the field aperture and secondary ion energy optimized in a $60 \mathrm{eV}$ energy window using the ${ }^{40} \mathrm{Ca}_{2}{ }^{31} \mathrm{P}^{16} \mathrm{O}_{3}$ species. These steps were followed by mass calibration adjustment using the ${ }^{40} \mathrm{Ca}^{31} \mathrm{P}^{16} \mathrm{O},{ }^{40} \mathrm{Ca}_{2}{ }^{31} \mathrm{P}^{16} \mathrm{O}_{3}{ }^{139} \mathrm{La}$, and ${ }^{40} \mathrm{Ca}_{2}{ }^{31} \mathrm{P}^{16} \mathrm{O}_{4}$ species. The mass spectrometer was set at a mass resolving power $(\mathrm{MRP})$ of $\sim 10,000(\mathrm{M} / \Delta \mathrm{M})$ with a $35-\mu \mathrm{m}$ entrance slit together with a $122-\mu \mathrm{m}$ exit slit to adequately separate heavy (HREE) ions from those of interfering light oxide species. After the centering and beam optimization steps, the data acquisition mass sequence comprised 16 scans with an overall integration time of $120 \mathrm{~s}$ each. Durango apatite was used as in-house reference material, analyses of which were regularly interspersed with the unknowns. Durango REE concentrations used for normalization are given in the supplemental table S3.

\section{Results}

The data obtained are consistent with existing trace element analyses covering the respective meteorite groups (e.g., Delaney et al. 1984b; Crozaz and Zinner, 1985; Crozaz et al. 1989; Davis et al. 1993; Wadhwa et al. 1993; Hsu and Crozaz, 1996; Jones et al. 2014), including a few samples which have been analyzed previously (e.g., Zipfel et al. 1995; Ruzicka et al. 2005; Shearer et al. 2015). Multiple analyses with both methods - LA-ICP-MS and SIMS - were applied on several apatite and merrillite grains within different samples (Devgaon, Villalbeto de la Peña, Acapulco, Northwest Africa (NWA) 5073), all providing consistent results. One representative example is provided in supplementary Figure S1, showing an apatite grain from Acapulco with the location of multiple spots of all applied methods, the corresponding REE data, as well as the range of literature values. 


\section{Occurrence and Distribution of Ca-phosphates}

Ca-phosphates are ubiquitous, yet accessory minerals within the sample suite, but both species do not necessarily occur simultaneously in the same meteorite. In the carbonaceous chondrite Karoonda (CK4), the acapulcoite Dhofar 125 and the winonaite Hammadah al Hamra (HaH) 193, only apatite was observed; whereas in the Allegan H5 ordinary chondrite, the acapulcoite NWA 1052, the depleted shergottites Sayh al Uhaymir (SaU) 005 and Dar al Gani (DaG) 1051, as well as in the mesosiderites Dalgaranga and Bondoc, only merrillite was found (Table 1).

\section{Chondrites}

Chondritic Ca-phosphates are predominantly located in two main mineral associations, independent from their host's chondrite class: (1) at the metal-sulfide interface (Fig. 1) and (2) in parageneses with silicates (Figs. 2-3). They are observed next to or in a few cases also within chondrules or in silicate fragments (Figs. 2-3), within the matrix (Figs. 2c and 3c) or in one case, in contact with a Ca,Al-rich inclusion (CAI; Fig. 2b). However, the occurrence within chondrules and also the direct contact to CAIs is rather uncommon. The dominant assemblages are the metal-sulfide interface and, for higher petrologic types, silicate assemblages in recrystallized areas. Phase abbreviations used in Figs. 1-3 are: Ap = apatite, $\mathrm{Mer}=$ merrillite, $\mathrm{Px}=$ low-Ca pyroxene, $\mathrm{Plg}=$ plagioclase, $\mathrm{Fsp}=$ feldspar, $\mathrm{Ol}=$ olivine, $\mathrm{SiO}_{2}=$ silica polymorph, $\mathrm{FeS}=$ iron-sulfide, $\mathrm{Kam}=$ kamacite, Tae $=$ taenite, $\mathrm{Chr}=$ chromite, $(\mathrm{Ti}-) \mathrm{Mag}=(\mathrm{Ti}-)$ magnetite, $\mathrm{Ilm}=$ ilmenite, $\mathrm{Sp}=$ spinel .

(1) Phosphates at the metal-sulfide interface (Fig. 1) are often located adjacent to or, in a few cases, enveloping sulfides and/or Fe-Ni-metal (Figs. 1a and b). They also occur as inclusions in metal (Fig. 1c), metal-sulfide intergrowths or with iron oxides (e.g. magnetite, Fig. 1d). Apatite in the metaland sulfide-dominated associations varies in size independently of the chondrite class, ranging from 15 to $350 \mu \mathrm{m}$; merrillite tends to reach slightly larger sizes, ranging from 20 to $450 \mu \mathrm{m}$. Both species increase in average grain size with higher petrologic types of their host rocks. Both apatite and 
merrillite usually exhibit subhedral to anhedral shapes, and sometimes contain small inclusions of silicates, metal or sulfides (Fig. 1a).

(2) Assemblages with silicates (predominantly pyroxene, olivine, and plagioclase) are common as well (Fig. 2). Metal or sulfides may be located in the vicinity, but the majority of the anhedral to subhedral phosphate grains are in contact with the silicates (Fig. 2a). In rare cases, both Caphosphate species occur intergrown, or may be replaced by each other. In each meteorite sample, the phosphate grain sizes in silicate association are slightly larger compared with those in phosphatemetal-sulfide assemblages, except for Landes (silicated IAB iron meteorite) and $\mathrm{HaH} 193$ (winonaite). The H3.8 chondrite Devgaon contains the unique assemblage of a CAI enveloped by several anhedral merrillite grains (Fig. 2b). Within the Karoonda CK4 carbonaceous chondrite, the only Ca-phosphates observed are sub- to anhedral apatite grains with a maximum size of $50 \mu \mathrm{m}$, occurring as fragments in contact with low-Ca pyroxene and plagioclase. All phases in this particular assemblage contain tiny inclusions of magnetite (Fig. 2c). Yet merrillite assemblages with pentlandite, troilite and schreibersite have been reported from other subgroups of carbonaceous chondrites (e.g. in CV and CO chondrites by Rubin and Grossman 1985).

The LL3-6 chondritic regolith breccia Adzhi-Bogdo (stone) has different Ca-phosphate bearing lithologies. It is highly metamorphosed, and hence recrystallized petrologic type 6 fragments frequently contain both apatite and merrillite (Figs. 3a-b), with apatite beeing more abundant than merrillite (Table 1). Ca-phosphates do occur, but are uncommon in the less- metamorphosed fragments and also the fine-grained matrix. Additionally, subhedral to euhedral apatite and merrillite grains are present in differentiated fragments (Fig. 3c-d) with clearly achondritic textures (alkaligranitoids or pyroxene-rich clasts with exsolution features), which have been previously described by Bischoff et al. (1993), Sokol et al. (2007a), and Terada and Bischoff (2009). 


\section{Differentiated meteorites}

Ca-phosphate-bearing mineral parageneses in achondrites commonly occur interstitial to the major rock-forming silicate, or within the late-crystallizing, incompatible-element enriched mesostasis areas. They are often more abundant than in chondrites (Table 1). Apatite can reach large grain-sizes of several hunded $\mu \mathrm{m}$ (e.g., Fig. 1c) and the grain shapes are predominantly anhedral to subhedral, except for apatite in two samples: apatite grains in the winonaite $\mathrm{HaH} 193$ tend to be elongated in shape, and the ureilitic trachyandesite ALM-A (Bischoff et al. 2014) contains euhedral, lath-shaped grains coexisting with feldspar and pyroxene (Fig. 2d). The lath sizes are up to $200 \mu \mathrm{m}$ in their longest dimension. In basaltic eucrites and shergottites, the silicate-dominated assemblages also include ilmenite, a $\mathrm{SiO}_{2}$-polymorph, as well as frequently observed chromite (Fig. 2e-f). In addition to the typical silicates, chromite and ilmenite occur as small inclusions within both Ca-phosphates (Figs. 2e-f). Merrillite in shergottites consistently exhibits larger grain sizes (mostly 50-500 $\mu \mathrm{m}$ ), in rare cases at the millimeter scale (Fig. 2f), while apatite remains in a range of 20-300 $\mu \mathrm{m}$. Furthermore, the enriched shergottite Kshar Ghilane (KG) 002 features an assemblage of merrillite with symplectites: fine-grained vermicular to microgranulitic textures dominated by intergrowths of fayalite, Ca-pyroxene, and silica (Fig. 2f); a detailed petrographic description is given by Llorca et al. (2013).

\section{Chemical Composition}

Tables $2 \mathrm{a}$ and $2 \mathrm{~b}$ give the average major element chemistry of apatite and merrillite for each sample. Individual analyses in $\mathrm{wt}^{\%} \%$, as well as atoms per formular unit (apfu) and the mole fraction $\mathrm{Mg} /(\mathrm{Mg}+\mathrm{Fe})$ are provided in the supplementary material (Table S1). Ionic quotas were determined according to atomic proportions based on 26 oxygens for apatite $\left(\mathrm{Ca}_{5}\left(\mathrm{PO}_{4}\right)_{3}(\mathrm{OH}, \mathrm{F}, \mathrm{Cl})\right)$ and 56 oxygens for merrillite $\left(\mathrm{Ca}_{18} \mathrm{Na}_{2} \mathrm{Mg}_{2}\left(\mathrm{PO}_{4}\right)_{14}\right)$. Figure 4 illustrates the observed chemical variations in the $\mathrm{FeO}, \mathrm{MgO}$, and $\mathrm{Na}_{2} \mathrm{O}$ content of apatite and merrillite. 
Compared to apatite, merrillite has higher concentrations of $\mathrm{Mg}, \mathrm{Na}$, and $\mathrm{Fe}$, as these elements are major structural constituents, which show considerable variations (Figs. $4 \mathrm{a}$ and c). In most meteorite groups, the merrillite $\mathrm{MgO}$ content varies between 3.1 and $3.8 \mathrm{wt} \%$, with a few merrillite grains from the Millbillillie eucrite extending the merrillite range down to $2.82 \mathrm{wt} \% \mathrm{MgO}$ (Fig. 4a). Merrillite in the enriched shergottites NWA 4864 and Zagami stands out due to its significantly lower $\mathrm{MgO}\left(1.89-2.48 \mathrm{wt}^{\%} \%\right)$ and higer $\mathrm{FeO}\left(2.46-3.4 \mathrm{wt}^{\mathrm{0}} \%\right)$ content compared to those occurring in the depleted subgroup (Fig. 4a). Merrillite from mesosiderites and eucrites has the lowest $\mathrm{Na}_{2} \mathrm{O}$ concentration $(\leq 1.1 \mathrm{wt} \%$; Fig. 4c). The mesosiderite Dalgaranga also has the highest spread in merrillite $\mathrm{FeO}$ content (1.58-5.02 wt\%), while merrillite from the Bondoc mesosiderite lies in the upper range of all samples ( up to $5 \mathrm{wt} \%$; Fig. 4).

In apatites, the $\mathrm{MgO}$ concentration ranges from 0.01 to $0.45 \mathrm{wt} \%$, but within each sample variations are only minor. Apatites in specific meteorite groups display distinct chemical ranges: apatite grains in ordinary chondrites, shergottites and eucrites have the lowest $\mathrm{MgO}$ contents $(0.01$ $0.19 \mathrm{wt} \%$ ), while apatite from the CK carbonaceous chondrite, acapulcoites, the winonaite and the IAB iron meteorite plot in the range of $0.15-0.3 \mathrm{wt} \% \mathrm{MgO}$. Apatite with the highest $\mathrm{MgO}$ and $\mathrm{Na}_{2} \mathrm{O}$ abundances is found in the ureilitic trachyandesite from the Almahata Sitta meteorite breccia (up to $0.45 \mathrm{wt} \% \mathrm{MgO}$ and $0.62 \mathrm{wt} \% \mathrm{Na}_{2} \mathrm{O}$; Figs. $4 \mathrm{~b}$ and d). The remaining apatites plot in two fields of the diagram: Those from most ordinary chondrites and the IAB iron meteorite have $\mathrm{Na}_{2} \mathrm{O}$ contents of 0.2-0.50 wt $\%$, while apatite from the remaining groups does not exceed $0.25 \mathrm{wt} \% \mathrm{Na}_{2} \mathrm{O}$. Only apatite from the Adzhi-Bogdo regolith breccia ranges from $0.13-0.33 \mathrm{wt} \% \mathrm{Na}_{2} \mathrm{O}$, yet no internal trend emerges between the dominant chondritic portion and the differentiated clasts (Fig. 4 and Table 3). In some cases, the $\mathrm{Na}$-concentrations are below the detection limit. This is the case for the winonaite sample, as well as for some apatite grains from eucrites (Table 3). Overall, apatite exhibits considerable variation in their $\mathrm{FeO}$ content (Fig. $4 \mathrm{~b})$. The spread in $\mathrm{FeO}$ is quite large $(\geq 1 \mathrm{wt} \%)$ in 
chondrites (Ybbsitz (H4): 0.36-2.27 wt\% and Karoonda (CK4): 0.59-1.76 wt\%), and the winonaite $\mathrm{HaH} 193(0.14-1.49 \mathrm{wt} \%)$. It is much smaller $(\leq 1 \mathrm{wt} \%)$ in acapulcoites $\left(0.07-0.85 \mathrm{wt}^{\mathrm{t}} \%\right)$, shergottites (0.40-0.99 wt $\%)$ and eucrites (0.64-1.41 wt $\%$; Fig. 4b).

Since $\mathrm{OH}$ could not be determined by electron microprobe measurements, it had to be calculated by difference. Therefore, this X-site component may also include other substitutions (e.g., Br or I; Roszjar et al. 2013) or vacancies in the apatite crystal structure. Furthermore Jones et al. (2014) demonstrated by SIMS measurements that apatite from several LL chondrites is very dry $\left(<96 \mathrm{ppm} \mathrm{H}_{2} \mathrm{O}\right)$, although the calculated difference accounts for up to $26 \%$ of the X-Site occupied by the $\mathrm{OH} \pm$ "other" component. Figure 5 demonstrates the variation of the apatite X-site composition within the analyzed sample suite. Ordinary chondrites contain apatite with the highest $\mathrm{Cl}$ content (up to $94 \%$ occupancy of the $\mathrm{X}$-site) and also a large variation within their X-site composition, (up to a measured occupation of $40 \% \mathrm{~F}$ ). Within literature data, the occupancy extends to 75\% F and 65\% OH (Patiño-Douce and Roden 2006; Jones et al. 2014; McCubbin and Jones 2015; Fig. 5a). These variations do not correlate with the subdivision of the ordinary chondrites into $\mathrm{H}, \mathrm{L}$ and LL chondrites. Apatite from the carbonaceous chondrites have similar $\mathrm{Cl}$ contents, but lower $\mathrm{F}$ abundances (14-17\% occupation of the $\mathrm{X}$-site) and higher $\mathrm{OH} \pm$ "other" proportions (up to $33 \%$ of their X-site; Fig. 5b). The X-site of apatite from differentiated meteorites has higher F content than in chondritic samples. Apatite from primitive achondrites additionally has a very low $\mathrm{OH} \pm$ "other" fraction: apatite from acapulcoites does not exceed 7\% $\mathrm{OH} \pm$ "other" occupancy of its X-site (Table 3). Apatite from acapulcoites in this study is F-rich (Fig. 5c), although literature data includes quite a large range of $\mathrm{Cl}$ and $\mathrm{F}$ occupancy (25-65\% and 35-75\%, respectively; Patiño-Douce and Roden, 2006). Apatite from the winonaite $\mathrm{HaH} 193$ lacks the $\mathrm{OH} \pm$ "other" component in its X-site and exhibits high F abundances (90-96\% X-site occupation; Fig. 5c). The X-site of apatite in the ureilitic trachyandesite ALM-A has a F/Cl value of approximately one (Fig. 5c), while apatite 
from eucrites predominantly clusters at the F-endmember (up to 97\% X-site occupancy), but the $\mathrm{OH}$ fraction reaches up to 30\% (Fig. 5c). Apatite in Martian meteorites exhibits a large variety in composition of their X-sites (Fig. 5d). Even within a single sample, significant variations exist and they exhibit the highest $\mathrm{OH} \pm$ "other" content within our sample set.

\section{Trace Element Inventory}

Rare Earth Elements (REE). Table 3 gives the average REE concentrations for apatite and merrillite from the sample suite studied in this work; individual analyses are provided within the supplementary material (Table S1). The REE appear evenly distributed within individual Caphosphate grains, as multiple analyses of the same grains overlap within error, which is illustrated in supplementary figure S1. Achondritic phosphates generally show significantly higher REE contents compared to chondritic samples (up to $21,000 \times \mathrm{CI}$ and up to $300 \times \mathrm{CI}$, respectively; Figs. 6-9). If both species are present, merrillite typically exceeds apatite in its REE enrichment by an order of magnitude (Table 3, Figs. 6-9).

Within a single sample, each phosphate species, regardless of its mineral assemblage, typically displays a constant shape of the REE-pattern, i.e., if variations occur, they are mainly restricted to the REE enrichment and not to the particular shape.

REE in Apatite. Apatite shows two different primary shapes of REE patterns. In general, chondrites have fractionated patterns with either positive or negative Eu anomalies (Fig. 6), while achondrites have smoothly fractionated patterns with prominent negative Eu anomalies (Fig. 7). In all investigated chondrites, apatite does not exceed an overall REE enrichment of $125 \times \mathrm{CI}$ and shows an enrichment of the LREE (La-Sm) over the HREE (Gd-Lu), with a ratio of $\mathrm{La} / \mathrm{Lu} \approx 2.6$ 8.4. However, chondrites show variation with respect to the Eu concentration in apatite. Europium anomalies are given as the ratio between $\mathrm{Eu}$ and the calculated value Eu* (interpolation between chondrite-normalized Sm and Gd abundances) expected on a smooth chondrite-normalized plot. 
While a distinct positive Eu anomaly (Fig. 6a) is observed in apatite from the ordinary chondrites Devgaon $\left(\mathrm{H} 3.8 ; \mathrm{Eu} / \mathrm{Eu}^{*} \approx 2.14\right)$ and Portales Valley $\left(\mathrm{H} 6 ; \mathrm{Eu} / \mathrm{Eu}^{*} \approx 3.35\right)$, a slightly negative Eu anomaly and a slightly higher overall REE enrichment (Fig. 6b) occur in apatite from the ordinary chondrites Ybbsitz $\left(\mathrm{H} 4 ; \mathrm{Eu} / \mathrm{Eu}^{*} \approx 0.88\right)$, Bruderheim (L6; Eu/Eu* $\left.\approx 0.71\right)$, and Villalbeto de la Peña $\left(\mathrm{L} 6 ; \mathrm{Eu} / \mathrm{Eu}^{*} \approx 0.75\right)$. The range and slope of the patterns coincide with the apatite REE data reported by Crozaz et al. (1989; Figs. 6a and b), yet previous data only included negative Eu anomalies. Apatite from the carbonaceous chondrite Karoonda (CK4) does not have a Eu anomaly, but is slightly enriched in Ce and Pr (Fig. 6c). Within the chondritic portion of the Adzhi-Bogdo breccia, REE in apatite show the characteristic smooth slope from La to $\mathrm{Lu}$ and no or only a minor Eu anomaly (Fig. 6d). However, those in the differentiated clasts (achondritic fragments) have flat REE patterns $(\mathrm{La} / \mathrm{Lu} \approx 0.94-1.34)$ and a prominent negative Eu anomaly $\left(\mathrm{Eu} / \mathrm{Eu}^{*} \approx 0.21\right)$, similar to apatites from differentiated meteorites (Fig. 7).

Apatite from achondritic samples is significantly more enriched in REE and shows slightly fractionated to flat REE-patterns with a pronounced negative Eu anomaly (Fig. 7). Apatite from the acapulcoites Dhofar 125 and Acapulco (Fig. 7a), as well as from the ureilitic trachyandesite ALM-A (Fig. 7b) exhibit similar enrichment of up to $300 \times$ CI. Their REE-patterns show a smooth decline from LREE to HREE $(\mathrm{La} / \mathrm{Lu} \approx 5.4)$ and a pronounced negative Eu anomaly $\left(\mathrm{Eu} / \mathrm{Eu}^{*} \approx 0.19\right)$. The pattern and enrichment of Acapulco apatite reported by Zipfel et al. (1995) are in good agreement with the data obtained in this study (Fig. 7a). Apatite from the winonaite $\mathrm{HaH} 193$ has a large spread in overall enrichment $(15-160 \times \mathrm{CI})$, but are in agreement with the values reported in Floss et al. (2007). The REE-patterns have a less prominent slope from LREE to HREE (La/Lu $\approx 1.99)$, but also have well-defined negative Eu anomalies $\left(\mathrm{Eu} / \mathrm{Eu}^{*} \approx 0.4\right)$. Overall the apatite is less enriched in LREE, ranging from 25 to $165 \times$ CI (Fig. 7b). 
Apatite in the eucrite NWA 5073 has the highest REE enrichment (up to 3,000 $\times$ CI) and its negative $\mathrm{Eu}$ anomaly $\left(\mathrm{Eu} / \mathrm{Eu}^{*} \approx 0.03\right)$ extends over two orders of magnitude. The analyses are similar to REE data on eucritic apatites published by Hsu and Crozaz (1996), although the HREE appear slightly less enriched (Fig. 7c). Apatite from the eucrite Millbillillie is significantly less REE enriched then apatite from NWA 5073 (Fig. 7c), but it exhibits the same smooth decrease from La to $\mathrm{Lu}(\mathrm{La} / \mathrm{Lu} \approx 2.1)$ and also the significant negative $\mathrm{Eu}$ anomaly $\left(\mathrm{Eu} / \mathrm{Eu}^{*} \approx 0.09\right.$; Fig. $\left.7 \mathrm{c}\right)$. Apatite from the Landes IAB iron meteorite is significantly less enriched in REE $(\sim 30 \times \mathrm{CI})$ and has a flat pattern with a small negative Eu anomaly $\left(\mathrm{Eu} / \mathrm{Eu}^{*} \approx 0.6\right)$ and a slightly positive slope, due to a slight depletion in $\mathrm{La}$ and enrichment in $\mathrm{Yb}$ and $\mathrm{Lu}$ (Fig. 7c).

REE in Merrillite. Meteoritic merrillite shows three main REE patterns with varying shapes, as illustrated in figures 8 and 9:

1) REE patterns of merrillite in ordinary chondrites (Fig. 8a) and acapulcoites (Fig. 8b) resemble those of achondritic apatites (Fig. 7). Ordinary chondrites (Fig. 8a) feature merrillite with flat REE-patterns showing a slight negative gradient from LREE to HREE and a prominent negative $\mathrm{Eu}$ anomaly $\left(\mathrm{La} / \mathrm{Lu} \approx 3.31 ; \mathrm{Eu} / \mathrm{Eu}^{*} \approx 0.56\right)$. The obtained data overlap with the results of Crozaz et al. (1989), but the samples Ybbsitz and Devgaon extend the lower limit of the REE-range, while Adzhi-Bogdo extends the upper limit (Fig. 8a). It is noted that the assemblage of merrillite surrounding the CAI in Devgaon (Fig. 2b) does not deviate in its REE pattern or enrichment. Merrillite in Acapulco exhibits the same basic shape of its REE-pattern, slightly depleted in the $\operatorname{HREE}(\mathrm{La} / \mathrm{Lu} \approx 1.99)$ and a prominent negative Eu anomaly $\left(\mathrm{Eu} / \mathrm{Eu}^{*} \approx 0.14\right)$, which is within the range of merrillite REE data provided by Zipfel et al. (1995; Fig. 8b). On the other hand merrillite from the second acapulcoite NWA 1052 analyzed deviates and shows a bow-shaped REE pattern: The negative Eu anomaly is less pronounced $\left(\mathrm{Eu} / \mathrm{Eu}^{*} \approx 0.55\right)$, and while the LREE decrease in their 
enrichment from $\mathrm{La}$ to Sm, the HREE increase in their enrichment from Gd to Lu, resulting in an overall La/Lu value of $\approx 1.29$ (Fig. $8 \mathrm{~b}$ ).

2) In some differentiated meteorites, merrillite has quite unfractionated REE-patterns without prominent anomalies, e.g. the mesosiderite Dalgaranga $(\mathrm{La} / \mathrm{Lu} \approx 0.99-1.50 ; \mathrm{Eu} / \mathrm{Eu} * \approx 1.1-1.5$; Fig. 8c). Crozaz et al. (1985) reported a similarly unfractionated pattern for merrillite from Emery mesosiderite, but also two LREE-depleted patterns for merrillite in Vaca Muerta and Morristown mesosiderites. The former shows a negative, the latter a positive Eu anomaly of similar magnitude (Fig. 8c). Merrillite from the Bondoc mesosiderite also lacks prominent fractionation, but abundances smoothly decrease from $\mathrm{La}$ to $\mathrm{Lu}(\mathrm{La} / \mathrm{Lu} \approx 1.93)$ and there only is a minor negative Eu anomaly $\left(\mathrm{Eu} / \mathrm{Eu}^{*} \approx 0.6\right.$; Fig. $\left.8 \mathrm{c}\right)$. The REE-pattern of merrillite from silicate portions of the silicatebearing Landes IAB iron meteorite is fairly flat (Fig. 8c).

Although REE patterns in enriched shergottites, a subgroup of the Martian meteorites, are similar to mesosiderites, REE abundances are an order of magnitude higher. Northwest Africa 4864 $\left(\mathrm{La} / \mathrm{Lu} \approx 1.15-1.45 ; \mathrm{Eu} / \mathrm{Eu}^{*} \approx 0.77-1.07 ;\right.$ Fig. $\left.9 \mathrm{~b}\right)$, Zagami $\left(\mathrm{La} / \mathrm{Lu} \approx 0.99-2.38 ; \mathrm{Eu} / \mathrm{Eu}^{*} \approx 0.76-\right.$ 1.09; Fig. 9b) and KG 002 (La/Lu $\approx 1.55-2.04 ; \mathrm{Eu} / \mathrm{Eu}^{*} \approx 0.65-0.81$; Fig. 9b).

3) Depleted Shergottites have a characteritic depletion in the LREE (i.a., La/Yb $\approx 0.1$; Borg et al. 1997; McCubbin et al. 2012), and merrillites from this subgroup show this feature as well. Merrillite in SaU 005 and $\mathrm{DaG} 1051$ shows highly LREE-depleted patterns $(\mathrm{La} / \mathrm{Lu} \approx 0.17)$ that are in the upper range of merrillite REE data reported from other depleted shergottites by Shearer et al. (2015). They have a small negative Eu anomaly $\left(\mathrm{Eu} / \mathrm{Eu}^{*} \approx 0.55\right.$; Fig. 9a). The Ca-phosphates in both enriched and depleted shergottites mimic the REE pattern of their respective bulk meteorite (except for Eu anomalies), but, compared to their hosts, their REE concentrations are elevated by two orders of magnitude (Fig. 9). 
Other trace elements. Additional Ca-phosphate trace element concentrations $(\mathrm{Sc}, \mathrm{Ti}, \mathrm{V}$, Cr, Mn, Co, As, Rb, Sr, Y, Zr, Nb, Ba, Hf, Ta, Pb, Th and U, obtained by LA-ICP-MS) are available within the supplemental material (supplemental Table S1). Their abundances in both species are variable from meteorite to meteorite (Figs. 13 and 14). In all investigated samples Ti, V, Cr, Mn, and Co always show subchondritic concentrations, while Sr, Y, Th and $\mathrm{U}$ are always enriched relative to $\mathrm{CI}$ in both phosphates. Arsenic, $\mathrm{Rb}, \mathrm{Zr}, \mathrm{Nb}, \mathrm{Ba}, \mathrm{Hf}, \mathrm{Ta}$, and $\mathrm{Pb}$ abundances vary from sub- to superchondritic (Figs. 13 and 14). In contrast to REE and $\mathrm{Y}$, the abundances of the remaining trace elements in merrillite do not generally exceed those of apatite.

Both phosphate species incorporate $\mathrm{U}$ and $\mathrm{Th}$, yet for most samples their concentration is higher in apatite, except for the ordinary chondrite Devgaon $(\mathrm{H} 3.8)$ in which merrillite exceeds apatite and the eucrite Millbillillie, in which apatite does exceed merrillite in U but not in Th content (Table S1). In apatite, both $\mathrm{U}$ and Th are positively correlated and their content increases both with their host-rock's grade of metamorphism (petrologic type), as well as with increasing differentiation of their respective parent body (Fig. 12): Apatite from Devgaon (H3.8) and Ybbsitz (H4) has the lowest concentrations of $<0.5 \mathrm{ppm} \mathrm{U}$ and $<0.3 \mathrm{ppm}$ Th, while apatite from Bruderheim (L6), Villalbeto de la Peña (L6), Portales Valley (H6) and in the petrologic type 6 fragments of AdzhiBogdo (LL3-6), has concentrations of 2.1-5.5 ppm U and 2.3-8.3 ppm Th (Table S1). Achondritic apatite has even higher concentrations (Fig. 12), starting with primitive achondrites at 3.1-10.7 ppm U and 4.85-17.4 ppm Th in acapulcoites, followed by Martian meteorites with 4.8-5 ppm U and 17.121.0 ppm Th in shergottites (Table S1, Fig. 12). Eucritic apatite has the highest abundances obtained in this study, with 35.8-164.3 ppm U and 22.4-104.9 ppm Th (Table S1), although Millbillillie apatite has a lower Th/U value (Fig. 12). The range of $\mathrm{U}$ and $\mathrm{Th}$ concentrations in apatite from lunar samples (Nemchin et al. 2009) as well as from terrestrial lherzolites (O'Reilly and Griffin 2000) exceed those of apatite from the HED-suite (Fig. 12). 
Otherwise, there are no universal systematic differences among differentiated samples and chondrites and we observed no resolvable trends in the remaining trace element inventory correlating with the petrologic type of their host rocks in chondritic Ca-phosphates.

Apatite from Bruderheim (L6) shows exceptionally high concentrations for $\mathrm{V}, \mathrm{Rb}, \mathrm{Sr}, \mathrm{Zr}$, $\mathrm{Nb}, \mathrm{Ba}, \mathrm{Hf}$, and $\mathrm{Ta}$ exceeding those of apatite from other chondrites by at least one order of magnitude (Fig. 13a). Ca-phosphate species in Ybbsitz (H4) stand out due to their high $\mathrm{Pb}$ concentrations in both apatite (200-1800 ppm) and merrillite (450-2200 ppm) (Fig. 13a, Tab. S1).

Although the Adzhi-Bogdo (LL3-6) polymict breccia is a fall (Tab. 1), some phosphate analyses contain relatively high concentrations of $\mathrm{Ba}$ and/or Sr. Both phosphate species in the exotic differentiated (granite-like) clasts show higher abundances of $\mathrm{Zr}, \mathrm{Nb}, \mathrm{Hf}$, $\mathrm{Ta}$ and $\mathrm{Pb}$ compared to their counterparts in the chondritic portion.

Merrillite in Devgaon has unusually high Ti, V, Cr and Mn content (Fig. 13b) and furthermore, its assemblage surrounding a CAI (Fig. 2b) has higher concentrations of the refractory elements $\mathrm{Sc}$, Ti, and $\mathrm{V}$, as well as of the more volatile elements $\mathrm{Cr}$ and $\mathrm{Mn}$ when compared with merrillite within the remaining sample. However, the REE pattern of the CAI-associated merrillite does not diverge from the remaining merrillite in Devgaon. Although its overall enrichment is in the upper range of all merrillite within this sample, some merrillites from silicate assemblages have indistinguishable enrichments (supplemental table S1).

The trace element inventory of phosphates from differentiated meteorites does not differ strikingly from that of chondrites (Figs. 14). Yttrium constantly has the highest abundances of the additional trace elements reaching contents of $\sim 1.8 \mathrm{wt} \%$ in the Millbillillie eucrite accompanied by high concentrations of $\mathrm{Zr}(\sim 1800 \mathrm{ppm})$ and $\mathrm{Hf}$ (up to $\sim 2000 \mathrm{ppm})$. Apatite from the other eucrite (NWA 5073) also has high Y- ( 2300 ppm) and Zr- ( 450 ppm) abundances (Fig. 14c). High 
abundances of Y and REE in eucritic merrillite (compare Fig. 10) were also observed by Delaney et al. (1984b), which are only exceeded in lunar merrillite (Jolliff et al. 2006).

Although Ca-phosphates in enriched and depleted shergottites can clearly be distinguished from each other in terms of their REE abundances, there are no striking differences among most of the remaining trace element concentrations (Fig. 14d), except for merrillite in depleted shergottites, which shows lower $\mathrm{Pb}(\sim 0.21$ vs. $\sim 1.6 \times \mathrm{CI})$ and $\mathrm{Th}(\sim 37 \mathrm{vs.} \sim 525 \times \mathrm{CI})$, but higher $\mathrm{Cr}(\sim 0.01$ vs. $\sim 0.0006 \times \mathrm{CI})$ abundances than those in the enriched subgroup. Merrillite from both mesosiderites Bondoc and Dalgaranga has high abundances of Co (up to $1400 \mathrm{ppm}$ ) and Cr (up to $190 \mathrm{ppm}$ ), as well as moderately high Mn (up to 1900 ppm) concentrations (Fig. 14b).

\section{Discussion}

\section{General observations on compositional variations in meteoritic Ca-phosphates.}

Both phosphate species are major hosts for REE in most investigated samples and, hence, usually incorporate a large fraction of their host rocks bulk REE budget, consistent with e.g., Ebihara and Honda (1983). However, this does not apply for all samples from our suite, as discussed later.

The high partition coefficients and consequently high suitability of REEs for the incorporation into the crystal structures of merrillite and apatite entails Ca-phosphate REE concentrations to be up to two orders of magnitude higher compared to the bulk concentrations of their hosts (Figs. 8-9). Within the different samples, both merrillite and apatite show variations in their REE enrichments. However, the particular shape of their REE-patterns remains similar, suggesting that the phosphates within each sample formed under similar conditions. Matching observations of the REE patterns have been reported by e.g., Delaney (1982), Ebihara and Honda (1983), Crozaz and Zinner (1985), Davis et al. (1993), Hsu and Crozaz (1996), or Shearer et al. (2015). Despite this uniformity within single samples, REE-patterns are not unique for distinct meteorite groups and members therein; 
instead, characteristic REE-patterns recur throughout the extraterrestrial suite of samples. These patterns do not seem to correlate to specific adjacent mineral assemblages (e.g. metal vs. silicate dominated), nor to the grade of metamorphism (petrologic type), or distinct grain-size intervals. Nevertheless, the presence of plagioclase in a given phosphate assemblage does influence the intensity of negative Eu anomalies as Eu is preferentially incorporated into plagioclase, and therefore allows to infer a crystallization sequence of these phases.

Furthermore, different groups do exhibit variations with regards to their overall Ca-phosphate REE concentrations, as both species from differentiated samples show higher REE contents than those of chondrites. Within the differentiated meteorites, Ca-phosphates of eucrites show significantly higher REE concentrations than e.g. those from mesosiderites (Fig. 8). In general, the overall REE enrichment of the Ca-phosphates is strongly influenced by their formation mechanism and environment (igneous/magmatic processes vs. metamorphism/metasomatism). For example, high phosphate/melt partition coefficients result in enormous REE concentrations in eucrites and lunar rocks (Delaney et al. 1984b, Jolliff et al. 1993, 2006). However, the overall REE enrichment does not appear to be universally diagnostic, as high REE abundances are not present in all $\mathrm{Ca}$ phosphates that have formed in a magmatic environment. For instance, Ca-phosphates from igneous assemblages in the ureilitic trachyandesite ALM-A (Fig. 7) and those from shergottites (Fig. 9) exhibit significantly lower REE contents than eucritic phosphates (Figs. 7 and 8). Nevertheless, the degree of REE enrichment in both phosphate species is strongly influenced by their crystallization environment and source melt composition. Ca-phosphates in shergottites and eucrites both crystallized in a magmatic environment, yet Mars is significantly less volatite depleted than the HED parentbody (Dreibus \& Wänke 1985). The lower phosphorus content - a moderately volatile element - in eucrites entails significantly lower modal abunances of Ca-phosphates. Therefore, the available REE, which are favorably incorporated in late crystallizing apatite and merrillite, are concentrated in 
the few crystallizing Ca-phosphates and therefore reach the higher abundancces observed in both species from eucrites compared to Martian shergottites.

\section{Phosphate characteristics in chondrites}

Despite modifications inflicted by shock, thermal metamorphism or aqueous alteration, chondrites represent the oldest and, much more importantly, very primitive extraterrestrial material that has not been processed by differentiation on a global/parent-body scale. Ca-phosphates are less common in carbonaceous chondrites, but remain typical accessory phases in all groups of the ordinary chondrites (Van Schmus and Ribbe 1969; Brearley and Jones 1998). Moreover, they occur in associations with all major chondrite constituents. Although they have been observed in primitive (type 3) samples (e.g., Rubin and Grossman 1985; Murty et al. 2004), they are more common and larger in chondrites of higher petrologic types. The initial process of Ca-phosphate formation in chondrites is the oxidation of P originally dissolved in alloys of Ni,Fe-metal (Göpel et al. 1994). In general, this takes place at relatively low temperatures, reliant on the quantity of available $\mathrm{P}$ in the Fe,Ni-metal, as well as on the oxygen fugacity present during the formation process (Olsen and Fuchs 1967; Zipfel et al. 1995). During the subsolidus reaction $\mathrm{CaO}$ and the remaining constituents are provided by adjacent silicates and matrix, predominantly pyroxene (but also olivine and plagioclase), enabling the formation of phosphates, which also inherit their trace elements from the surrounding silicates during metamorphic redistribution (Zipfel et al. 1995). Jones et al. (2014, 2016) correlate this process primarily with the formation of merrillite, as the apatite X-site composition (c.f. Fig. 5) does not equilibrate with increasing petrologic type. Therefore, they suggest that chondritic phosphates either have been formed by precipitation from a very dry, P- and S-bearing, halogen-rich fluid, or by metasomatic reactions with major silicate phases and/or (in the case of apatite) preexisting metamorphic merrillite. 
Most chondrites commonly feature both Ca-phosphates, yet the Allegan H5 chondrite contains only merrillite. Possibly, the necessary volatiles to form apatite (ordinary chondrites are dominated by $\mathrm{Cl}$-apatite, cf. Fig. 5) were not available in sufficient quantity during their formation.

Despite the variety of chondritic groups, both Ca-phosphate species maintain a remarkably constant chemical composition (Fig. 4; Table 3): Apatite from ordinary chondrites varies by only 0.17 $\mathrm{wt} \%$ in its $\mathrm{MgO}$ content (b.d. $-0.17 \mathrm{wt} \%$ ), and by $0.25 \mathrm{wt} \%$ in its $\mathrm{Na}_{2} \mathrm{O}$ concentration $(\sim 0.25-0.5$ $\mathrm{wt}^{\mathrm{\%}} \%$ ). However, $\mathrm{FeO}$ variations are scattered and exceed $2 \mathrm{wt} \%$ (Fig. 4). For Karoonda (CK4), the high $\mathrm{FeO}$ range might be caused by a partial overlap with small magnetite inclusions within some apatite grains (Fig. 2c). Merrillite in ordinary chondrites exhibits slightly larger variations, as $\mathrm{Na}, \mathrm{Mg}$ (and $\mathrm{Fe}$ ) are among its structural components. Apatite in ordinary chondrites shows a limited range of REE enrichment (up to $125 \times \mathrm{CI}$ ), smoothly decreasing from La to Lu. Europium shows the only deviations, either exhibiting positive anomalies in Devgaon and Portales Valley, or slightly negative anomalies in Bruderheim, Villalbeto de la Peña, Adzhi-Bogdo and Ybbsitz, the latter congruent with previously reported data (Fig. 6). The largest influence on the orientation and intensity of a Eu anomaly is the formation of plagioclase: $\mathrm{Eu}$ (in bivalent state at oxidizing conditions prevailing during phosphate formation) favors the plagioclase crystal structure over phosphates. Therefore, if plagioclase has formed prior to the phosphates, or is present in high proportions in the vicinity of phosphate formation, a negative Eu anomaly is likely to form within the phosphates. Phosphates that do not have to compete significantly with plagioclase, exhibit a positive Eu anomaly. However, there is no resolvable diagnostic correlation between the plagioclase modal abundances or number of plagioclase grains in contact with the apatite grains and the type of the Eu anomaly (positive or negative). Merrillite patterns are, except for their overall REE enrichment, even less variable (Fig. 6). Their higher enrichment compared to that of coexisting apatite, as well as the smooth drop of their REE patterns from $\mathrm{La}$ to $\mathrm{Lu}$, paired with the prominent negative Eu anomaly, appear to be strictly 
controlled by the partitioning coefficients, except for Eu. This leaves the overall enrichments, as well as the orientation and intensity of the Eu anomaly as the only remaining variables of merrillite REE patterns. Enrichment in the LREE might also be induced by terrestrial contaminants during weathering in hot deserts (Crozaz et al. 2003), which raises a possible concern for all NWA samples (Table 1). However, the weathering degree of the host meteorites and their discovery as falls or finds (Table 1), shows no systematic correlation with neither the LREE enrichment and La/Lu value of the phosphates (Table 3 and Fig. 6), or their Ba and Sr abundances, indicative for terrestrial alteration (Stelzner et al. 1999).

Although merrillite from the unique assemblage surrounding a CAI in Devgaon (H3.8) does not show anomalies in its REE patterns, the elevated concentrations of Sc, Ti, V, Cr and Mn indicate that its composition is locally controlled by (a) the refractory character of the inclusion (Sc, Ti, V) and (b) its high abundance of secondarily altered spinel (Cr, Mn).

The only significant variations in REE abundances among chondritic Ca-phosphates are documented by the REE-concentrations obtained from phosphates of the exotic clasts in the AdzhiBogdo LL3-6 regolith breccia (Figs. 3c-d and 6d). The enrichment and REE patterns of their apatite grains is not found in any typical chondrite or chondritic fragment and the patterns resemble those shown by achondritic apatite (Fig. 7). In general, the same holds also for merrillite (Fig. 8). Several EDX and EPMA analyses and mappings rule out an accidental measurement of apatite-merrilliteintergrowth. The question remains, wether these achondritic fragments represent remnants of an achondritic projectile that may have hit the Adzhi-Bogdo parent body or if they originated on the LL chondrite parent body. Oxygen isotopic investigations indicate a close relationship of these clasts to ordinary chondrites (Sokol et al. 2007b). However, it may be possible that a differentiated parent body existed in the neighborhood of the LL chondrites within a very similar oxygen isotope 
environment, reconciling the close relationship in oxygen isotopes with the differentiated nature of these fragments.

Elevated concentration of $\mathrm{Pb}$ in both apatite and merrillite of $\sim$ one to two orders of magnitude are observed in Ybbsitz (H4), when compared to other ordinary chondrites (Fig. 13a, Tab. S1). This could indicate an unusual natural enrichment of radiogenic $\mathrm{Pb}$ or common $\mathrm{Pb}$ contamination. It is noted that in Ybbsitz only shows evidence for minor terrestrial wetharing ( $\sim$ W1 stage; Table 1) and other trace element concentrations (i.e., REEs in Fig.6) are within the same range or even have lower abundances when compared to other ordinary chondrites. We therefore interpret this unusual enrichment of highly mobile $\mathrm{Pb}$ as terrestrial contamination of this particular sample.

\section{Phosphate characteristics in differentiated meteorites}

Acapulcoites: This group documents the processing from primitive material (their bulk composition is more or less chondritic) to evolved (differentiated) parent bodies (Mittlefehldt 2007). General mineralogy and modal compositions resemble those of chondritic samples, but chondrules are absent or just occur as relicts, and, furthermore, mineral compositions deviate from the chondritic predecessors (Mittlefehldt 2007). Both species of Ca-phosphates occur in acapulcoites, but not necessarily within the same samples. While the Acapulco meteorite contains both Caphosphates with an apatite/merrillite ratio of 2:1, apatite is the only species observed in Dhofar 125 , and merrillite in NWA 1052, respectively (Table 1). As illustrated in Fig. 4, merrillite exhibits constant composition regarding its $\mathrm{MgO}, \mathrm{FeO}$, and $\mathrm{Na}_{2} \mathrm{O}$ content, which covers the same compositional range occupied by chondritic merrillite. However, apatite from acapulcoites generally shows higher $\mathrm{MgO}$, but lower $\mathrm{Na}_{2} \mathrm{O}$ concentrations than in chondrites (Fig. 4). When comparing apatite within the group, Dhofar 125 shows slightly elevated FeO contents (Fig. 4). Nevertheless, this

might, despite its low weathering degree, be due to terrestrial contamination, since it is a meteorite find (Table 1). On the other hand, Crozaz et al. (2003) reported little indication for terrestrial 
alteration of Dhofar 125.

Acapulcoites feature Ca-phosphates that were most likely generated during metamorphic reactions. However, Zipfel et al. (1995) have demonstrated that this does not account for the entire fraction of phosphates in Acapulco, since the LREE distribution between silicates and phosphates are not equilibrated; the authors instead suggested a volatile-rich, metasomatic melt as possible explanation for the phosphate generation and REE inventory. Regarding their apatite REE inventory, acapulcoites show a large range of REE enrichment, but nevertheless a constant relative depletion in the HREE, despite variations in the LREE/HREE ratios from sample to sample (Fig. 7a). Merrillite REE patterns from Acapulco are identical to those of its apatite but are slightly more enriched. Merrillite from NWA 1052 represents the only Ca-phosphate species observed in this sample and exhibits low REE abundances, as well as a quite different bow-shaped REE pattern with a less pronounced negative Eu anomaly when compared to other acapulcoite merrillite grains (Fig. 8). This divergence may be explained by the genetic relation of this sample. Despite the first classification of NWA 1052 as an acapulcoite published in Russell et al. (2005), Eugster and Lorenzetti (2005) argued that NWA 1058 (most likely paired with NWA 1052) is rather associated with the winonaite group, based on oxygen isotopes, cosmic-ray exposure ages, and bulk chemistry. Hence, Greenwood et al. (2012) list NWA 1052 among the winonaites as well, and hence a genetic relation to the winonaites may explain the uncommon bow-shaped REE patterns, which might have been inherited from pyroxenes during metamorphic redistribution, since similar patterns have been reported for clinopyroxene in winonaites by Floss et al. (2008).

Winonaites: On the broad scale, winonaites generally have chondritic mineralogy and compositions, but have undergone extensive thermal metamorphism (Mittlefehldt, 2007; Floss et al. 2008). Furthermore, oxygen isotopic data possibly links the parent bodies of winonaites and IAB iron meteorites (Clayton and Mayeda, 1996; Benedix et al. 2000; Floss, 2007). Although merrillite has 
been documented in the winonaite NWA 1463, apatite appears to be winonaites' dominating Caphosphate (Floss et al. 2008). This is supported by our study of $\mathrm{HaH} 193$, where only apatite was found in the analyzed section. Note that Floss et al. (2008) as well as Prinz et al. (1980) have reported significant variations in the modal abundance of apatite concerning studies of different sections of the same meteorite, as well as between different members of the winonaite group. The inhomogeneous distribution of phosphates within different samples is likely responsible for a range of different bulk REE patterns reported for winonaite samples so far (Floss et al. 2008). A large spread in REE patterns is not only reflected in the bulk rock signatures, but also observed in individual apatite grains within a single section of $\mathrm{HaH} 193$ (Fig. 7b). This may point towards different growth episodes of apatite grains, and/or to local compositional heterogeneity within $\mathrm{HaH} 193$ resulting in different microenvironments for Ca-phosphate formation. The general shape of the REE patterns are closely associated with those obtained from acapulcoites, but the average enrichment is lower (Figs. 6a-b). The bulk rock REE pattern of HaH 193 calculated by Floss et al. (2007) exhibits chondritic or slightly subchondritic enrichments and is strongly dependent on apatite modal abundances in the given sample, which we further discussed below. Concerning the overall REE budget, apatite remains the main carrier for REEs in $\mathrm{HaH} 193$, with its CI normalized enrichment exceeding the calculated bulk patterns (Floss et al. 2008) by two orders of magnitude. Its orthopyroxene has HREE-enriched patterns, inversy shaped in contrast to the slightly LREE enriched patterns of clinopyroxene and apatite (Floss et al. 2007). Plagioclase shows large positive Eu anomalies (two orders of magnitude; Floss et al. 2007), partially balancing the negative anomalies shown by the former phases.

Note that merrillite from NWA 1052 might rather indicate that this sample is associated with the winonaites instead of acapulcoites (c.f. previous paragraph). Its low REE abundances overlap with apatite from $\mathrm{HaH}$ 193, consistent with a comparable, metamorphic formation environment. Yet 
the negative Eu anomaly is less pronounced and the HREE enrichment entails a bow-shaped REE pattern. Similar patterns occur in clinopyroxene from winonaites (Floss et al., 2008), which might have handed down their REE signatures to the merrillite.

HED-meteorites: Both phosphate species occur in the HED-suite, but while they occur in numerous eucrites, they are absent in most diogenites as a consequence of their low bulk rock $\mathrm{P}$ abundances (Delaney et al. 1984b). Ca-phosphates also occur in howardites (Yagi et al. 1978), which are breccias consisting of eucritic and diogenitic components. Despite widespread impact-related and thermal-metamorphic modifications (e.g., Hsu and Crozaz 1996; Mittlefehldt 2007), the majority of the eucritic Ca-phosphates are clearly of igneous origin (Delaney et al. 1984a, 1984b). They are heterogeneously distributed within the eucrites (Hsu and Crozaz 1996) and are typically located in interstitial assemblages together with Ca-rich pyroxenes, ilmenite, and troilite, implying a late crystallization from local, residual melts. Delaney et al. (1984b) inferred crystallization temperatures close to the solidus, slightly below $1000^{\circ} \mathrm{C}$, at the point when the bulk composition of the remaining melt had become silicic. The late crystallization from residual melts also explains the heterogeneous distribution as well as variations in apatite-merrillite proportions (Hsu and Crozaz 1996), observed throughout the eucrites. These variations are likely related to properties of the residual melts (Delaney et al. 1984b). Eucritic apatites are almost exclusively F-apatites (Fig. 5) and merrillite does not include either $\mathrm{F}$ or $\mathrm{Cl}$ (Jolliff et al. 2006). Hence, the concentration of $\mathrm{F}$ in the melt will have a strong effect on the apatite/merrillite ratio, as higher $\mathrm{F}$ contents in the melt will result in higher apatite abundances (Sarafian et al. 2017). The presence of Sc-Group (IIIA) elements possibly triggered merrillite crystallization from the interstitial melts (Delaney et al. 1984b) and variations of major elements $(\mathrm{Ca}, \mathrm{Na}, \mathrm{Mg}, \mathrm{Fe}, \mathrm{P})$ between the interstitial residual melts will certainly have had an impact on the crystallization. Both Ca-phosphates in eucrites exhibit the lowest $\mathrm{Na}_{2} \mathrm{O}$ contents (Fig. 4) but the highest REE abundances (up to 30,000 × CI; Delaney et al. 1984a, 1984b), which are only 
exceeded by lunar samples (e.g. Jolliff et al. 2006). Nevertheless, the REE enrichment of apatite in Stannern-trend eucrite NWA 5073 exceeds that of apatite from Millbillillie main group eucrite by almost an order of magnitude. High REE enrichments in the NWA 5073 apatites are consistent with data from Hsu and Crozaz (1996) - although especially the HREE are slightly less enriched - as well as the host rocks bulk composition, as it belongs to the rare group of the so-called Stannern-trend eucrites characterized by high abundances in Ti and incompatible elements (Hsu and Crozaz 1996; Roszjar et al., 2011). In Millbillillie, apatite has smaller grain sizes $(\sim 10-15 \mu \mathrm{m}$ vs. up to $65 \mu \mathrm{m}$ in NWA 5073) and lower REE abundances than in NWA 5073 (Table 3), but the REE pattern (smooth decreasing concentration with increasing ionic radii) is still present and other trace elements do not exhibit unusual concentrations. Therefore, the low REE enrichment might be attributed to local dilution effects or a metamorphic formation (Crozaz et al. 1985). Nevertheless, the high REE abundances and textural context of merrillite from Millbillillie clearly corresponds to an igneous formation process, although some intergrown assemblages of apatite and merrillite in NWA 5073 may indicate a metasomatic overprint, as discussed by Roszjar et al. (2011).

Despite the very low modal abundance of Ca-phosphates in eucrites $(<0.1 \mathrm{vol} \%$; Table 1$)$, Hsu and Crozaz (1996) estimated over 80\% of the eucrite REE budget to be located in both species combined. Additionally, zircon also incorporates great amounts of (H- and M-)REEs and is present in both analyzed eucrites (Roszjar et al. 2011, 2014), where it is located within the late-stage mesostatis areas together with Ca-phosphates. Therefore, Ca-phosphates in eucrites lacking adjacent zircon may reach even higher REE abundances. Interestingly, Th of Millbillillie Ca-phosphates appears to favor merrillite over apatite (Table S1) which results in a lower U/Th values than in NWA 5073 (Fig. 12).

The observed extreme REE-enrichment in the Millbillillie merrillites require charge balances and result in lower $\mathrm{Ca}$ contents (Table 2b), as well as vacancies in the Na-lattice position, consistent 
with results from Jolliff et al. (2006) and Shearer et al. (2015); the negative correlation of Na vs. $\mathrm{Y}+\mathrm{REE}$ apfu is illustrated in Figure 10. Both phosphate species exhibit a similar shape of REE patterns with a smooth decrease from La to Lu and a very prominent Eu anomaly, skipping an entire order of magnitude (Fig. 7). The REE patterns of pyroxene and plagioclase from numerous eucrites have been reported by Hsu and Crozaz (1996), which show coverse features compared to those of the Ca-phosphates: Plagioclase shows very prominent positive Eu anomalies, also covering two orders of magnitude and pyroxene REE patterns smoothly increase from La to Lu. Since plagioclase occurs early in the eucritic crystallization sequence (Stolper 1977; Hsu and Crozaz, 1996), it consumes the majority of the available Eu, incorporating most bivalent Eu ions. The HREE are better suited for the pyroxene crystal structure, generating the slope of their pattern as a function of the REE's ionic radii. The phosphates are located late in the crystallization sequence and have consumed the remaining REE during their crystallization in the intersticial pockets of highly evolved, REE enriched melt. The large spread of varying REE enrichment of phosphates within the same sample, or also within different sections of the same meteorite is most likely attributed to variation in the composition of the different interstitial melt pockets.

Martian meteorites: The shergottites are basaltic meteorites originated in the shallow subsurface, and their parental melts are assumed to have their origin in partial melting of the Martian mantle (e.g., Borg et al. 1997, McCubbin et al. 2012). They can be divided into different subtypes (enriched, intermediate, and depleted) based on their $\mathrm{La} / \mathrm{Yb}$ and ${ }^{87} \mathrm{Sr} /{ }^{86} \mathrm{Sr}$ and $\varepsilon \mathrm{Nd}$ values (Borg et al. 1997; Kruijer et al. 2016). While the enriched subtype is assumed to have originated by varying degrees of mixing or assimilation of an enriched mantle or crustal source, the depleted subtype is interpreted to correspond to a mantle source region spared from substantial alteration (McCubbin et al. 2012). The differences in major and minor element geochemistry between the enriched and depleted shergottites are attributed to their different source regions and different proportions of 
crustal assimilation, hence, to their different basaltic parental melts, which in turn exhibit further local variations (Shearer et al. 2015, Borg et al. 1997). Shergottites generally feature both Caphosphates, but merrillite is far more common (Tab. 2). Within the analyzed samples, all shergottites feature merrillite, but apatite was only observed in the enriched subtype. Since the shergottites have originated from basaltic melts (Wadhwa et al. 1994), the low phosphorous saturation (bulk shergottites from this study do not esceed 1.5 wt.\% P; cf. Table 1), inititally prevented the crystallization of Ca-phosphates (Watson 1979; Green and Watson 1982) until it evolved and fractionated. Therefore, the Ca-phosphates in shergottites are formed very late in the crystallization sequence and are usually located in interstitial assemblages, residual melt pockets, or in symplectitic associations (Figs. 2e-f). Apatite X-site composition extends over a large range (Fig. 5d) and might be modified by shock events and hence does present itself as a diagnostic tool. The order of crystallization concerning apatite and merrillite differs from sample to sample. Textural evidence was presented by Warren et al. (2004), Gross et al. (2013), McCubbin et al. (2014), and Shearer et al. (2015) for both cases. For the analyzed enriched shergottites Zagami and NWA 4864, textural association of micrometer-sized apatite rims along merrillite grains (Fig. 3e), as well as large merrillite grains (of several $100 \mu \mathrm{m}$ ) and a residual $\mathrm{SiO}_{2}$-rich melt pocket cornering significantly smaller apatite grains $(\sim 25-50 \mu \mathrm{m})$ indicate that merrillite crystallized prior to apatite.

The ranges of merrillite $\mathrm{Na}, \mathrm{Fe}$ and $\mathrm{Mg}$ abundances from shergottitic samples are consistent with findings from Shearer et al. (2015). The significantly lower Mg and higher Fe content of merrillite from enriched shergottites (Figs. 2a and c) most likely corresponds to varying degrees of mixing and crustal assimilation during the evolution of the enriched parental melt. However, both subtypes (enriched and depleted) show significantly lower $\mathrm{Na}$ concentration when compared to other meteorite groups, as illustrated in Figure 4. Merrillite mimics the bulk rock REE pattern (but is enriched by two orders of magnitude), except for Eu, which is favorably incorporated in plagioclase, 
hence creating a negative Eu anomaly in the phosphate (Fig. 9). Therefore, in shergottites, the diagnostic shape of phosphate REE patterns is dictated by their parental melts.

Mesosiderites: Although both Ca-phosphate species have been reported in mesosiderites, merrillite is the dominant species (Delaney et al. 1984b) and the only one observed in this study. Merrillite from Dalgaranga stands out due to their lower $\mathrm{Na}_{2} \mathrm{O}$, but higher $\mathrm{FeO}$ concentrations when compared to those of other meteorite groups. Merrillite from Bondoc also exhibits a lower $\mathrm{Na}_{2} \mathrm{O}$ content, but does not show a large range in FeO-concentration (Fig. 4). The low $\mathrm{Na}_{2} \mathrm{O}$ abundances in mesosiderite merrillite appear characteristic, but unlike merrillite from the HED suite, may not be a function of charge balances due to their REE budget, but are rather attributed to the low bulk $\mathrm{Na}$ inventory of the mesosiderites as illustrated in the supplement (Fig. S2). Hence, the slope of the trend shown by Jolliff et al. (2006) and Shearer et al. (2015) might be even steeper than expected.

The unusually large range in $\mathrm{FeO}$ may have originated either in the bulk Dalgaranga meteorite, or is a consequence of terrestrial alteration. Both mesosiderates are finds and show evidence of weathering (stage W3; Table 1). However, the alignment of either phosphate species from mesosiderites with those of other meteorite groups based on overlap in $\mathrm{Na}_{2} \mathrm{O}$ and $\mathrm{FeO}$ vs. $\mathrm{MgO}$ characteristics (Fig. 4), is not reflected by either the shape or enrichment of their REE profiles (Fig. 8c). Merrillite grains from mesosiderites show REE enrichment of 70-200 $\times$ CI, which is rather modest compared to other achondrites (Figs. 8 and 9) and a similar range to those of ordinary chondrites (Fig. 8a). However, they lack the prominent negative Eu anomaly of ordinary chondrites, although Bondoc merrillite does have a small negative Eu anomaly (Fig. 8). Nevertheless, extraordinarily high positive Eu anomalies occur in pigeonite-plagioclase-clasts within mesosiderites, which so far exceed other extraterrestrial material (Mittlefehldt et al. 1992). The modest REE abundances of Ca-phosphates from mesosiderites probably is a result of enormous metal-oversilicate enrichment, followed by phosphorus partitioning out of that metal (and associated 
phosphide) and into the nonmetallic matter as a consequence of moderating oxygen fugacity (e.g. Delaney et al. 1980; Harlow et al. 1982).

The Dalgaranga merrillite REE patterns basically mimic the pattern of the bulk silicate portion presented by Hidaka and Yoneda (2011), but it is enriched by two orders of magnitude and lacks the slight positive anomalies in La and Lu (Fig. 8c). On the bulk rock scale, Gast and McConnell (1972) and Wasson (1974) suggested moderate to extensive partial melting of a source with chondritic REE distributions that would generate these flat REE patterns, which are also observable in many bulk howardites, eucrites, as well as in lunar samples.

Merrillite likely originates from subsequent metamorphic redox reactions of the silicate portion and metal (Harlow et al. 1982; Crozaz et al. 1985), adopting the flat REE pattern, but incorporating the majority of the available REE budget. Different orientations of Eu anomalies (positive or negative, yet consistent within a given sample) or variations in the enrichment of the LREE, as seen in Bondoc or reported from merrillite within other mesosiderites (Crozaz et al. 1985) are probably a function of mineral-proportions in the silicate fraction contributing to the REE during Ca-phosphate formation. For example, merrillite showing LREE depletion coupled with a positive Eu anomaly reported in the Morristown mesosiderite by Crozaz et al. (1985) was interpreted to be induced by the orthopyroxene-dominated host from which the merrillite crystallized.

IAB iron meteorites: Trace amounts of phosphates are described in numerous IAB iron meteorites (Benedix et al. 2000), and although many different and complex phosphate minerals are reported in iron meteorites in general (c.f. Olsen et al. 1999), Cl-apatite and merrillite are the dominant phosphate species, even though more exotic phosphates such as brianite $\left[\mathrm{Na}_{2} \mathrm{CaMg}\left(\mathrm{PO}_{4}\right)_{2}\right]$ occasionally occur (Scott and Bild, 1974; Benedix et al. 2000). Phosphorus is not solely located in Caphosphates but may also be present in phosphides [e.g. schreibersite: $(\mathrm{Fe}, \mathrm{Ni})_{3} \mathrm{P}$ ] and subordinately in the metal phase. The section of the silicated Landes IAB iron meteorite analyzed in this study 
contains merrillite and $\mathrm{Cl}$-apatite (Tables 2), and both were situated as large inclusions within the Fe,Ni-metal (Fig. 1c). Landes is the only sample analyzed in this study in which apatite REE concentrations slightly exceed those of merrillite $(\sim 20-50 \times \mathrm{CI}$ vs. $\sim 15-25 \times \mathrm{CI})$, although abundances in both are low (Table 3). Both Ca-phosphate species show unfractionated LREE patterns, slightly depleted in La. However, some differences are evident in the Eu and HREE abundances: (1) the minor negative Eu anomaly featured in apatite is absent in merrillite and (2) the HREE enrichment from merrillite slightly drops from Gd to Tm, while the apatite HREE pattern remains flat (Figs. 7c and 8c). These diverging patterns occur in grains located in close proximity $(\sim 250 \mu \mathrm{m})$ to each other (Fig. 1c). The higher apatite REE content is puzzling, since the merrillite crystal structure is more suitable for the uptake of REE cations (Jolliff et al. 1993), typically resulting in higher REE concentration. Therefore, the REE abundances of both phosphates appear to reflect their crystallization sequence. Possibly, the apatite inclusion formed prior to the merrillite, incorporating higher portions REE available in their vicinity, and only some Eu was preferred by the adjacent plagioclase. Bild (1977) analyzed La, Sm, Eu, Yb, and Lu from the nonmetallic portion of Landes (among other IAB irons), and the REE concentrations of both Ca-phosphates are enriched by an order of magnitude compared to the bulk portion, which is almost of chondritic REE concentration $(0.64-2.61 \times \mathrm{CI})$. Furthermore, the bulk silicate portion, as well as both Ca-phosphate species exhibit a depletion of La compared to Sm by about a factor of two. The ratios of other REE (e.g., $\mathrm{Sm} / \mathrm{Eu} \approx 1 ; \mathrm{Eu} / \mathrm{Yb} \approx 1.1 ; \mathrm{Yb} / \mathrm{Lu} \approx 1.3$ ) reported by Bild (1977) correspond well with those observed in merrillite, but not with those shown by apatite (Tables 4 and S1). The two phosphate species are not the exclusive REE host phases within the silicate portion. This might be an effect of its equilibration under more reducing conditions than found for example in chondrites, which initially prevented the formation of Ca-phosphates by oxidization, as suggested by Luzius-Lange and Palme (1987) and Palme et al. (1991). The low REE enrichment of both phosphates, as well as their 
exclusive textural association with the metal phase indicates a secondary origin by subsequent oxidization of metal or phosphides after equilibration of the silicate portion.

The overlap of winonaites and IAB iron meteorites in their oxygen isotopic signatures and thus proposed genetic relationship (Clayton and Mayeda 1996; Benedix et al. 2000; Floss 2007) is however not reflected in the REE inventory of their Ca-phosphates observed here (Fig. 7). This consequently implies different formation conditions for the phosphates from both meteorite suites. The REE enrichment of apatite in the winonaite $\mathrm{HaH} 193$ exceeds that of the Landes apatite by more than one order of magnitude and features a very prominent Eu anomaly absent in the Landes apatite (Figs. 7bc). Moreover, unlike Landes, $\mathrm{HaH} 193$ does not contain merrillite (Table 1), precluding a direct comparison. Nevertheless, the differences in Ca-phosphate REE signatures certainly do not rule out a common parent body for both meteorite groups, but rather point to diverging preconditions during their formation, supporting the model from Benedix et al. (2000) for a multi-stage formation scenario involving (re)heating, partial melting and melt-mixing, catastrophic disruption, metamorphism and quenching of the host parent body.

Ureilitic trachyandesite ALM-A: Apatite is the predominant Ca-phosphate in the ALM-A sample, which represents a trachyandesitic fragment of the ureilitic parent body (Bischoff et al. 2014). The assemblage of the lath-shaped apatites among pyroxenes and feldspar (Fig. 2d) was clearly produced by an igneous formation process. The unique composition of this sample with its high feldspar abundance $\left(\sim 70\right.$ vol\%; plagioclase with $\sim \mathrm{An}_{10-55}$ and anorthoclase with $\sim \mathrm{An}_{5-12}$; Bischoff et al. 2014) determines its trachyandesitic classification and is also reflected in the isolated (chemical) position of its apatites in Fig. 4. The composition corresponds well to the experimental data by Feldstein et al. (2001) on disequilibrium partial melt compositions (51-56 wt $\% \mathrm{SiO}_{2}$, up to $4.4 \mathrm{wt}^{\mathrm{0}} \%$ $\mathrm{Na}_{2} \mathrm{O}$ ) of an ordinary chondrite starting material used to reconstruct silica and $\mathrm{Na}$-rich bulk content of the ALM-A sample (Bischoff et al. 2014). Apatite from ALM-A shows very constant REE 
enrichments smoothly dropping from $\sim 260 \times$ CI for La to $\sim 45 \times$ CI for Lu, with a well-defined negative Eu anomaly (Figs. 7b and 11). The bulk REE pattern (Bischoff et al. 2014), as well as the REE patterns of the remaining phases in the assemblage are given in Figure 11 (their concentraion is available in supplemental table S4). The calculated REE pattern (Fig. 11), derived from the average REE composition of individual phases (Table S4) and their modal abundances (Table 1 and Bischoff et al. 2014) is able to reproduce the measured bulk REE pattern within error, indicating that the entire REE budget and carriers are recorded. The prominent positive Eu anomaly paired with the high modal abundance of feldspar reconciles the negative Eu anomaly of the highly REE-enriched apatite and the slight positive Eu anomaly of the bulk rock REE pattern. Pyroxenes are slightly enriched in the HREE, and the feldspar REE enrichment also increases slightly from Dy to Lu, which partially balances the decreasing REE enrichment in apatite with their increasing ionic radii. Texture and REE patterns suggest that the apatite crystallized simultaneously with the surrounding phases, producing the euhedral apatite laths that occur in various sizes, either isolated within the feldspar, or sometimes embedded into pyroxenes (Fig. 2d).

\section{REE mass balance calculations of achondrites}

The high REE abundances in apatite and merrillite raises the question to quantify the proportion they claim from their host rocks bulk REE consumption. Samarium was chosen as a representative element to conduct some basic mass balance calculations, summarized in supplemental Table S5. The calculations are based on the evaluated modal abundances of both species, their respective $\mathrm{Sm}$ concentrations and on available bulk Sm concentration of the host meteorite. Note that Ca-phosphates intergrown and/or replaced on a small spatial resolution and grains $<5 \mu \mathrm{m}$ may not be sufficiently covered, and therefore in few cases may not taken into account adequately for the modal abundance evaluations, which is based on elemental mappings and/or SEM image documentation. Available literature data often list "phosphates" among given modal 
abundances without distinguishing between apatite and merrillite. However, since the REE abundances in the latter often exceed the first by an order of magnitude, it is important to establish modal abundances taking both specied into account if they coexist in a given meteorite. Hence, the modal abundances turn out to be the limiting factor in quantifying the portion of the REE budget incorporated in the corresponding Ca-phosphate species. With increasing differences in REE content among both Ca-phosphate species, the impact of the accuracy of the determined modal proportions rises significantly. This culminates for instance in the eucrite Millbillillie, in which 0.01 vol $\%$ of merrillite consumes roughly $20 \%$ of the bulk REE Sm budget (Table S5). However, the available modal data is far from precise enough for a reliable discrimination down to this level, awaiting more carful future studies. Although some uncertainties must be taken into account here and only rough estimates can be made, it is observed that although the REE patterns of both species have constant shapes within each sample, some samples vary more in REE enrichment, than others. This entails strong deviations in the fraction of the consumed bulk REE budget, depending if the average, minimum or maximum concentration of the corresponding phosphate species is taken into account (Table S5). For example in the acapulcoite Dhofar 125, the Sm concentrations of apatite (the only Ca-phosphate species in this sample, $1.1 \mathrm{vol} \%$ ) ranges from 17.7 to $23.2 \mu \mathrm{g} / \mathrm{g}$ with an average of $19.1 \mu \mathrm{g} / \mathrm{g}$, consumes $96 \%$ of the bulk Sm budget if the average is used. However, applying the apatite maximum of $23.2 \mu \mathrm{g} / \mathrm{g}$ overexeeds the available Sm budget (Table S5). For Acapulco, the obtained modal abundances and Sm concentrations of both phosphates account for $97 \%$ of the available Sm. In the analyzed eucrites, the phosphates account for up to $88 \%$ of the bulk Sm budget (Table S5). However, the enormous Sm enrichment, especially in merrillite, requires a much better accuracy in the determination of modal abundances, which is not available at this point. Variations in the reported and obtained modal abundances in shergottites entail significant differences in the consumed portion of the Sm budget, starting with $\sim 26 \%$ in SaU 005, $\sim 50 \%$ in Zagami and ending 
with an overconsumption of the available Sm for DaG 1051 and NWA 4864 (Table S5). The latter either indicates the available bulk Sm contents are too low (which we consider unlikely) or an overestimated modal phosphate abundance and/or a heterogenous distribution of phosphates. In the latter case, several (thin) sections of the same sample should be taken into account to better evaluate the distribution and occurrence of both phosphate species in a given sample, especially if the REE concentrations are high and the species differ considerably in REE content. While the high REE abundances make Ca-phosphates major carrier phases for the majority of meteorite groups, they only account for $\sim 5 \%$ of the available Sm in the Landes IAB iron meteorite and only $2-19 \%$ (average $6 \%$ ) in the winonaite $\mathrm{HaH} 193$ (Table S5), indicating the presense of other REE-consuming phases.

Despite of the considerable uncertainties induced by the limited accuracy of the determination of precise modal abundances $(<1 \mathrm{vol} \%)$ and also by the range auf REE abundances, the distribution of REE among its various carrier phases needs to be understood in order to advance our understanding of the igneous processes that have shaped the samples we are studying. We therefore advice caution concerning the estimation of modal fractions and furthermore encourange to discriminate different species, instead of merging them under the lable "phosphates". In order to achive more reliable mass balance calculations, the necessary accuracy of modal estimations are strongly dependent on the spatial occurrence and clear identification of the present Ca-phosphate species, as well as on variation in their overall REE abundances within the sample.

\section{Implications}

Previous studies of extraterrestrial Ca-phosphates have usually targeted single meteorite samples or groups, while this approach adresses the phosphate characteristics of a great variety of parent bodies, shaped by different conditions and processes. We present an extensive survey of occurrences, phase associations, mineralogy, and trace element chemistry of apatite-group minerals and merrillite in meteorites and provide a robust and comprehensive dataset of numerous trace 
elements, most of which have not been reported in previous studies. Hence, the dataset enables cross comparison of Ca-phosphate mineralogy and chemistry in different meteorite groups, as well as samples therein. Furthermore, it allows discrimination between different lithologies from brecciated samples, providing a more detailed view on the complex history and evolution of brecciated rocks as clearly shown here for Adzhi Bogdo (stone) and its clasts.

Although the Ca-phosphate trace element inventory of a distinct meteorite group is not universally diagnostic to specific formation scenarios or alteration processes, the presence or absence of overlap in their abundances and proportions among different meteorite groups provides the basis for new approaches and correlations and also raises new questions to be addressed in future work. Clearly, more work is needed to fully constrain the mechanisms during Ca-phosphate formation, alteration, and their role in the evolution of planetary bodies, relevant within the context of chronological constraints (e.g. U-Th-Pb systematics) in particular. Nonetheless, this study provides a solid foundation and extensive data set for future studies of trace elements in meteoritic apatite and merrillite, and contributes to our understanding of formation and distribution of extraterrestrial Caphosphates.

\section{Acknowledgements}

We thank Marian Horstmann and Herbert Palme for fruitful discussions, Beate Schmitte, Lev Ilyinsky, and Kerstin Lindén for analytical support, Ulla Heitmann for thin section preparation, Klaus Mezger as a cooperation partner of a related sub-project on the chronology and chemistry of meteoritic zircon and phosphate grains, and Celeste Brennecka for editorial support. Moreover, Xiande Xie and Rhian Jones provided very helpful comments on an earlier version of this manuscript. The NordSIMS laboratory is funded by Denmark, Iceland, Norway and Sweden; this is NordSIMS publication \#\#\#. This work was partly supported by the German Research Foundation 
(DFG; Project BI 344/9-2) within the Priority Program “The First 10 Million Years - a Planetary Materials Approach” (SPP 1385).

\section{References Cited}

Armstrong, J.T. (1991) Quantitative elemental analysis of individual microparticles with electron beam instruments. In K.F.J. Heinrich and D.E. Newbury, Eds., Electron Probe Quantitation, p. 261-315. Springer US, Boston, MA.

Barrat, J.A., Blichert-Toft, J., Nesbitt, R.W., and Keller, F. (2001) Bulk chemistry of Saharan shergottite Dar al Gani 476. Meteoritics \& Planetary Science, 36 (1), 23-29.

Barrat, J.A., Zanda, B., Moynier, F., Bollinger, C., Liorzou, C., and Bayon, G. (2012) Geochemistry of CI chondrites: Major and trace elements, and $\mathrm{Cu}$ and $\mathrm{Zn}$ isotopes. Geochimica et Cosmochimica Acta, 83, 79-92.

Bellucci, J.J., Whitehouse, M.J., John, T., Nemchin, A.A., Snape, J.F., Bland, P.A., and Benedix, G.K. (2017) Halogen and $\mathrm{Cl}$ isotopic systematics in Martian phosphates: Implications for the $\mathrm{Cl}$ cycle and surface halogen reservoirs on Mars. Earth and Planetary Science Letters, 458, 192202.

Bendel, V. (2013) Volatilitätskontrollierte Fraktionierung refraktär-lithophiler Elemente in Meteoriten und der Erde: Dissertation zur Erlangung des mathematischnaturwissenschaftlichen Doktorgrades der Georg-August-Universität Göttingen, 157 p. Dissertation, Georg-August-Universität, Göttingen.

Benedix, G.K., McCoy, T.J., Keil, K., and Love, S.G. (2000) A petrologic study of the IAB iron meteorites: Constraints on the formation of the IAB-winonaite parent body. Meteoritics \& Planetary Science, 35 (6), 1127-1141.

Bischoff, A., and Geiger, T. (1995) Meteorites from the Sahara: Find locations, shock classification, degree of weathering and pairing. Meteoritics, 30 (1), 113-122.

Bischoff, A., Geiger T., Palme H., Spettel, B., Schultz L., Scherer P., Schlüter J., and Lkhamsuren J. (1993) Mineralogy, chemistry, and noble gas contents of Adzhi-Bogdo - an LL3-6 chondritic breccia with foreign clasts. Meteoritics, 28 (4), 570-578.

Bischoff, A., Dyl, K.A., Horstmann, M., Ziegler, K., Wimmer, K., and Young, E.D. (2013) Reclassification of Villalbeto de la Peña - occurrence of a winonaite-related fragment in a hydrothermally metamorphosed polymict L-chondritic breccia. Meteoritics \& Planetary Science, 48 (4), 628-640. 
Bischoff, A., Horstmann, M., Barrat, J.A., Chaussidon, M., Pack, A., Herwartz, D., Ward, D., Vollmer, C., and Decker, S. (2014) Trachyandesitic volcanism in the early solar system. Proceedings of the National Academy of Sciences of the United States of America, 111 (35), 12689-12692.

Bild, R.W. (1977) Silicate inclusions in group IAB irons and a relation to the anomalous stones Winona and Mt. Morris. Geochimica et Cosmochimica Acta, 41 (10), 1439-1456.

Borg, L.E., Nyquist, L.E., Taylor, L.A., Wiesmann, H., and Shih, C.-Y. (1997) Constraints on Martian differentiation processes from $\mathrm{Rb}-\mathrm{Sr}$ and $\mathrm{Sm}-\mathrm{Nd}$ isotopic analyses of the basaltic shergottite QUE 94201. Geochimica et Cosmochimica Acta, 61 (22), 4915-4931.

Boyce, J.W., Tomlinson, McCubbin, F.M., Treiman, A.H., and Greenwood, J.P. (2014) The lunar apatite paradox. Science, 344, 400-402.

Brearley, A.J., and Jones, R.H. (1998) Chondritic meteorites. In: J.J. Papike (ed), Reviews in Mineralogy: Planetary Materials, 36, pp. 3-1-3-398, Mineralogical Society of America, Washington, D.C.

Bunch, T.E., Keil, K., and Huss, G.I. (1972) The Landes meteorite. Meteoritics \& Planetary Science, 7, 31-38.

Clayton, R.N., and Mayeda, T.K. (1996) Oxygen isotope studies of achondrites. Geochimica et Cosmochimica Acta, 60 (11), 1999-2017.

Crozaz, G., and Zinner, E. (1985) Ion probe determinations of the rare earth concentrations of individual meteoritic phosphate grains. Earth and Planetary Science Letters, 73 (1), 41-52.

Crozaz, G., Zinner, E., and Delaney, J.S. (1985) Rare earth element concentrations of mesosiderite merrillite. Meteoritics, 20, 629.

Crozaz, G., Pellas, P., Bourot-Denise, M., de Chazal, S.M., Fiéni, C., Lundberg, L.L., and Zinner, E. (1989) Plutonium, uranium and rare earths in the phosphates of ordinary chondrites - the quest for a chronometer. Earth and Planetary Science Letters, 93 (2), 157-169.

Crozaz, G., Floss, C., and Wadhwa, M. (2003) Chemical alteration and REE mobilization in meteorites from hot and cold deserts. Geochimica et Cosmochimica Acta, 67 (24), 4727-4741.

Davis, A.M., and Olsen, E.J. (1991) Phosphates in pallasite meteorites as probes of mantle processes in small planetary bodies. Nature, 353 (6345), 637-640.

Davis, A.M., Prinz, M., and Weisberg, M.K. (1993) Trace element distributions in primitive achondrites. REE in primitive achondrites. Proceedings of the 24th Lunar and Planetary Science Conference, 375-376, Lunar and Planetary Institute, Woodlands, Texas. 
Delaney, J.S., Prinz, M., and Nehru, C.E. (1980) Olivine clasts from mesosiderites and howardites clues to the nature of achondritic parent bodies. Proceedings of the 11th Lunar Planetary Science Conference, 1073-1087, Lunar and Planetary Institute, Woodlands, Texas.

Delaney, J.S. (1982) Minor components of basaltic Achondrites - ii. Phosphorus. Proceedings of the 13th Lunar and Planetary Science Conference, 150-151, Lunar and Planetary Institute, Woodlands, Texas.

Delaney, J.S., Prinz, M., and Takeda, H. (1984a) The polymict eucrites. Journal of Geophysical Research, 89 (S01), C251.

Delaney, J.S., O'Neill, C., and Prinz, M. (1984b) Phosphate minerals in eucrites. Proceedings of the 15th Lunar and Planetary Science Conference, 208-209, Lunar and Planetary Institute, Woodlands, Texas.

Dreibus, G., and Wänke, H. (1985) Mars, a volatile-rich planet. Meteoritics, 20, 367-381.

Dreibus, G., Spettel, B., Haubold, R., Jochum, K.P., Palme, H., Wolf, D., and Zipfel, J. (2000) Chemistry of a new shergottite: Sayh al Uhaymir 005. Meteoritics \& Planetary Science, 35 (S5), A49.

Dyl, K.A., Bischoff, A., Ziegler, K., Young, E.D. Wimmer, K., and Bland, P.A. (2012) Early solar system hydrothermal activity in chondritic asteroids on 1-10-year timescales. Proceedings of the National Academy of Sciences of the United States of America, 109:18306-18311.

Easton, A.J., and Elliott, C.J. (1977) Analyses of some meteorites from the British Museum (Natural History) collection. Meteoritics, 12 (4), 409-416.

Ebihara, M., and Honda, M. (1983) Rare earth abundances in chondritic phosphates and their implications for early stage chronologies. Earth and Planetary Science Letters, 63 (3), 433-445.

Eugster, O., and Lorenzetti, S. (2005) Cosmic-ray exposure ages of four acapulcoites and two differentiated achondrites and evidence for a two-layer structure of the acapulcoite/lodranite parent asteroid. Geochimica et Cosmochimica Acta, 69 (10), 2675-2685.

Fitzgerald, M.J. (1979) The chemical composition and classification of the Karoonda meteorite. Meteoritics, 14, 109-115.

Floss, C., Jolliff, B.L., Benedix, G.K., Stadermann, F.J., and Reid, J. (2007) Hammadah al Hamra 193: the first amphibole-bearing winonaite. American Mineralogist, 92 (4), 460-467.

Floss, C., Crozaz, G., Jolliff, B.L., Benedix, G.K., and Colton, S. (2008) Evolution of the winonaite parent body: Clues from silicate mineral trace element distributions. Meteoritics \& Planetary Science, 43 (4), 657-674. 
Folco, L., Franchi, I.A., D'Orazio, M., Rocchi, S., and Schultz, L. (2000) A new Martian meteorite from the Sahara: The shergottite Dar al Gani 489. Meteoritics \& Planetary Science, 35 (4), 827-839.

Gast, P.W., and McConnell, R.K. (1972) Evidence for initial chemical layering of the Moon. Proceedings of the 3rd Lunar and Planetary Science Conference, 289-290, Lunar and Planetary Institute, Woodlands, Texas.

Gladney, E.S., and Roelandts, I. (1988) 1987 compilation of elemental concentration data for USGS BIR-1, DNC-1 and W-2. Geostandards and Geoanalytical Research, 12 (1), 63-118.

Green, T.H., and Watson, E.B. (1982) Crystallization of apatite in natural magmas under high pressure, hydrous conditions, with particular reference to 'Orogenic' rock series. Contributions to Mineralogy and Petrology (79), 96-105.

Greenwood, R.C., Franchi, I.A., Gibson, J.M., and Benedix, G.K. (2012) Oxygen isotope variation in primitive achondrites: The influence of primordial, asteroidal and terrestrial processes. Geochimica et Cosmochimica Acta, 94, 146-163.

Greshake, A., Clayton, R.N., and Mayeda, T.K. (2001) Dhofar 125: a new acapulcoite from Oman. Proceedings of the 32nd Lunar and Planetary Science Conference, 1325, Lunar and Planetary Institute, Woodlands, Texas.

Gross, J., Filiberto, J., and Bell, A.S. (2013) Water in the Martian interior: Evidence for terrestrial MORB mantle-like volatile contents from hydroxyl-rich apatite in olivine-phyric shergottite NWA 6234. Earth and Planetary Science Letters, 369-370, 120-128.

Göpel, C., Manhès, G., and Allègre, C.J. (1994) U-Pb systematics of phosphates from equilibrated ordinary chondrites. Earth and Planetary Science Letters, 121 (1-2), 153-171.

Haas, J.R., and Haskin, L.A. (1991) Compositional variations among whole-rock fragments of the L6 chondrite Bruderheim. Meteoritics, 26 (1), 13-26.

Harlow, G.E., Delaney, J.S., Nehru, C.E., and Prinz, M. (1982) Metamorphic reactions in mesosiderites: origin of abundant phosphate and silica. Geochimica et Cosmochimica Acta, 46 (3), 339-348.

Herpfer, M.A., Larimer, J.W., and Goldstein, J.I. (1994) A comparison of metallographic cooling rate methods used in meteorites. Geochimica et Cosmochimica Acta, 58 (4), 1353-1365.

Hidaka, H., and Yoneda, S. (2011) Neutron capture records of mesosiderites and an iron meteorite. Geochimica et Cosmochimica Acta, 75 (19), 5706-5715. 
Horstmann, M., and Bischoff, A. (2014) The Almahata Sitta polymict breccia and the late accretion of asteroid $2008 \mathrm{TC}_{3}$. Chemie der Erde - Geochemistry, 74 (2), 149-183.

Hsu, W., and Crozaz, G. (1996) Mineral chemistry and the petrogenesis of eucrites: i. noncumulate eucrites. Geochimica et Cosmochimica Acta, 60 (22), 4571-4591.

Hughes, J.M., Jolliff, B.L., and Rakovan, J. (2008) The crystal chemistry of whitlockite and merrillite and the dehydrogenation of whitlockite to merrillite. American Mineralogist, 93 (8-9), 13001305.

Jarosewich, E. (1990) Chemical analyses of meteorites: A compilation of stony and iron meteorite analyses. Meteoritics, 25 (4), 323-337.

Jolliff, B.L., Haskin, L.A., Colson, R.O., and Wadhwa, M. (1993) Partitioning in REE-saturating minerals: theory, experiment, and modelling of whitlockite, apatite, and evolution of lunar residual magmas. Geochimica et Cosmochimica Acta, 57 (16), 4069-4094.

Jolliff, B.L., Hughes, J.M., Freeman, J.J., and Zeigler, R.A. (2006) Crystal chemistry of lunar merrillite and comparison to other meteoritic and planetary suites of whitlockite and merrillite. American Mineralogist, 91 (10), 1583-1595.

Jones, R.H., McCubbin, F.M., Dreeland, L., Guan, Y., Burger, P.V., and Shearer, C.K. (2014) Phosphate minerals in LL chondrites: a record of the action of fluids during metamorphism on ordinary chondrite parent bodies. Geochimica et Cosmochimica Acta, 132, 120-140.

Jones, R.H., McCubbin, F.M., and Guan, Y. (2016) Phosphate minerals in the H group of ordinary chondrites, and fluid activity recorded by apatite heterogeneity in the Zag H3-6 regolith breccia. American Mineralogist, 101, 2451-2467.

Kiesl, W., and Kluger, F. (1981) The Ybbsitz-Meteorite. Meteoritics, 16, 339.

Joy, K.H., Nemchin, A.A., Grange, M.L., Lapen, T.J., Peslier, A.H., Ross, D.K., Zolensky, M.E., and Kring, D.A. (2014) Petrography, geochronology and source terrain characteristics of lunar meteorites Dhofar 925, 961 and Sayh al Uhaymir 449. Geochimica et Cosmochimica Acta, 144, 299-325.

Kiesl, W., and Kluger, F. (1981) The Ybbsitz-Meteorite. Meteoritics, 16, 339.

Klemme, S., Prowatke, S., Münker, C., Magee, C., Lahaye, Y., Zack, T., Kasemann, S.A., Cabato, E.J.A., and Kaeser, B. (2008) Synthesis and preliminary characterisation of new silicate, phosphate and titanite reference glasses. Geostandards and Geoanalytical Research (32), 3954. 
Kruijer, T.S., Kleine, T., Borg, L., Brennecka, G.A., Fischer-Gödde, M., Irving, A.J. , Bischoff, A., and Agee, C. B. (2016) Coupled ${ }^{142} \mathrm{Nd}^{-182}{ }^{18} \mathrm{~W}$ evidence for early crust formation on Mars. Lunar Planet. Sci. XLVII, \#2115, Lunar and Planetary Institute, Houston.

Laul, J.C., and Smith, M.R. (1986) Rare earth patterns in shergottite phosphates. Proceedings of the 17th Lunar and Planetary Science Conference, 464-465, Lunar and Planetary Institute, Woodlands, Texas.

Lepland, A., and Whitehouse, M.J. (2011) Metamorphic alteration, mineral paragenesis and geochemical re-equilibration of early Archean quartz-amphibole-pyroxene gneiss from Akilia, Southwest Greenland. International Journal of Earth Sciences, 100 (1), 1-22.

Lewis, J.A., and Jones, R.H. (2016) Phosphate and feldspar mineralogy of equilibrated L chondrites: The record of metasomatism during metamorphism in ordinary chondrite parent bodies. Meteoritics \& Planetary Science, 51 (10), 1886-1913.

Llorca, J., Roszjar, J., Cartwright, J.A., Bischoff, A., Ott, U., Pack, A., Merchel, S., Rugel, G., Fimiani, L., Ludwig, P., Casado, J.V., and Allepuz, D. (2013) The Ksar Ghilane 002 shergottite - the $100^{\text {th }}$ registered Martian meteorite fragment. Meteoritics \& Planetary Science, 48 (3), 493-513.

Lodders, K. (1998) A survey of shergottite, nakhlite and chassigny meteorites whole-rock compositions. Meteoritics \& Planetary Science, 33 (S4), A183-A190.

Luzius-Lange, D., and Palme, H. (1987) Trace elements in single mineral Grains from silicate inclusions in the Landes meteorite. Proceedings of the 18th Lunar and Planetary Science Conference, 586-587, Lunar and Planetary Institute, Woodlands, Texas.

McCoy, T.J., Taylor, G., and Keil, K. (1992) Zagami: Product of a two-stage magmatic history. Geochimica et Cosmochimica Acta, 56 (9), 3571-3582.

McCubbin, F.M., and Jones, R.H. (2015) Extraterrestrial apatite: Planetary geochemistry to astrobiology. Elements, 11 (3), 183-188.

McCubbin, F.M., Steele, A., Hauri, E.H., Nekvasil, H., Yamashita, S., and Hemley, R.J. (2010) Nominally hydrous magmatism on the moon. Proceedings of the National Academy of Sciences of the United States of America, 107 (25), 11223-11228.

McCubbin, F.M., Jolliff, B.L., Nekvasil, H., Carpenter, P.K., Zeigler, R.A., Steele, A., Elardo, S.M., and Lindsley, D.H. (2011) Fluorine and chlorine abundances in lunar apatite: implications for heterogeneous distributions of magmatic volatiles in the lunar interior. Geochimica et Cosmochimica Acta, 75 (17), 5073-5093. 
McCubbin, F.M., Hauri, E.H., Elardo, S.M., Vander Kaaden, K. E., Wang, J., and Shearer, C.K. (2012) Hydrous melting of the Martian mantle produced both depleted and enriched shergottites. Geology, 40 (8), 683-686.

McCubbin, F.M., Shearer, C.K., Burger, P.V., Hauri, E.H., Wang, J., Elardo, S.M., and Papike, J.J. (2014) Volatile abundances of coexisting merrillite and apatite in the Martian meteorite Shergotty: implications for merrillite in hydrous magmas. American Mineralogist, 99 (7), 1347 1354.

Mikouchi, T., Miyamoto, M., and McKay, G.A. (2001) Mineralogy and petrology of the Dar al Gani 476 Martian meteorite: Implications for its cooling history and relationship to other shergottites. Meteoritics \& Planetary Science, 36 (4), 531-548.

Min, K., Farley, K.A., Renne, P.R., and Marti, K. (2003) Single grain (U-Th)/He ages from phosphates in Acapulco meteorite and implications for thermal history. Earth and Planetary Science Letters, 209 (3-4), 323-336.

Mittlefehldt, D.W. (2007) Achondrites. In: Holland, H.D., and Turekian, K.K., Eds, Treatise on Geochemistry - Volume 1: Meteorites and Cosmochemical Processes, p. 235-266, Elsevier, Oxford.

Mittlefehldt, D.W., Rubin, A.E., and Davis, A.M. (1992) Mesosiderite clasts with the most extreme positive europium anomalies among solar system rocks. Science (New York, N.Y.), 257 (5073), 1096-1099.

Moggi-Cecchi, V., Pratesi, G., and Mancini, L. (2005) NWA 1052 and NWA 1054: Two new primitive achondrites from North West Africa. Proceedings of the 36th Lunar and Planetary Science Conference, 1808, Lunar and Planetary Institute, Woodlands, Texas.

Murty, S.V.S., Rai, V.K., Shukla, A.D., Srinivasan, G., Shukla, P.N., Suthar, K.M., Bhandari, N., and Bischoff, A. (2004) Devgaon (H3) chondrite: Classification and complex cosmic ray exposure history. Meteoritics \& Planetary Science, 39 (3), 387-399.

Nehru, C.E., Zucker, S.M., Harlow, G.E., and Prinz, M. (1980) Olivines and olivine coronas in mesosiderites. Geochimica et Cosmochimica Acta, 44 (8), 1103-1118.

Nemchin, A.A., Pidgeon, R.T., Healy, D., Grange, M.L., Whitehouse, M.J., and Vaughan, J. (2009) The comparative behavior of apatite-zircon U-Pb systems in Apollo 14 breccias: Implications for the thermal history of the Fra Mauro Formation. Meteoritics \& Planetary Science, 44 (11), 1717-1734. 
Olsen, E., and Fuchs, L.H. (1967) The state of oxidation of some iron meteorites. Icarus, 6 (1-3), $242-253$.

Olsen, E.J., Kracher, A., Davis, A.M., Steele, I.A., Hutcheon, I.D., and Bunch T.E. (1999) The phosphates of IIIAB iron meteorites. Meteoritics \& Planetary Science, 34 (2), 285-300.

O'Reilly, S.Y., and Griffin, W. (2000) Apatite in the mantle: Implications for metasomatic processes and high heat production in Phanerozoic mantle. Lithos, 53 (3-4), 217-232.

Palme, H., Schultz, L., Spettel, B., Weber, H.W., Wänke, H., Michel-Levy, M.C., and Lorin, J.C. (1981) The Acapulco meteorite - chemistry, mineralogy and irradiation effects. Geochimica et Cosmochimica Acta, 45, 727-729.

Palme, H., Hutcheon, I.D., Kennedy, A.K., Sheng, Y.J., and Spettel, B. (1991) Trace Element Distribution In Minerals From A Silicate Inclusion In The Caddo IAB-Iron Meteorite. Proceedings of the $22^{\text {nd }}$ Lunar and Planetary Science Conference, 1015-1016, Lunar and Planetary Institute, Woodlands, Texas.

Patiño-Douce, A.E., and Roden, M. (2006) Apatite as a probe of halogen and water fugacities in the terrestrial planets. Geochimica et Cosmochimica Acta, 70 (12), 3173-3196.

Patiño-Douce, A.E., Roden, M.F., Chaumba, J., Fleisher, C., and Yogodzinski, G. (2011) Compositional variability of terrestrial mantle apatites, thermodynamic modeling of apatite volatile contents, and the halogen and water budgets of planetary mantles. Chemical Geology, $288,14-31$.

Powell, B.N. (1971) Petrology and chemistry of mesosiderites - ii. silicate textures and compositions and metal-silicate relationships. Geochimica et Cosmochimica Acta, 35 (1), 5-34.

Prinz, M., Delaney, J.S., Harlow, G.E., Bedell, R.L., and Nehru, C.E. (1980) Modal studies of mesosiderites and related achondrites, including the new mesosiderite ALHA 77219. Proceedings of the $11^{\text {th }}$ Lunar and Planetary Science Conference, 1055-1071, Lunar and Planetary Institute, Woodlands, Texas.

Reed, S.J.B., Smith, D.G.W., and Long, J.V.P. (1983) Rare earth elements in chondritic phosphates — implications for ${ }^{244} \mathrm{Pu}$ chronology. Nature, 306 (5939), 172-173.

Roszjar, J., Metzler, K., Bischoff, A., Barrat, J.A., Geisler, T., Greenwood, R.C., Franchi, I.A., and Klemme, S. (2011) Thermal history of Northwest Africa 5073 - a coarse-grained Stannerntrend eucrite containing cm-sized pyroxenes and large zircon grains. Meteoritics \& Planetary Science, 46 (11), 1754-1773. 
Roszjar, J., John, T., Whitehouse, M.J., and Layne, G.D. (2013) Halogens in the early solar system inferred from meteoritic phosphates. Mineralogical Magazine, 77 (5), 2015-2107.

Roszjar, J., Whitehouse, M.J., and Bischoff, A. (2014) Meteoritic zircon - Occurrence and chemical characteristics. Chemie der Erde - Geochemistry, 74, 453-469.

Rubin, A.E. (1997) Mineralogy of meteorite groups. Meteoritics \& Planetary Science (32), 231-247.

Rubin, A.E., and Grossman, J.N. (1985) Phosphate-sulfide assemblages and Al/Ca ratios in type-3 chondrites. Meteoritics \& Planetary Science, 20, 479-489.

Russell, S.S., Zolensky, M.E., Righter, K., Folco, L., Jones, R.H., Conolly, H.C., Grady, M.M., and Grossman, J.N. (2005) The Meteoritical Bulletin, no. 89, 2005 September. Meteoritics \& Planetary Science, 40 (S9), A201-A263.

Ruzicka, A., Killgore, M., Mittlefehldt, D.W., and Fries, M.D. (2005) Portales Valley: Petrology of a metallic-melt meteorite breccia. Meteoritics \& Planetary Science, 40 (2), 261-295.

Ruzicka, A., Grossman, J.N., and Garvie, L. (2014) The Meteoritical Bulletin, no. 100, 2014 June. Meteoritics \& Planetary Science, 49 (8), E1-E101.

Sarafian, A.R., Roden, M.F., and Patiño-Douce, A.E. (2013) The volatile content of Vesta: Clues from apatite in eucrites. Meteoritics \& Planetary Science, 48 (11), 2135-2154.

Sarafian, A.R., John, T., Roszjar, J. and Whitehouse, M.J. (2017) Chlorine and hydrogen degassing in Vesta's magma ocean. Earth and Planetary Science Letters 459, 311-319.

Van Schmus, W.R., and Ribbe, P.H. (1969) Composition of phosphate minerals in ordinary chondrites. Geochimica et Cosmochimica Acta, 33 (5), 637-640.

Scott, E.R., and Bild, R.W. (1974) Structure and formation of the San Cristobal meteorite, other IB irons and group IIICD. Geochimica et Cosmochimica Acta, 38 (9), 1379-1391.

Sepp, B., Bischoff, A., and Bosbach, D. (2001) Low-temperature phase decomposition in iron-nickel metal of the Portales Valley meteorite. Meteoritics \& Planetary Science, 36 (5), 587-595.

Shearer, C.K., Burger, P.V., Papike, J.J., McCubbin, F.M., and Bell, A.S. (2015) Crystal chemistry of merrillite from Martian meteorites: Mineralogical recorders of magmatic processes and planetary differentiation. Meteoritics \& Planetary Science, 50 (4), 649-673.

Sokol, A.K., Bischoff, A., Marhas, K.K., Mezger, K., and Zinner, E. (2007a) Late accretion and lithification of chondritic parent bodies: $\mathrm{Mg}$ isotope studies on fragments from primitive chondrites and chondritic breccias. Meteoritics \& Planetary Science 42, 1291-1308. 
Sokol, A.K., Mezger, K., Chaussidon, M. and Bischoff, A. (2007b) Simultaneous accretion of differentiated or metamorphosed asteroidal clasts and chondrules. Meteoritics \& Planetary Science 42, A143.

Stelzener, T., Heide, K., Bischoff, A., Weber, D., Scherer, P., Schultz, L., Happel, M., Schrön, W., Neupert, U., Michel, R., Clayton, R.N., Mayeda, T.K., Bonani, G., Haidas, I., Ivy-Ochs, S., and Suter, M. (1999) An interdisciplinary study of weathering effects in ordinary chondrites from the Acfer region, Algeria. Meteoritics \& Planetary Science, 34 (5), 787-794.

Stöffler, D., Keil, K., and Scott, E.R.D. (1991) Shock metamorphism of ordinary chondrites. Geochimica et Cosmochimica Acta, 55 (12), 3845-3867.

Stolper, E. (1977) Experimental petrology of eucritic meteorites. Geochimica et Cosmochimica Acta, 41 (5), 587-611.

Terada, K., and Sano, Y. (2004) Ion microprobe U-Th-Pb dating and REE analyses of phosphates in the Nakhlites Lafayette and Yamato-000593/000749. Meteoritics \& Planetary Science, 39 (12), 2033-2041.

Terada K., and Bischoff A. (2009) Asteroidal granite-like magmatism 4.53 Gyr ago. The Astrophysical Journal 699, L68-L71.

Wadhwa, M., McSween, H.Y., and Crozaz, G. (1994) Petrogenesis of shergottite meteorites inferred from minor and trace element microdistributions. Geochimica et Cosmochimica Acta, 58 (19), 4213-4229.

Ward, D., Roszjar, J., Bischoff, A., and Leschner, L. (2014) Accessory Ca-phosphates in meteorites distribution and composition (abstract MET-P01). DMG-Meeting Jena, 210.

Ward, D., Bischoff, A., Roszjar, J., and Whitehouse, M.J. (2015) REE content of meteoritic Caphosphates. Meteoritics \& Planetary Science 50, Special Issue, \#5056.

Ward, D., Bischoff, A., Roszjar, J., and Whitehouse, M.J. (2016) Trace element inventory of meteoritic Ca-phosphates. Lunar Planet. Sci. XLVII, \#1456, Lunar and Planetary Institute, Houston.

Warren, P.H., Greenwood, J.P., and Rubin, A.E. (2004) Los Angeles: A tale of two stones. Meteoritics \& Planetary Science, 39 (1), 137-156.

Wasson, J.T. (1974) Meteorites: Classification and Properties, 316p. Springer-Verlag, Berlin.

Watson, E.B. (1979) Apatite saturation in basic to intermediate magmas. Geophysical Research Letters, 6 (12), 937-940. 
Weisberg, M.K., Smith, C., Benedix, G.K., Folco, L., Righter, K., Zipfel, J., Yamagushi, A., and Aoudjehane, H.C. (2008) The Meteoritical Bulletin, no. 94, September 2008. Meteoritics \& Planetary Science, 43 (9), 1551-1584.

Wittke, J.H., Bunch, T.E., Irving, A.J., Farmer, M., and Strope, J. (2006) Northwest Africa 2975: an evolved basaltic shergottite with vesicular glass pockets and trapped melt inclusions. Proceedings of the 37th Lunar and Planetary Science Conference, 1368, Lunar and Planetary Institute, Woodlands, Texas.

Whitehouse, M.J., Kamber, B.S., and Moorbath, S. (1999) Age significance of U-Th-Pb zircon data from early Archaean rocks of West Greenland - a reassessment based on combined ionmicroprobe and imaging studies. Chemical Geology, 160 (3), 201-224.

Wlotzka, F. (1993) The Meteoritical Bulletin, no. 74, Meteoritics, 28 (1), 146-153.

Yagi, K., Lovering, J.F., Shima, M., and Okada, A. (1978) Petrology of the Yamato meteorites (j), (k), (l), and (m) from Antarctica. Meteoritics, 13 (1), 23-45.

Yamaguchi, A., Takeda, H., Bogard, D.D., and Garrison, D. (1994) Textural variations and impact history of the Millbillillie eucrite. Meteoritics 29 (2), 237-245.

Yang, S., Humayun, M., Jefferson, G., Fields, D., Righter, K., and Irving, A.J. (2013) Chemical composition of four shergottites from Northwest Africa (NWA 2800, NWA, 5214, NWA 5990, NWA 6342). Proceedings of the 44th Lunar and Planetary Science Conference, \#1738, Lunar and Planetary Institute, Woodlands, Texas.

Xie, X., Yang, H., Gu, X., and Downs, R.T. (2015) Chemical composition and crystal structure of merrillite from the Suizhou meteorite. American Mineralogist, 100 (11-12), 2753-2756.

Zipfel, J., Palme, H., Kennedy, A.K., and Hutcheon, I.D. (1995) Chemical composition and origin of the Acapulco meteorite. Geochimica et Cosmochimica Acta, 59 (17), 3607-3627.

Zipfel, J., Scherer, P., Spettel, B., Dreibus, G., and Schultz, L. (2000) Petrology and chemistry of the new shergottite Dar al Gani 476. Meteoritics \& Planetary Science, 35 (1), 95-106.

\section{Supplementary Material}

SUPPLEMENTARY TABLE S1.

SUPPLEMENTARY TABLE S2.

SUPPLEMENTARY TABLE S3.

SUPPLEMENTARY TABLE S4.

SUPPLEMENTARY TABLE S5.

SUPPLEMENTARY FIG. S1

SUPPLEMENTARY FIG. S2
Individual phosphate analyses, provided in an excel spreadsheet.

Analyzed additional reference material, provided in an excel spreadsheet.

Composition of the Durango apatite and comparison to literature data.

Average REE concentrations of the major REE carrier phases in ALM-A.

Mass balance calculations forSm in achondrites.

Apatite with labeled SIMS and LA-ICP-MS spots and corresponding REE patterns Bulk range of the $\mathrm{Na}_{2} \mathrm{O}$ vs $\mathrm{P}_{2} \mathrm{O}_{5}$ content from the meteorite groups analyzed. 


\section{List of figure captions}

Figure 1. Back-scattered electron (BSE) images of meteoritic Ca-phosphates at the metal-sulfide interface. (a) Both phosphate species associated with the Fe-Ni-alloys kamacite and taenite. (b) Merrillite assembled with Fe-sulfide, chromite, olivine, and $\mathrm{Fe}-\mathrm{Ni}$ alloys. (c) Large apatite-pyroxene and merrillite inclusions within the metal phase. The small white areas are remnants of prior gold coating and not indigenous to the sample. (d) Apatite inclusion within magnetitesulfide.

Figure 2. BSE images of silicate assemblages with meteoritic Ca-phosphates. (a) Apatite located among plagioclase, low-Ca pyroxene and olivine. (b) Merrillite grains enveloping a CAI. (c) Fragment composed of pyroxene, plagioclase, and apatite with small magnetite inclusions. (d) Lath-shaped apatite in paragenesis with pyroxene and feldspar. (e) Merrillite grain with a thin apatite rim in one corner facing a silica polymorph, which also occurs as inclusions within the merrillite. It is associated with pyroxene, plagioclase. (f) Large merrillite grain with inclusions of plagioclase, olivine, ilmenite, Ti-magnetite and $\mathrm{SiO}_{2}$-polymorph, located within a symplectite area (Llorca et al. 2013).

Figure 3. Mineral assemblages of Ca-phosphates in the Adzhi-Bogdo (stone) LL3-6 chondritic breccia. (a) Merrillite in contact with chromite, olivine, pyroxene and plagioclase in a chondritic, strongly recrystallized type 6 fragment. (b) Apatite with small olivine inclusions (mostly $<5 \mu \mathrm{m}$ ) in a similar highly metamorphic association. (c) Subhedral to anhedral apatite at the corner of an "achondritic fragment" consisting of K-feldspar and plagioclase embedded in the fine-grained, clastic matrix. The small white spots are remnants of past gold-coating of the section. (d) Euhedral and subhedral apatite grains within an "achondritic fragment" dominated by silica polymorph and Kfeldspar.

Figure 4. Chemical variation of $\mathrm{MgO}$ vs. $\mathrm{FeO}$ ( $\mathrm{a}$ and $\mathrm{b}$ ) and $\mathrm{Na}_{2} \mathrm{O}$ (c and d) for merrillite (a and c) and apatite (b and d). Each point illustrates a single analysis: circles and diamonds represent apatite, while triangles and squares correspond to merrillite. 
Figure 5. Ternary plot of anion abundances in apatite within the different meteorite groups. The marked areas correspond to the ranges of data published by Patiño-Douce and Roden (2006), Sarafian et al. (2013), Jones et al. (2014), McCubbin et al. (2014), and McCubbin and Jones (2015). Restricted variation is observed for most meteorite types, with Cl-rich apatite in undifferentiated samples and F-rich apatite in primitive achondrites other differentiated meteorites, except for Martian samples which show a lot of scatter.

Figure 6. Apatite REE abundances in chondrites normalized to bulk CI chondrite (Barrat et al. 2012); individual analyses are available in the supplement (Tab. S1). Colored fields mark the range obtained by all analyses of the same phosphate species within the context of this study; lines correspond to the average of the given field. Gray areas indicate literature data from Bremervörde (H4), Forest Vale (H4), Beaver Creek (H4), Alta'ameem (LL5), Guidder (LL5), St.Severin (LL6) and Uden (LL6) from Crozaz et al. (1989). Apatite REE-patterns (a) with positive Eu anomaly in Devgaon (H3.8) and Portales Valley (H6); (b) without pronounced Eu anomaly in Ybbsitz (H4), Bruderheim (L6), and Villalbeto de la Peña (L6); (c) with enrichment in Ce and $\operatorname{Pr}$ from the Karoonda CK4 carbonaceous chondrite; (d) in the Adzhi-Bogdo LL3-6 regolith breccia. The purple field marks the range in the chondritic portion consistent with patterns of other ordinary chondrites shown in (b). Colored lines correspond to single analyses of apatite located in the achondritic fragments, each color representing a different fragment. Apatite from these fragments is more enriched $(\sim 100-250 \times \mathrm{CI})$ and has flat REE patterns with negative Eu anomalies, similar to patterns observed in achondrites (Fig.7).

Figure 7. Apatite REE abundances in achondrites normalized to CI chondrite (Barrat et al. 2012); individual analyses are available in the supplement (Tab. S1). Colored fields mark the range obtained by all analyses of the same phosphate species within this study; the lines correspond to the average of the given field. Gray areas mark available literature data for the corresponding samples or meteorite groups. Apatite REE-patterns from (a) the acapulcoites Dhofar 125 and Acapulco, relative to literature data from Zipfel et al. (1995); (b) the winonaite HaH 193 and the ureilitic trachyandesite ALM-A. Apatite REE-patterns from both samples resemble those of (a). While ALM-A apatite exhibits a more pronounced slope from La to $\mathrm{Lu}, \mathrm{HaH} 193$ apatite shows a much higher spread of overall REE-enrichment (but consistent pattern shapes); (c) the eucrites NWA 5073 and Millbillillie, 
and Landes IAB iron meteorite. The gray area marks the range of eucritic apatite documented by Hsu and Crozaz (1996).

Figure 8. Merrillite REE abundances normalized to CI chondrite (Barrat et al. 2012); individual analyses are available in the supplement (Tab. S1). The colored fields mark the range obtained by all analyses of the same phosphate species, lines correspond to the average of the given field. Gray areas illustrate available literature data for the corresponding meteorite groups or samples. (a) average of each sample is illustrated by the numbered solid lines (\#1-6). Patterns are generally congruent with literature data from Crozaz et al. (1989), yet Ybbsitz (\#5) and Portales Valley (\#6) are less REE-enriched. (b) Merrillite REE data for acapulcoites and the Millbillillie eucrite, relative to literature data from Zipfel et al. (1995) for acapulcoites (light gray) and Hsu and Crozaz (1996) for eucrites (dark gray); both are in good agreement with the obtained data. (c) REE patterns in Dalgaranga (purple field) and Bondoc (green field) mesosiderites, as well as from the Landes IAB silicate iron meteorite (red field). Data for mesosiderites Vaca Muerta, Emery, and Morristown (Crozaz et al. 1985) are outlined in gray, with the individual patterns from these samples displayed as the gray, dotted lines.

Figure 9. Merrillite REE abundances in shergottites normalized to CI (Barrat et al. 2012); individual analyses are available in the supplement (Tab. S1). The colored fields mark the range of all merrillite analyses; the solid lines correspond to the average of the given sample. The gray areas are literature data for the corresponding subtype after Shearer et al. (2015); (a) from the depleted shergottites DaG 1051 (purple) and SaU 005 (yellow). Dotted lines correspond to whole rock REE patterns by Folco et al. (2000; note that the pattern illustrates data on DaG 476 which is paired with DaG 1051) and Dreibus et al. (2000; SaU 005); (b) from the enriched shergottites Zagami (blue) and NWA 4864 (magenta). Both dotted lines correspond to whole rock REE patterns by Barrat et al. (2001; Zagami) and Bendel (2013; NWA 4864).

Figure 10. Plot of the REE $+\mathrm{Y}$ atoms vs. Na atoms (both per formula unit (apfu), based on 56 oxygen atoms) in the analyzed merrillite grains, relative to literature data. REE substitution of $\mathrm{Ca}$ within the merrillite crystal structure requires charge balance, which then in turn leads to vacancies that were initially occupied by $\mathrm{Na}$ in the ideal merrillite structure (Jolliff et al. 2006). Hence, eucritic and lunar merrillite high in REE, show very low Na atoms per formula unit. While mesosiderites also show very low $\mathrm{Na}$ content $(<0.75$ apfu.), the remaining, non-Martian 
meteorites exhibit higher $\mathrm{Na}$ abundances close to the ideal formula of 2 atoms per 56 oxygens. Figure after Jolliff et al. (2006; Figs. 5 and 6) and Shearer et al. (2015; Fig. 8).

Figure 11. Average REE concentrations of the main REE carrier phases in the ALM-A ureilitic trachyandesite. The bulk rock REE pattern is calculated based on REE averages of each phase (details in supplemental table S4) and the modal abundances given by Bischoff et al. (2014).

Figure 12. Positive correlation of apatite $U$ vs. Th concentrations, given in $\mu \mathrm{g} / \mathrm{g}$ among different meteorites and planetary bodies. Note that both abundances increase with the grade of metamorphism (petrologic type) and with the degree of differentiation of the respective parent body. Colored areas label literature data for Lunar (blue), Martian (orange) and mafic terrestrial (gray) apatite by Nemchin et al. (2009), Terada and Sano (2004), and O'Reilly and Griffin (2009).

Figure 13. CI-normalized non-REE trace element abundances in (a) apatite and (b) merrillite from chondrites. Data are presented relative to CI from Barrat et al. (2012). The abundances do not correlate with the petrologic type of the host chondrite in either species, yet apatite shows more variation in its non REE trace element inventory, especially considering $\mathrm{Sc}-\mathrm{Y}$, when compared with merrillite.

Figure 14. CI-normalized (Barrat et al. 2012) non-REE trace element abundances in (a) primitive achondrites and (b-d) differentiated meteorites (mesosiderites, eucrites and shergottites). In contrast to the REE, the remaining trace elements are not universally enriched in merrillite when compared to apatite, if both are present in the same sample. 


\section{Tables}

TABLE 1: Details of the analyzed Ca-phosphate bearing meteorites from the sample suite.

\begin{tabular}{|c|c|c|c|c|c|c|c|c|c|c|c|c|}
\hline group & subgroup type & sample & sample id & discovery & shock & weathering & literature & $\begin{array}{c}\text { bulk } \mathrm{P}_{2} \mathrm{O}_{5} \\
\text { wt\% }\end{array}$ & $\begin{array}{l}\text { modal } \\
\text { abunance } \\
\text { vol\% }\end{array}$ & Ap & Mer & $\begin{array}{l}\text { ratio } \\
\text { Ap/Mer }\end{array}$ \\
\hline \multirow{8}{*}{$\begin{array}{l}\text { Ordinary } \\
\text { chondrites }\end{array}$} & H3.8 & Devgaon & PL15259 & fall & S2 & W0 & a & & $0.18^{*}$ & yes & yes & $1: 1.75$ \\
\hline & H4 & Ybbsitz & PL89476 & find & S2 & W1 & $b$ & & & yes & yes & $2: 1$ \\
\hline & H5 & Allegan & PL00252 & fall & S1 & wo & c & $0.27^{y}$ & & no & yes & \\
\hline & H6 & Portales Valley & PL99051 & fall & S2 & wo & $d$ & & $2.95^{2}$ & yes & yes & $1: 1.5$ \\
\hline & L3.8 & Aguemour 009 & PL92311 & find & S3 & W1 & e & & & & yes & \\
\hline & L6 & Bruderheim & PL90272 & fall & S4 & wo & $f$ & $0.21^{y}$ & & yes & yes & $2: 1$ \\
\hline & L6 & Villalbeto de la Peña & $\begin{array}{l}\text { PL13067 } \\
\text { PL13068 }\end{array}$ & fall & S4 & wo & g & & $0.31 *$ & yes & Yes & $1: 2$ \\
\hline & LL3-6 & Adzhi-Bogdo (stone) & $\begin{array}{l}\text { PL92505 A } \\
\text { PL92505 C } \\
\text { PL02135 }\end{array}$ & fall & S2 & W2 & $\mathrm{h}$ & & $0.29 *$ & yes & yes & $2.5: 1$ \\
\hline $\begin{array}{l}\text { Carbonaceous } \\
\text { chondrite }\end{array}$ & CK4 & Karoonda & PL89180 & fall & S1 & Wo & $\mathrm{i}$ & & & yes & no & \\
\hline \multirow{3}{*}{\multicolumn{2}{|c|}{ Acapulcoites }} & Acapulco & $\begin{array}{l}\text { PL11017 } \\
\text { PL11018 }\end{array}$ & fall & S2 & W0 & $\bar{j}$ & $1.0^{j}-1.6^{\text {aa }}$ & $<1.1^{*}$ & yes & yes & $2: 1$ \\
\hline & & Dhofar 125 & PL01019 & find & S1 & W1-2 & k & & $0.65^{*}$ & yes & no & \\
\hline & & NWA 1052 & PL02138 & find & S1 & W2-3 & 1 & & $0.85^{*}$ & no & yes & \\
\hline \multicolumn{2}{|l|}{ Winonaite } & HaH 193 & PL96276 & find & S1 & W3 & $\mathrm{m}$ & & $0.1-0.3^{\mathrm{m}-}$ & yes & no & \\
\hline \multirow[t]{2}{*}{ HED } & \multirow[t]{2}{*}{ eucrites } & NWA 5073 & PL15260 & find & S2 & W2-3 & $\mathrm{n}$ & & $<0.1^{*}$ & yes & yes & $4: 1$ \\
\hline & & Millbillillie & PL89504 & fall & S3 & Wo/1 & o & & $<0.1^{*}$ & yes & yes & $3: 1$ \\
\hline \multirow{5}{*}{$\begin{array}{l}\text { Martian } \\
\text { meteorites }\end{array}$} & \multirow[t]{5}{*}{ shergottites } & SaU 005 & PL00123 & find & S5 & W1 & $p$ & $0.31^{p^{-}}$ & $0.24 *$ & no & yes & \\
\hline & & DaG 1051 & PL09224 & find & S5 & W1 & q & $0.32^{\mathrm{ab}}-0.49^{\mathrm{q}}$ & $0.69^{*}-1^{\mathrm{ac}}$ & no & yes & \\
\hline & & Zagami & PL97001 & fall & S5 & wo & $r$ & $0.5^{\mathrm{ad}}-0.58^{\mathrm{ae}}$ & $0.6-1.2^{\mathrm{ae}}$ & yes & yes & $1: 2$ \\
\hline & & KG 002 & PL11155 & find & S5 & W2-3 & s & $1.5^{\mathrm{s}}$ & $2.7^{\mathrm{s}}$ & yes & yes & $1: 2$ \\
\hline & & NWA 4864 & PL08011 & find & S5 & W1 & $\mathrm{t}$ & $1.45^{\text {af }}$ & $1.7^{\mathrm{ag}}$ & yes & yes & $1: 3$ \\
\hline Ureilite & trachyandesite (ALM-A) & Almahata Sitta & PL13030 & fall & S2 & wo & $\mathrm{u}$ & $0.52^{\mathrm{u}}$ & $0.95^{*}$ & yes & yes & \\
\hline Stony irons & Mesosiderites & $\begin{array}{l}\text { Dalgaranga } \\
\text { Bondoc }\end{array}$ & $\begin{array}{l}\text { PL05175 } \\
\text { PL05176 }\end{array}$ & find & $\begin{array}{l}\text { S2 } \\
\text { S2 }\end{array}$ & $\begin{array}{l}\text { W3 } \\
\text { W3 }\end{array}$ & $\mathrm{v}$ & & $\begin{array}{c}1^{*}-3.4^{\text {ah }} \\
0.2^{\text {ah }}\end{array}$ & no & $\begin{array}{l}\text { yes } \\
\text { yes }\end{array}$ & \\
\hline Iron meteorite & $\mathrm{IAB}$ & Landes & $\begin{array}{l}\text { PL15257 } \\
\text { PL15258 }\end{array}$ & find & noPTs & $\begin{array}{l}\text { no } \\
\text { PTS }\end{array}$ & $\mathrm{x}$ & $0.24^{x}$ & & yes & yes & \\
\hline \multicolumn{13}{|c|}{$\begin{array}{l}\text { Ap = apatite; Mer = merrillite; NWA = Northwest Africa; HaH = Hammadah al Hamra; SaU = Sayh al Uhaymir; DaG = Dar al Gani; KG = Ksar Ghilane; PTS = polished thin } \\
\text { section; }{ }^{*}=\text { obtained from mappings, see text for details. }{ }^{* *}=\text { Ca-phosphate grains were identified in mappings. The ratio corresponds to the number of the identified grains. } \\
\text { Shock stages determined based on Stöffler et al. (1991) for ordinary chondrites. }\end{array}$} \\
\hline \multicolumn{13}{|c|}{$\begin{array}{l}\text { References: a) Murty et al. 2004; b) Kiesl 1981; c) Easton and Elliot 1977; d) Sepp et al. 2001; e) Wlotzka, 1993; f) Haas \& Haskin 1991; g) Dyl et al. 2012; Bischoff et al. 2013; } \\
\text { h) Bischoff et al. 1993; i) Fitzgerald 1979; j) Palme et al. 1981; Zipfel et al 1995; Min et al. 2003 k) Greshake et al. 2001; I) Moggi-Cecchi et al. 2005; m) Floss et al. 2007; n) } \\
\text { Roszjar et al. 2011; o) Yamaguchi et al. 1994; p) Dreibus et al. 2000; q) Folco et al. } 2000 \text { on DaG 489, paired with DaG 1051; r) McCoy et al. 1992; s) Llorca et al. 2013; t) } \\
\text { Weisberg et al. 2008; Ruzicka et al. 2014; u) Bischoff et al. 2014; Horstmann \& Bischoff 2014; v) Delaney et al. 1980; Nehru et al. 1980; w) Powell 1971; x) Bunch et al. 1972; } \\
\text { Herpfer et al. (1994); y) Jarosewich 1990; z) Ruzicka et al. 2005; aa) Mittlefehldt 2007; ab) Zipfel et al. 2000; ac) Mikouchi et al. 2001 on DaG 476 paired with DaG 1051; ad) } \\
\text { Lodders 1998; ae) McCoy et al. 1992; af) Yang et al. } 2013 \text { on NWA 5214, paired with NWA 4864; ag) Wittke et al. } 2006 \text { on NWA 2975, paired with NWA 4864); ah) Prinz et al. } \\
\text { 1980; }\end{array}$} \\
\hline
\end{tabular}




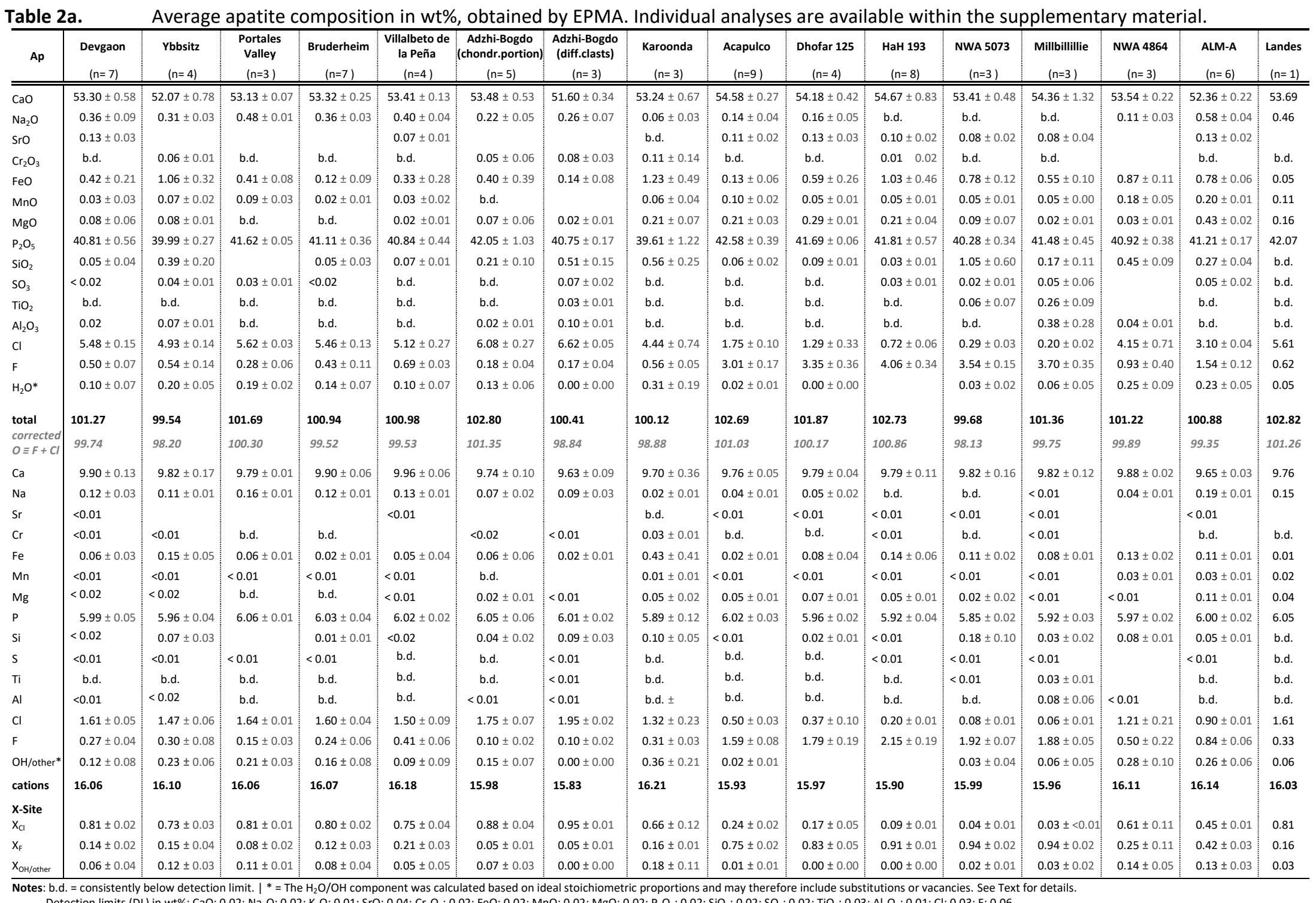

Detection limits (DL) in wt\%: $\mathrm{CaO}: 0.02 ; \mathrm{Na}_{2} \mathrm{O}: 0.02 ; \mathrm{K}_{2} \mathrm{O}: 0.01 ; \mathrm{SrO}: 0.04 ; \mathrm{Cr}_{2} \mathrm{O}_{3}: 0.02 ; \mathrm{FeO}: 0.02 ; \mathrm{MnO}: 0.02 ; \mathrm{MgO}: 0.02 ; \mathrm{P}_{2} \mathrm{O}_{5}: 0.02 ; \mathrm{SiO}_{2}: 0.02 ; \mathrm{SO}_{3}: 0.02 ; \mathrm{TiO}_{2}: 0.03 ; \mathrm{Al}_{2} \mathrm{O}_{2}: 0.01 ; \mathrm{Cl}: 0.03 ; \mathrm{F}: 0.06$ 
Table 2b.

Average merrillite composition in wt\%, obtained by EPMA. Individual analyses are available within the supplementary material.

\begin{tabular}{|c|c|c|c|c|c|c|c|c|c|c|c|c|c|c|c|c|c|c|}
\hline Mer & $\begin{array}{c}\text { Devgaon } \\
(\mathrm{n}=7) \\
\end{array}$ & $\begin{array}{r}\begin{array}{r}\text { Ybbsitz } \\
(\mathrm{n}=3)\end{array} \\
\end{array}$ & $\begin{array}{l}\text { Allegan } \\
(n=5)\end{array}$ & $\begin{array}{l}\text { Portales } \\
\text { Valley } \\
(\mathrm{n}=7) \\
\end{array}$ & 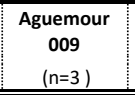 & $\begin{array}{c}\text { Villalbeto } \\
(\mathrm{n}=10)\end{array}$ & $\begin{array}{c}\text { Adzhi-Bogdo } \\
(\mathrm{n}=5)\end{array}$ & $\begin{array}{c}\text { Acapulco } \\
(n=7)\end{array}$ & $\begin{array}{c}\text { NWA } 1052 \\
(\mathrm{n}=3)\end{array}$ & $\begin{array}{c}\text { Milllillillie* } \\
(\mathrm{n}=2)\end{array}$ & $\begin{array}{c}\mathrm{SaU} 005 \\
(\mathrm{n}=3)\end{array}$ & $\begin{array}{c}\text { DaG1051 } \\
(\mathrm{n}=5) \\
\end{array}$ & $\begin{array}{c}\text { NWA 4864 } \\
(n=4)\end{array}$ & $\begin{array}{r}\text { Zagami } \\
(n=11)\end{array}$ & $\begin{array}{r}K G 002 \\
(n=4)\end{array}$ & $\begin{array}{c}\text { Dalgaranga } \\
(n=5)\end{array}$ & $\begin{array}{r}\text { Bondoc } \\
(n=12) \\
\end{array}$ & $\begin{array}{c}\text { Landes } \\
(\mathrm{n}=1)\end{array}$ \\
\hline $\mathrm{CaO}$ & $46.79 \pm 0.52$ & $46.87 \pm 0.40$ & $46.85 \pm 0.22$ & $46.76 \pm 0.18$ & $45.50 \pm 0.05$ & $46.67 \pm 0.39$ & $46.11 \pm 0.42$ & $46.53 \pm 0.59$ & $46.73 \pm 0.20$ & $42.89 \pm 1.71$ & $46.63 \pm 0.60$ & $47.78 \pm 0.16$ & $47.17 \pm 0.20$ & $46.49 \pm 0.68$ & $46.44 \pm 0.31$ & $43.99 \pm 2.03$ & $48.26 \pm 0.20$ & 47.09 \\
\hline $\mathrm{Na}_{2} \mathrm{O}$ & $2.86 \pm 0.09$ & $2.78 \pm 0.06$ & $2.77 \pm 0.06$ & $2.77 \pm 0.04$ & $2.71 \pm 0.01$ & $2.79 \pm 0.09$ & $2.63 \pm 0.06$ & $2.70 \pm 0.12$ & $2.63 \pm 0.04$ & $0.56 \pm 0.18$ & $1.74 \pm 0.15$ & $1.32 \pm 0.17$ & $1.35 \pm 0.07$ & $1.39 \pm 0.08$ & $1.15 \pm 0.08$ & $0.68 \pm 0.08$ & $0.95 \pm 0.05$ & 2.90 \\
\hline $\mathrm{K}_{2} \mathrm{O}$ & $0.04 \pm 0.01$ & $0.06 \pm 0.01$ & $0.05 \pm 0.01$ & $0.06 \pm 0.01$ & $0.07 \pm 0.01$ & $0.06 \pm 0.01$ & $0.04 \pm 0.01$ & $0.07 \pm 0.03$ & $0.07 \pm 0.01$ & $0.05 \pm 0.01$ & $0.02 \pm<0.01$ & & & $0.06 \pm 0.02$ & $0.12 \pm 0.07$ & $0.02 \pm 0.01$ & $0.07 \pm 0.02$ & \\
\hline SrO & $0.09 \pm 0.03$ & b.d. & & & & $0.09 \pm 0.03$ & & $0.09 \pm 0.01$ & $0.12 \pm 0.02$ & $0.08 \pm 0.03$ & $0.08 \pm 0.01$ & & & $0.10 \pm 0.02$ & & $0.10 \pm 0.03$ & & \\
\hline $\mathrm{Cr}_{2} \mathrm{O}_{3}$ & $0.04 \pm 0.02$ & b.d. & b.d. & b.d. & $0.13 \pm 0.01$ & b.d. & $0.07 \pm 0.02$ & $0.08 \pm 0.04$ & b.d. & b.d. & $0.03 \pm 0.01$ & $0.02 \pm 0.01$ & b.d. & b.d. & $0.07 \pm 0.05$ & $0.03 \pm<0.01$ & b.d. & 0.03 \\
\hline $\mathrm{FeO}$ & $0.61 \pm 0.25$ & $0.82 \pm 0.26$ & $0.32 \pm 0.03$ & $0.45 \pm 0.07$ & $0.48 \pm 0.01$ & $0.67 \pm 0.18$ & $0.66 \pm 0.20$ & $0.36 \pm 0.08$ & $0.39 \pm 0.13$ & $1.77 \pm 0.12$ & $1.04 \pm 0.14$ & $1.28 \pm 0.07$ & $3.31 \pm 0.07$ & $3.01 \pm 0.26$ & $4.78 \pm 0.33$ & $3.63 \pm 1.31$ & $0.78 \pm 0.10$ & 0.13 \\
\hline $\mathrm{MnO}$ & $<0.02$ & $0.03 \pm 0.01$ & $0.03 \pm 0.01$ & $0.03 \pm 0.01$ & b.d. & $0.03 \pm 0.02$ & & $0.03 \pm 0.01$ & b.d. & $0.08 \pm 0.02$ & $0.04 \pm 0.02$ & $0.08 \pm 0.03$ & $0.17 \pm 0.02$ & $0.11 \pm 0.02$ & $<0.02$ & $0.22 \pm 0.02$ & $0.07 \pm 0.02$ & 0.03 \\
\hline $\mathrm{MgO}$ & $3.61 \pm 0.05$ & $3.50 \pm 0.03$ & $3.57 \pm 0.04$ & $3.55 \pm 0.03$ & $3.37 \pm 0.05$ & $3.50 \pm 0.09$ & $3.54 \pm 0.12$ & $3.57 \pm 0.15$ & $3.59 \pm 0.06$ & $2.92 \pm 0.10$ & $3.56 \pm 0.32$ & $3.27 \pm 0.03$ & $2.04 \pm 0.09$ & $2.16 \pm 0.12$ & $0.88 \pm 0.17$ & $3.27 \pm 0.10$ & $3.52 \pm 0.06$ & 3.65 \\
\hline $\mathrm{P}_{2} \mathrm{O}_{5}$ & $45.96 \pm 0.44$ & $45.55 \pm 0.46$ & $46.72 \pm 0.15$ & $46.64 \pm 0.34$ & $47.14 \pm 0.11$ & $46.22 \pm 0.42$ & $46.64 \pm 0.22$ & $46.83 \pm 0.24$ & $46.47 \pm 0.01$ & $43.34 \pm 0.53$ & $45.34 \pm 0.85$ & $46.42 \pm 0.40$ & $45.85 \pm 0.28$ & $45.51 \pm 0.98$ & $45.73 \pm 0.09$ & $43.10 \pm 2.07$ & $46.37 \pm 0.36$ & 46.51 \\
\hline $\mathrm{SiO}_{2}$ & $0.06 \pm 0.03$ & $0.35 \pm 0.14$ & $0.06 \pm 0.04$ & & $0.20 \pm 0.04$ & b.d. & $0.28 \pm 0.08$ & $0.13 \pm 0.10$ & $0.02 \pm 0.01$ & $0.39 \pm 0.07$ & $0.45 \pm 0.54$ & $0.06 \pm 0.02$ & $0.12 \pm 0.03$ & $0.25 \pm 0.34$ & $0.54 \pm 0.33$ & $1.26 \pm 0.96$ & $0.19 \pm 0.16$ & b.d. \\
\hline $\mathrm{SO}_{3}$ & $<0.02$ & b.d. & $0.02 \pm 0.01$ & b.d. & $0.13 \pm 0.03$ & b.d. & $0.07 \pm 0.04$ & & & $0.08 \pm 0.08$ & $0.02 \pm<0.01$ & & & b.d. & $0.09 \pm 0.04$ & $0.60 \pm 0.35$ & b.d. & \\
\hline $\mathrm{TiO}_{2}$ & b.d. & b.d. & b.d. & b.d. & $0.05 \pm 0.01$ & b.d. & b.d. & $0.02 \pm 0.01$ & $0.03 \pm 0.01$ & $0.12 \pm 0.07$ & b.d. & & & b.d. & $0.02 \pm<0.01$ & b.d. & b.d. & \\
\hline $\mathrm{Al}_{2} \mathrm{O}_{3}$ & $<0.02$ & $0.04 \pm 0.02$ & b.d. & b.d. & $0.04 \pm 0.01$ & b.d. & $0.05 \pm 0.02$ & $<0.02$ & $<0.01$ & b.d. & $0.10 \pm 0.08$ & $<0.01$ & $\begin{array}{ll}0.02 & 0.02\end{array}$ & $0.02 \pm 0.01$ & $0.23 \pm 0.10$ & $0.45 \pm 0.32$ & b.d. & b.d. \\
\hline $\mathrm{Cl}$ & $<0.03$ & & & & & b.d. & & b.d. & b.d. & $0.04 \pm 0.01$ & b.d. & b.d. & b.d. & $0.03 \pm 0.02$ & b.d. & b.d. & & b.d. \\
\hline $\begin{array}{l}F \\
\text { total }\end{array}$ & $\begin{array}{c}0.06 \pm 0.02 \\
100.14\end{array}$ & 99.99 & 100.40 & 100.24 & 99.83 & $\begin{array}{l}<0.02 \\
100.02\end{array}$ & 100.08 & 100.42 & $\begin{array}{c}0.03 \pm 0.01 \\
\mathbf{1 0 0 . 0 9}\end{array}$ & $\begin{array}{l}\text { b.d. } \\
92.32\end{array}$ & $\begin{array}{l}\text { b.d. } \\
99.05\end{array}$ & $\begin{array}{c}0.06 \pm 0.01 \\
\mathbf{1 0 0 . 2 8}\end{array}$ & $\begin{array}{l}<0.01 \\
100.03\end{array}$ & $\begin{array}{l}0.04 \pm 0.02 \\
\mathbf{9 9 . 1 8}\end{array}$ & 100.04 & $\begin{array}{l}\text { b.d. } \\
\quad 97.34\end{array}$ & 100.19 & $\begin{array}{r}\text { b.d. } \\
100.34\end{array}$ \\
\hline $\mathrm{Ca}$ & $17.96 \pm 0.12$ & $18.01 \pm 0.04$ & $17.83 \pm 0.11$ & $17.84 \pm 0.12$ & $17.32 \pm 0.01$ & $17.90 \pm 0.15$ & $17.53 \pm 0.17$ & $17.74 \pm 0.28$ & $17.86 \pm 0.06$ & $17.28 \pm 0.35$ & $18.05 \pm 0.19$ & $18.27 \pm 0.09$ & $18.24 \pm 0.09$ & $18.11 \pm 0.12$ & $17.99 \pm 0.17$ & $17.37 \pm 0.49$ & $18.47 \pm 0.11$ & 17.96 \\
\hline $\mathrm{Na}$ & $1.98 \pm 0.06$ & $1.93 \pm 0.03$ & $1.91 \pm 0.04$ & $1.91 \pm 0.03$ & $1.87 \pm<0.01$ & $1.94 \pm 0.06$ & $1.80 \pm 0.04$ & $1.87 \pm 0.10$ & $1.82 \pm 0.03$ & $0.41 \pm 0.14$ & $1.22 \pm 0.10$ & $0.91 \pm 0.11$ & $0.94 \pm 0.05$ & $0.98 \pm 0.06$ & $0.80 \pm 0.06$ & $0.48 \pm 0.05$ & $0.66 \pm 0.04$ & 2.00 \\
\hline K & $<0.02$ & $0.03 \pm<0.01$ & $0.02 \pm 0.01$ & $0.03 \pm 0.01$ & $0.03 \pm<0.01$ & $0.03 \pm 0.01$ & $0.02 \pm 0.01$ & $0.03 \pm 0.02$ & $0.03 \pm<0.01$ & $0.02 \pm<0.01$ & $<0.01$ & & & $0.03 \pm 0.01$ & $0.05 \pm 0.03$ & $<0.01$ & $<0.01$ & \\
\hline $\mathrm{Sr}$ & $0.02 \pm 0.01$ & & & & & $0.02 \pm<0.01$ & & $0.02 \pm<0.01$ & $0.02 \pm<0.01$ & $0.02 \pm<0.01$ & $<0.01$ & & & $0.02 \pm 0.01$ & & $0.02 \pm 0.01$ & & \\
\hline $\mathrm{Cr}$ & $<0.01$ & & b.d. & $<0.01$ & $0.04 \pm<0.01$ & b.d. & $0.02 \pm 0.01$ & $0.02 \pm<0.01$ & b.d. & & $<0.01$ & $<0.01$ & b.d. & b.d. & $0.02 \pm 0.01$ & $<.01$ & $<0.01$ & 0.01 \\
\hline $\mathrm{Fe}$ & $0.18 \pm 0.07$ & $0.25 \pm 0.08$ & $0.09 \pm 0.01$ & $0.13 \pm 0.02$ & $0.14 \pm<0.01$ & $0.20 \pm 0.05$ & $0.20 \pm 0.06$ & $0.11 \pm 0.02$ & $0.12 \pm 0.04$ & $0.56 \pm 0.03$ & $0.31 \pm 0.04$ & $0.38 \pm 0.02$ & $1.00 \pm 0.02$ & $0.92 \pm 0.07$ & $1.44 \pm 0.10$ & $1.13 \pm 0.42$ & $0.23 \pm 0.03$ & 0.04 \\
\hline $\mathrm{Mn}$ & $<0.01$ & $<0.01$ & $<0.01$ & $<0.01$ & b.d. & $0.01 \quad 0.01$ & & $0.01 \pm<0.01$ & $<0.01$ & $0.03 \pm<0.01$ & $<0.02$ & $0.02 \pm 0.01$ & $0.05 \pm 0.01$ & $0.03 \pm 0.01$ & $<0.01$ & $0.07 \pm 0.01$ & $0.02 \pm 0.01$ & 0.01 \\
\hline $\mathrm{Mg}$ & $1.93 \pm 0.03$ & $1.87 \pm 0.01$ & $1.89 \pm 0.02$ & $1.88 \pm 0.02$ & $1.78 \pm 0.03$ & $1.87 \pm 0.05$ & $1.88 \pm 0.06$ & $1.89 \pm 0.09$ & $1.91 \pm 0.03$ & $1.64 \pm 0.03$ & $1.92 \pm 0.18$ & $1.74 \pm 0.02$ & $1.10 \pm 0.05$ & $1.17 \pm 0.07$ & $0.47 \pm 0.09$ & $1.80 \pm 0.05$ & $1.87 \pm 0.03$ & 1.93 \\
\hline $\mathrm{P}$ & $13.93 \pm 0.05$ & $13.83 \pm 0.05$ & $14.05 \pm 0.02$ & $14.06 \pm 0.06$ & $14.18 \pm 0.03$ & $14.00 \pm 0.06$ & $14.04 \pm 0.03$ & $14.11 \pm 0.04$ & $14.04 \pm 0.02$ & $13.81 \pm 0.10$ & $13.87 \pm 0.19$ & $14.02 \pm 0.04$ & $14.01 \pm 0.04$ & $14.01 \pm 0.11$ & $13.99 \pm 0.07$ & $13.45 \pm 0.40$ & $14.02 \pm 0.05$ & 14.01 \\
\hline $\mathrm{Si}$ & $0.02 \pm 0.01$ & $0.13 \pm 0.05$ & $<0.02$ & & $0.07 \pm 0.01$ & b.d. & $0.11 \pm 0.03$ & $0.05 \pm 0.04$ & $<0.01$ & $0.15 \pm 0.02$ & $0.16 \pm 0.20$ & $0.02 \pm 0.01$ & $0.04 \pm 0.01$ & $0.09 \pm 0.13$ & $0.19 \pm 0.12$ & $0.47 \pm 0.36$ & $<0.01$ & \\
\hline s & $<0.01$ & b.d. & $<0.01$ & b.d. & $0.03 \pm 0.01$ & b.d. & $0.04 \pm 0.03$ & & & $0.05 \pm 0.05$ & $<0.01$ & & & b.d. & $0.05 \pm 0.02$ & $0.17 \pm 0.10$ & b.d. & \\
\hline $\mathrm{Ti}$ & b.d. & b.d. & b.d. & b.d. & $<0.01$ & b.d. & b.d. & $<0.01$ & $<0.01$ & $0.02 \pm<0.01$ & b.d. & & & b.d. & $<0.01$ & b.d. & b.d. & \\
\hline $\mathrm{Al}$ & $<0.01$ & $0.02 \pm 0.01$ & b.d. & b.d. & $<0.02$ & b.d. & $0.02 \pm 0.01$ & 0.01 & $<0.01$ & b.d. & $<0.01$ & $<0.01$ & $<0.01$ & $<0.01$ & $0.07 \pm 0.03$ & $0.20 \pm 0.14$ & b.d. & \\
\hline $\mathrm{Cl}$ & $<0.01$ & & & & & b.d. & & b.d. & $<0.01$ & $<0.01$ & $<0.01$ & $<0.01$ & $<0.01$ & $<0.01$ & b.d. & b.d. & & \\
\hline $\begin{array}{l}F \\
\text { total }\end{array}$ & $\begin{array}{l}<0.01 \\
\quad 36.03\end{array}$ & 36.06 & 35.79 & 35.85 & 35.47 & $\begin{array}{l}<0.01 \\
35.95\end{array}$ & 35.66 & 35.85 & $\begin{array}{l}<0.01 \\
35.81\end{array}$ & $\begin{array}{l}\text { b.d. } \\
33.98\end{array}$ & $\begin{array}{l}\text { b.d. } \\
35.53\end{array}$ & $\begin{array}{c}<0.01 \\
\mathbf{3 5 . 3 7}\end{array}$ & $\begin{array}{l}<0.01 \\
35.39\end{array}$ & $\begin{array}{l}<0.01 \\
35.36\end{array}$ & 35.09 & $\begin{array}{l}\text { b.d. } \\
35.15\end{array}$ & 35.27 & 35.96 \\
\hline
\end{tabular}


Table 3. REE concentration of apatite and merrillite. Results in $\mu \mathrm{g} / \mathrm{g}$ (average and standard deviation of the mean (SD), individual analyses are available in supplemental table S1).

\begin{tabular}{|c|c|c|c|c|c|c|c|c|c|c|c|c|c|c|c|}
\hline Sample & & La & $\mathrm{Ce}$ & $\mathrm{Pr}$ & $\mathrm{Nd}$ & $\mathrm{Sm}$ & Eu & Gd & Tb & Dy & $\mathrm{Ho}$ & $\mathrm{Er}$ & $\mathrm{Tm}$ & $\mathrm{Yb}$ & Lu \\
\hline \multirow[t]{4}{*}{ Devgaon } & apatite & 12 & 25 & 3 & 11 & 2 & 2 & 3 & 0.5 & 3 & 0.6 & 2 & 0.2 & 1.6 & 0.20 \\
\hline & $(n=7) S D$ & 1 & 1 & 0.3 & 1 & 0.4 & 0.2 & 0.1 & 0.07 & 0.5 & 0.06 & 0.2 & 0.04 & 0.4 & 0.03 \\
\hline & merrrillite & 28 & 83 & 11 & 49 & 12 & 2 & 17 & 3 & 18 & 4 & 12 & 1.7 & 11 & 1.6 \\
\hline & $(n=7) S D$ & 11 & 39 & 4 & 12 & 4 & 0.5 & 5 & 1 & 5 & 1 & 3 & 0.4 & 3 & 0.6 \\
\hline \multirow[t]{4}{*}{ Ybbsitz } & apatite & 10 & 21 & 3 & 9 & 3 & 0.8 & 3 & 0.4 & 3 & 0.8 & 2 & 0.2 & 1.4 & 0.19 \\
\hline & $(n=4) S D$ & 1 & 4 & 0.5 & 2 & 1 & 0.2 & 1 & 0.2 & 0.7 & 0.2 & 0.5 & 0.07 & 0.4 & 0.06 \\
\hline & merrillite & 35 & 99 & 12 & 57 & 18 & 1.1 & 19 & 4 & 28 & 5.5 & 14 & 2.1 & 11 & 1.8 \\
\hline & $(n=3) S D$ & 4 & 23 & 1 & 7 & 3 & 0.3 & 3 & 1 & 2 & 0.7 & 2 & 0.3 & 2 & 0.4 \\
\hline \multirow[t]{2}{*}{ Allegan } & merrillite & 48 & 129 & 19 & 88 & 28 & 1.8 & 37 & 6 & 43 & 9 & 28 & 3.8 & 24 & 3.3 \\
\hline & $(n=5) S D$ & 7 & 22 & 4 & 18 & 6 & 0.3 & 8 & 2 & 10 & 2 & 7 & 0.9 & 6 & 0.9 \\
\hline \multirow[t]{4}{*}{ Portales Valley } & apatite & 4 & 9 & 1 & 4 & 1 & 0.9 & 0.9 & 0.12 & 0.8 & 0.2 & 0.5 & 0.07 & 0.4 & 0.07 \\
\hline & $(n=3) S D$ & 1 & 3 & 0.4 & 1 & 0.3 & 0.1 & 0.4 & 0.08 & 0.3 & 0.1 & 0.2 & 0.02 & 0.1 & 0.03 \\
\hline & merrillite & 28 & 74 & 10 & 47 & 14 & 1.7 & 15 & 3 & 19 & 4 & 12 & 2 & 15 & 2.1 \\
\hline & $(n=7) S D$ & 1 & 3 & 0.6 & 3 & 1 & 0.2 & 1 & 0.2 & 1 & 0.3 & 1 & 0.2 & 1 & 0.2 \\
\hline \multirow[t]{2}{*}{ Aguemour 009} & merrillite & 76 & 215 & 32 & 147 & 44 & 2.4 & 51 & 9 & 59 & 13 & 37 & 4.9 & 30 & 3.9 \\
\hline & $(n=3) S D$ & 3 & 7 & 1 & 6 & 3 & 0.1 & 3 & 0.4 & 5 & 0.8 & 3 & 0.2 & 2 & 0.3 \\
\hline \multirow[t]{2}{*}{ Bruderheim } & apatite & 28 & 46 & 5 & 20 & 3 & 0.8 & 3 & 0.5 & 3 & 0.7 & 2.2 & 0.3 & 2.2 & 0.3 \\
\hline & $(n=7) S D$ & 1 & 2 & 0.4 & 2 & 1 & 0.1 & 1 & 0.1 & 0.4 & 0.1 & 0.4 & 0.07 & 0.4 & 0.1 \\
\hline Villalbeto & apatite & 18 & 39 & 5 & 20 & 5 & 1.3 & 6 & 0.86 & 5 & 1 & 2.9 & 0.38 & 2.3 & 0.3 \\
\hline de la Peña & $(n=4) S D$ & 1 & 1 & 0.2 & 1 & 0.5 & 0.1 & 0.5 & 0.05 & 0.5 & 0.1 & 0.2 & 0.03 & 0.3 & 0.1 \\
\hline & merrillite & 81 & 224 & 31 & 142 & 42 & 1.9 & 55 & 10 & 62 & 14 & 38 & 5.2 & 32 & 4.8 \\
\hline & $(n=10) S D$ & 15 & 68 & 8 & 26 & 9 & 0.3 & 12 & 2 & 15 & 3 & 9 & 1.2 & 7 & 1 \\
\hline Adzhi-Bogdo & apatite & 18 & 40 & 5 & 22 & 5.63 & 1.2 & 6 & 1 & 6 & 1.3 & 4 & 0.5 & 2.7 & 0.34 \\
\hline (chondritic portion) & $(n=5) S D$ & 2 & 2 & 0.3 & 2 & 0.4 & 0.2 & 1 & 0.1 & 1 & 0.2 & 0.3 & 0.05 & 0.4 & 0.04 \\
\hline & merrillite & 101 & 275 & 41 & 200 & 62 & 2.7 & 84 & 15 & 93 & 20 & 54 & 6.7 & 39 & 5 \\
\hline & $(n=5) S D$ & 9 & 36 & 5 & 25 & 8 & 0.6 & 8 & 2 & 13 & 3 & 9 & 1.2 & 7 & 1 \\
\hline Adzhi-Bogdo & apatite & 50 & 125 & 17 & 79 & 25 & 1.7 & 27 & 6 & 38 & 9 & 28 & 4.5 & 30 & 4.5 \\
\hline (differentiated clasts) & $(n=3) S D$ & 8 & 26 & 4 & 15 & 5 & 0.3 & 3 & 1 & 6 & 2 & 5 & 0.7 & 5 & 0.9 \\
\hline & merrillite & 63 & 236 & 39 & 176 & 65 & 6 & 90 & 15 & 107 & 23 & 67 & 9.4 & 52 & 6.4 \\
\hline & $(n=2) S D$ & 5 & 16 & 5 & 17 & 5 & 0.1 & 4 & 1 & 4 & 2 & 5 & 0.5 & 4 & 0.8 \\
\hline Karoonda & apatite & 11 & 38 & 5 & 16 & 4 & 1.3 & 3 & 0.7 & 3.3 & 0.6 & 1.5 & 0.2 & 1.3 & 0.2 \\
\hline & $(n=3) S D$ & 1 & 8 & 1 & 3 & 1 & 0.1 & 1 & 0.1 & 0.6 & 0.1 & 0.1 & 0.02 & 0.4 & 0.04 \\
\hline Acapulco & apatite & 56 & 125 & 15 & 64 & 17 & 1 & 20 & 3 & 21 & 4 & 11 & 1.3 & 8 & 1.0 \\
\hline & $(n=9) S D$ & 7 & 15 & 2 & 11 & 4 & 0.1 & 4 & 1 & 5 & 1 & 3 & 0.3 & 1 & 0.2 \\
\hline & merrillite & 90 & 236 & 32 & 140 & 43 & 1.8 & 55 & 10 & 66 & 15 & 41 & 5.5 & 36 & 4.8 \\
\hline & $(n=7) S D$ & 21 & 63 & 11 & 62 & 23 & 0.1 & 31 & 5 & 34 & 7 & 18 & 2.0 & 13 & 1 \\
\hline Dhofar 125 & apatite & 60 & 115 & 14 & 60 & 19 & 1.4 & 28 & 5 & 39 & 9 & 27 & 3.4 & 19 & 2.6 \\
\hline & $(n=4) S D$ & 16 & 26 & 4 & 16 & 4 & 0.2 & 6 & 0.9 & 7 & 2 & 3 & 0.3 & 2 & 0.3 \\
\hline NWA 1052 & merrillite & 29 & 54 & 6 & 25 & 7 & 1.5 & 12 & 2 & 18 & 4 & 14 & 2.1 & 17 & 2.3 \\
\hline & $(n=3) S D$ & 11 & 19 & 2 & 9 & 4 & 0.04 & 5 & 1 & 10 & 2 & 7 & 1.2 & 5 & 0.9 \\
\hline $\mathrm{HaH} 193$ & apatite & 13 & 32 & 4 & 20 & 6 & 0.7 & 8 & 1 & 9 & 2 & 6 & 0.9 & 7 & 1.8 \\
\hline & $(n=8) S D$ & 11 & 21 & 2 & 10 & 3 & 0.2 & 4 & 0.7 & 5 & 1 & 3 & 0.5 & 4 & 0.7 \\
\hline NWA 5073 & apatite & 545 & 1852 & 273 & 1369 & 417 & 3.6 & 482 & 76 & 455 & 89 & 225 & 28 & 175 & 22 \\
\hline & $(n=3) S D$ & 482 & 1421 & 228 & 1174 & 328 & 2 & 374 & 55 & 307 & 57 & 127 & 14 & 76 & 8 \\
\hline Millbillillie & apatite & 99 & 280 & 43 & 201 & 62 & 2 & 69 & 12 & 75 & 15 & 41 & 5.4 & 37 & 5 \\
\hline & $(n=3) S D$ & 15 & 22 & 4 & 34 & 13 & 0.4 & 15 & 3 & 16 & 2 & 7 & 0.7 & 8 & 1 \\
\hline & merrillite & 4856 & 11571 & 1702 & 8871 & 2597 & 19 & 3501 & 553 & 3184 & 686 & 1791 & 224 & 1267 & 176 \\
\hline & $(n=2) S D$ & 117 & 599 & 80 & 179 & 48 & 1 & 361 & 26 & 125 & 19 & 25 & 12 & 10 & 8 \\
\hline SaU 005 & merrillite & 14 & 46 & 8 & 59 & 49 & 13 & 100 & 20 & 132 & 28 & 75 & 10.12 & 64 & 8.7 \\
\hline & $(n=3) S D$ & 1 & 4 & 1 & 5 & 2 & 1 & 8 & 1 & 8 & 2 & 6 & 0.80 & 3 & 0.4 \\
\hline DaG 1051 & merrillite & 17 & 55 & 10 & 77 & 62 & 15 & 137 & 27 & 180 & 37 & 99 & 12.6 & 76 & 10 \\
\hline & $(n=5) S D$ & 2 & 5 & 1 & 9 & 8 & 1 & 17 & 3 & 21 & 4 & 10 & 1.1 & 6 & 1 \\
\hline NWA 4864 & apatite & 100 & 250 & 36 & 175 & 69 & 18 & 109 & 19 & 126 & 26 & 71 & 9.2 & 60 & 8 \\
\hline & $(n=3) S D$ & 8 & 16 & 2 & 13 & 6 & 3 & 9 & 1 & 7 & 2 & 6 & 1.3 & 10 & 1 \\
\hline & merrillite & 118 & 312 & 42 & 190 & 73 & 25 & 111 & 21 & 142 & 30 & 80 & 10.4 & 66 & 9 \\
\hline & $(n=4) S D$ & 11 & 35 & 4 & 25 & 9 & 1 & 13 & 2 & 12 & 2 & 6 & 0.6 & 4 & 0.5 \\
\hline KG 002 & merrillite & 163 & 417 & 59 & 288 & 109 & 32 & 165 & 30 & 191 & 39 & 103 & 13 & 77 & 10 \\
\hline & $(n=4) S D$ & 13 & 43 & 6 & 33 & 12 & 2 & 20 & 3 & 15 & 3 & 6 & 0.6 & 3 & 1 \\
\hline Zagami & merrillite & 61 & 126 & 16 & 68 & 68 & 1.5 & 19 & 3 & 18 & 4 & 10 & 1.3 & 8 & 1.1 \\
\hline & $(n=11) S D$ & 2 & 11 & 1 & 2 & 18 & 0.1 & 1 & 0.2 & 0.5 & 0.2 & 0.5 & 0.1 & 0.3 & 0.2 \\
\hline ALM-A & apatite & 23 & 66 & 10 & 49 & 15 & 71 & 20 & 3 & 24 & 5 & 16 & 2 & 15 & 2.1 \\
\hline & $(n=6) S D$ & 3 & 13 & 2 & 9 & 2 & 11 & 20 & 0.4 & 3 & 1 & 2 & 0.3 & 2 & 0.3 \\
\hline Dalgaranga & merrillite & 42 & 121 & 18 & 85 & 27 & 6 & 31 & 5 & 33 & 7 & 19 & 2.5 & 16 & 2.3 \\
\hline & $(n=5) S D$ & 6 & 20 & 3 & 12 & 4 & 0.4 & 8 & 1 & 8 & 2 & 5 & 0.6 & 3 & 0.6 \\
\hline Bondoc & merrillite & 5 & 19 & 3 & 18 & 6 & 1.5 & 9 & 2 & 11 & 2 & 7 & 1 & 7 & 1.1 \\
\hline & $(n=12) S D$ & 0.1 & 1 & 0.2 & 1 & 0.4 & 0.05 & 1 & 0.1 & 1 & 0.2 & 0.5 & 0.04 & 0.2 & 0.02 \\
\hline Landes & apatite & 3 & 13 & 2 & 11 & 4 & 1.5 & 4 & 0.7 & 5 & 1 & 3 & 0.4 & 4 & 0.48 \\
\hline & $(n=2) S D$ & 0.02 & 0.1 & 0.05 & 0.4 & 0.1 & 0.02 & 0.1 & 0.02 & 0.3 & 0.07 & 0.1 & 0.007 & 0.2 & 0.02 \\
\hline & merrillite & 12 & 25 & 3 & 11 & 2 & 1.9 & 3 & 0.5 & 3 & 0.6 & 2 & 0.25 & 1.7 & 0.20 \\
\hline & $(n=2) S D$ & 1 & 1 & 0.3 & 1 & 0.4 & 0.2 & 0.1 & 0.1 & 0.5 & 0.06 & 0.2 & 0.04 & 0.4 & 0.03 \\
\hline
\end{tabular}




\section{Figures}

Figure 1

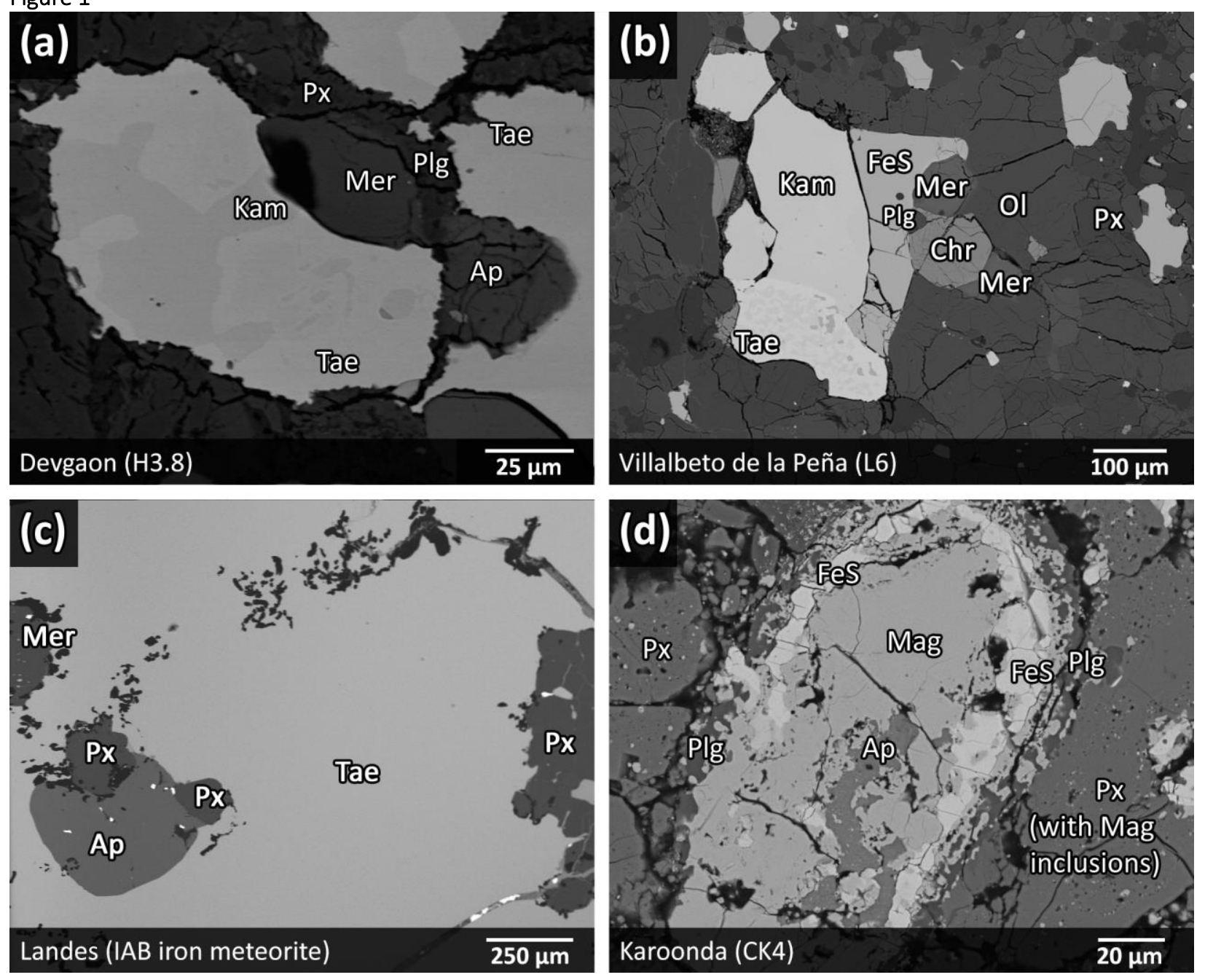


Figure 2

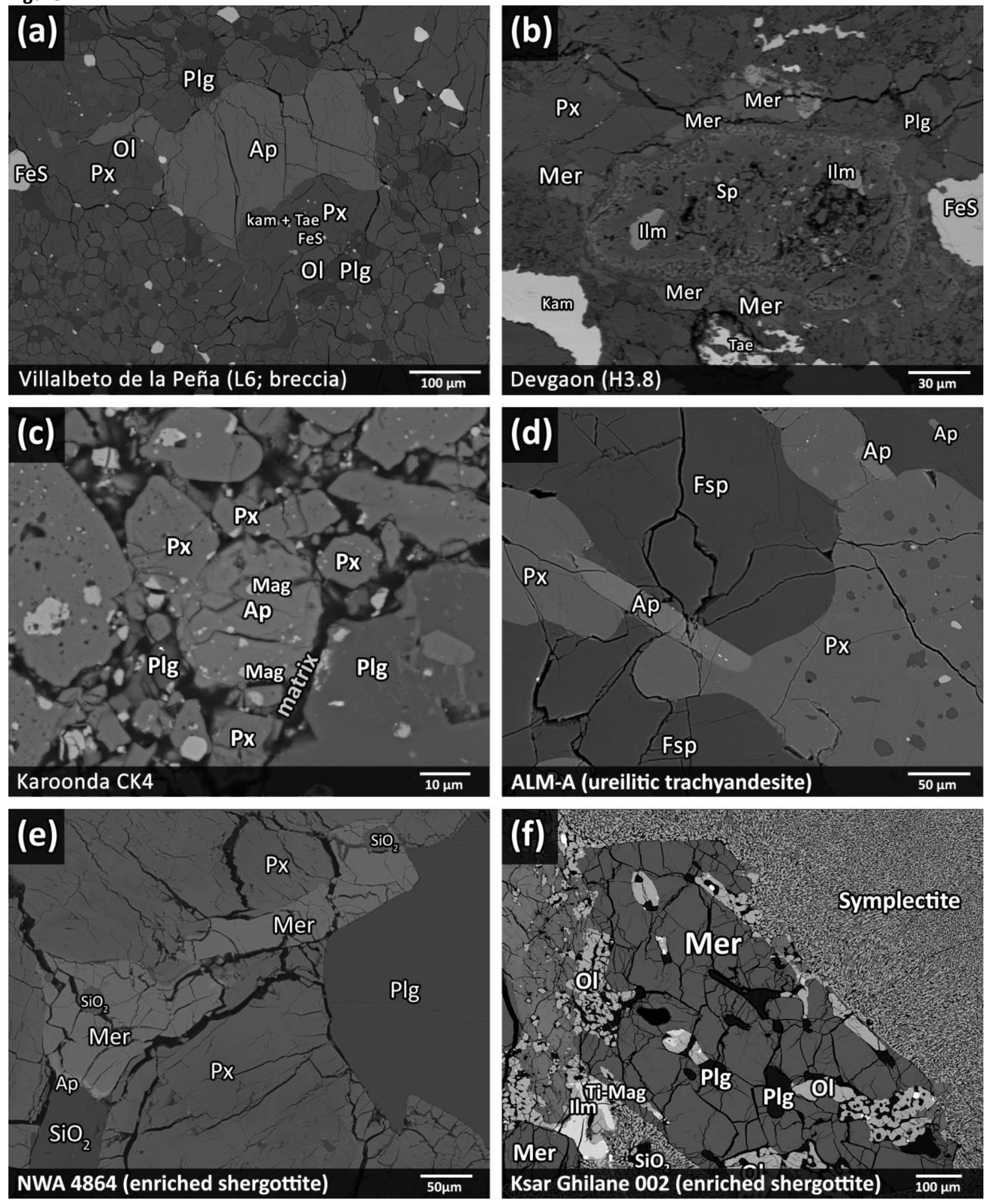




\section{Figure 3}
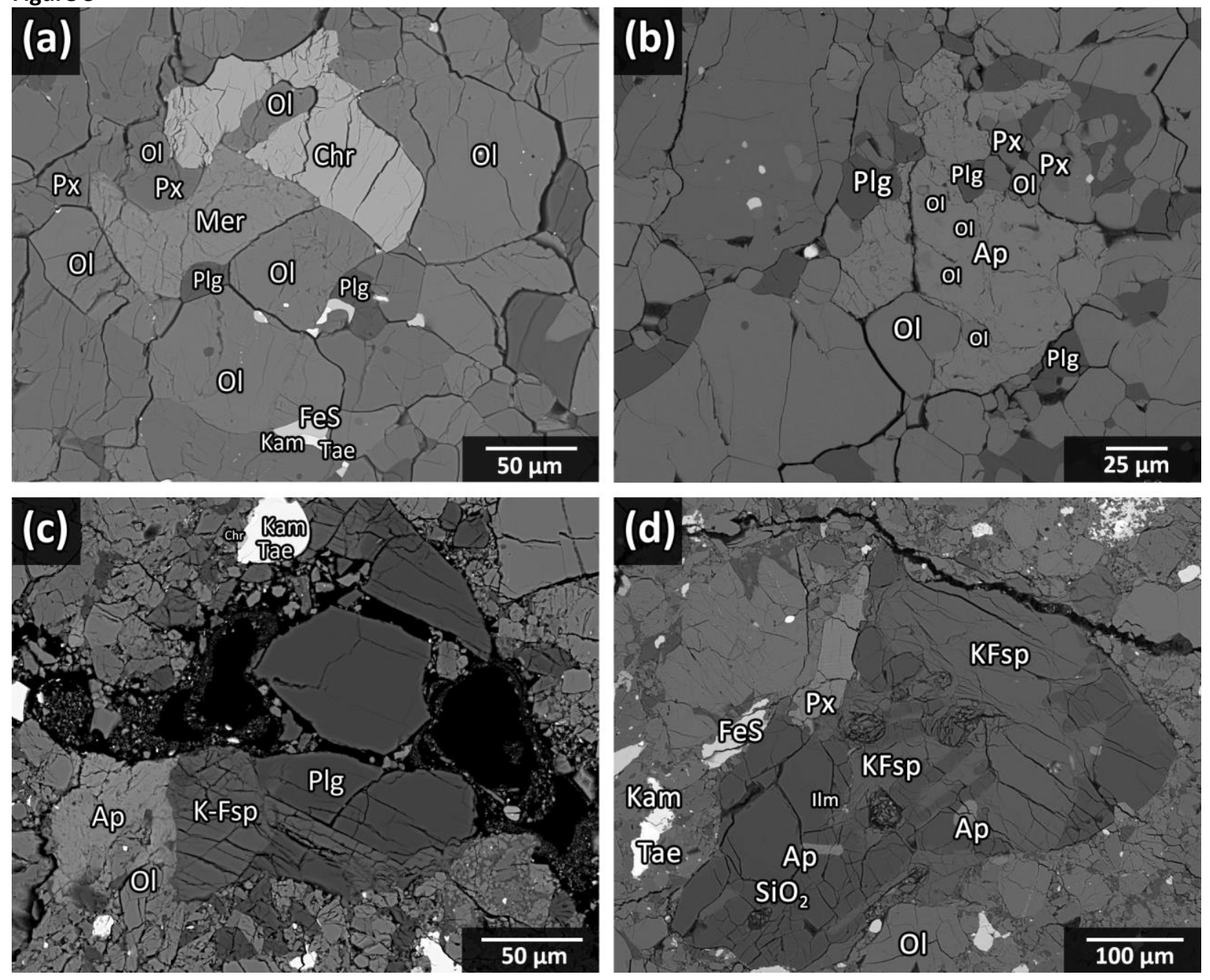
Figure 4
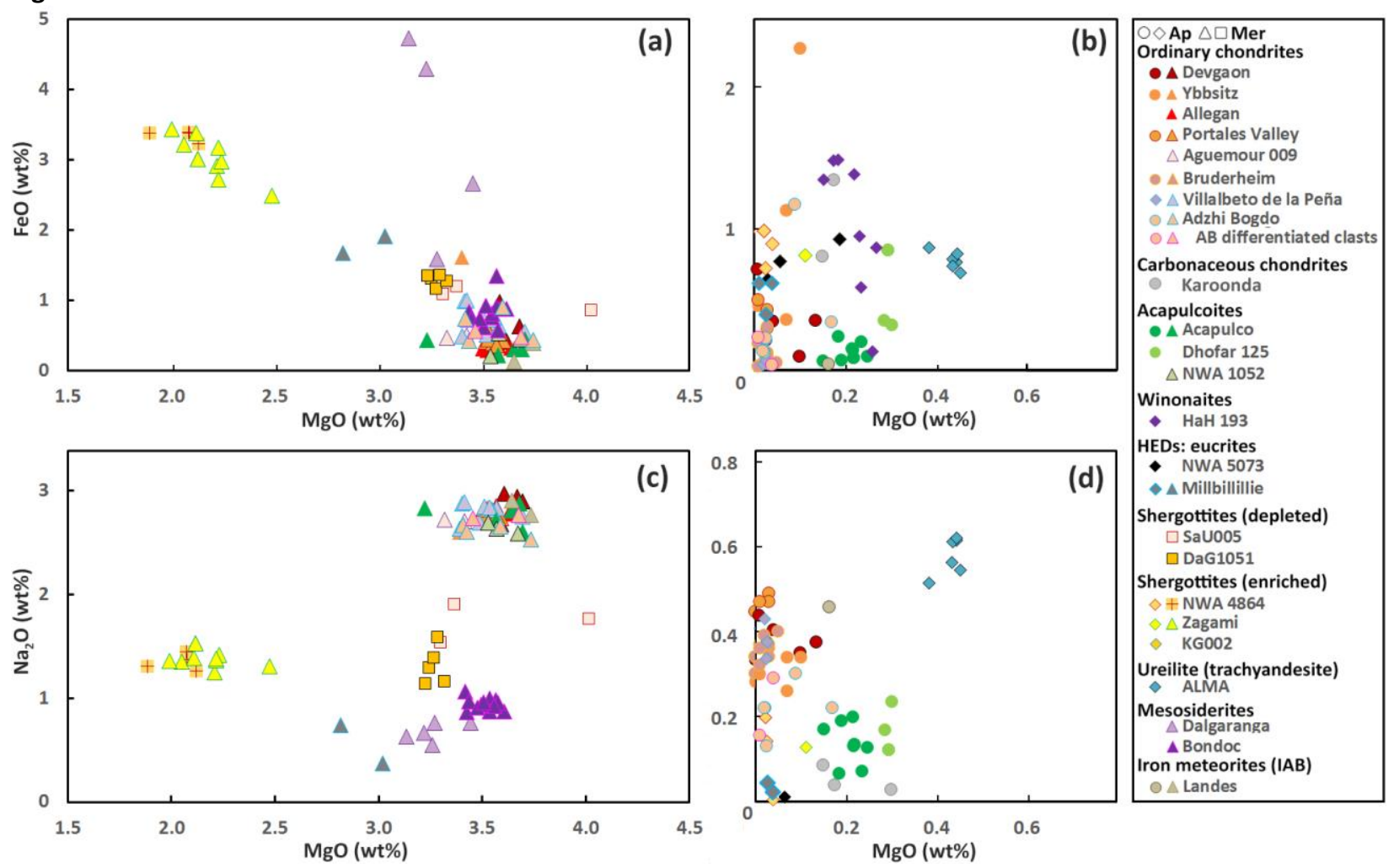

Figure 5

(a)

$\mathrm{OH}$
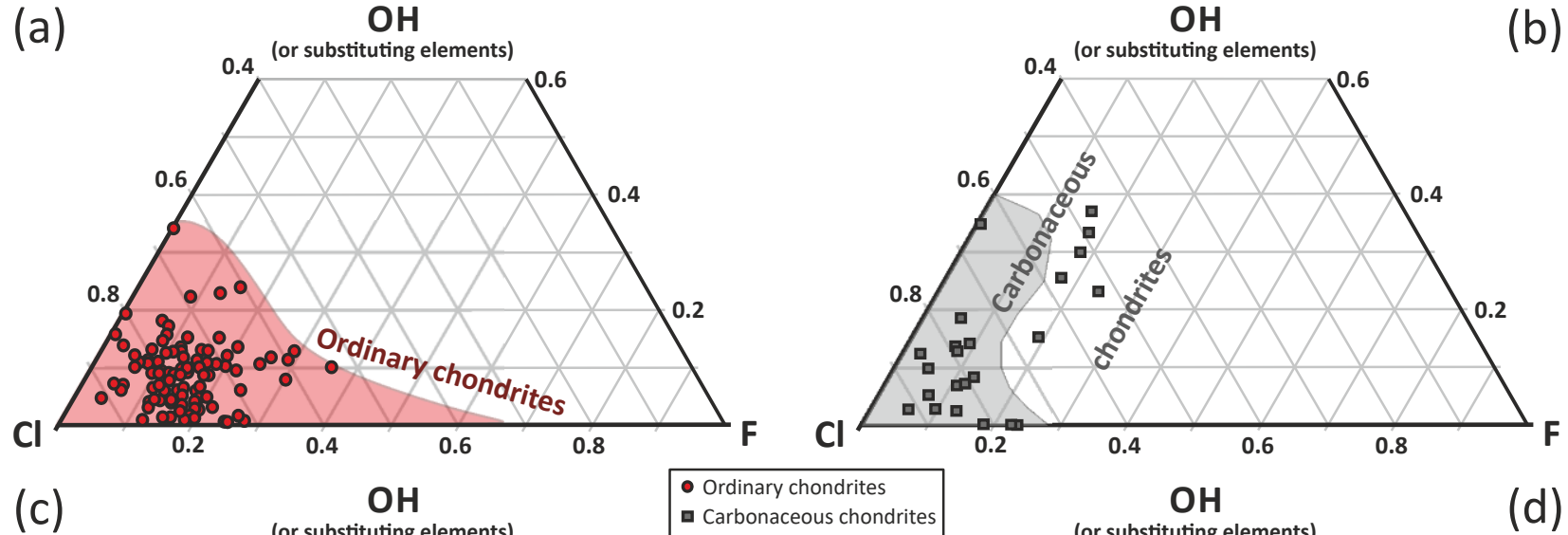

(c)
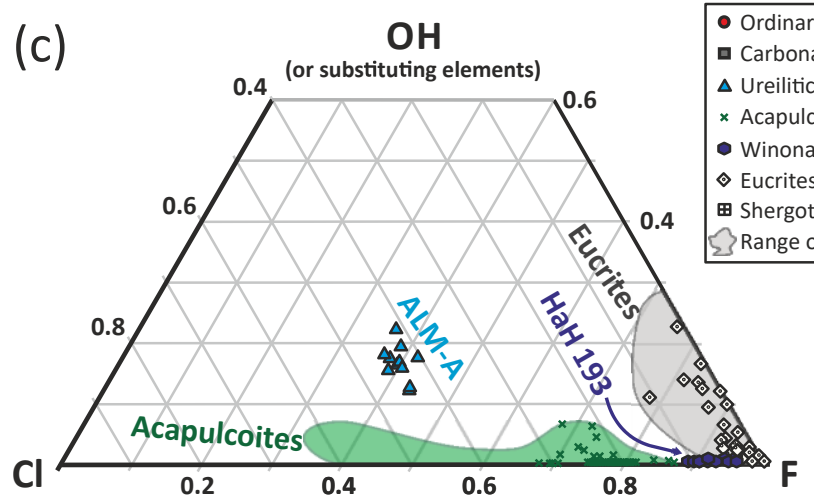

- Ordinary chondrites

- Carbonaceous chondrites

$\Delta$ Ureilitic trachyandesite

× Acapulcoites

- Winonaites

$\diamond$ Eucrites

田 Shergottites

terauture data

$\quad 0.4$ (or substituting elements)

$O \diamond$ Ap $\triangle \square$ Mer
Ordinary chondrites

Ordinary chondrite
$\triangle \mathrm{D}$ Devgaon

- $\triangle$ Ybbsitz

$\triangle$ Portales Valley

$\triangle$ Aguemour 009

- $\Delta$ Bruderheim

- $\Delta$ Villalbeto de la Peña

- $\triangle$ Adzhi Bogdo

Carbonaceous chondrites

- Karoonda

Acapulcoites

- $\triangle$ Acapulco

- Dhofar 125

$\triangle$ NWA 1052

Winonaites

\begin{tabular}{l} 
HaH 193 \\
\hline$\quad 19$
\end{tabular}

HEDs: eucrites

hergottites (depleted)

Shergottites (enriched)

\# NWA 4864

KG002

Ureilite (trachyandesite)

esosiderites

(IAB)
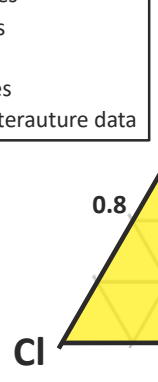

0.6 -
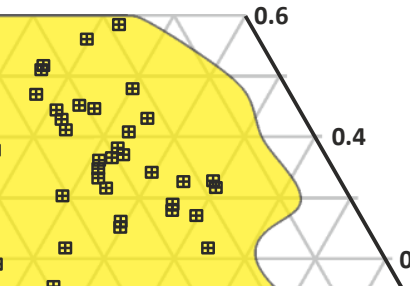

Shergottites

(b)

(d) 
Figure 6
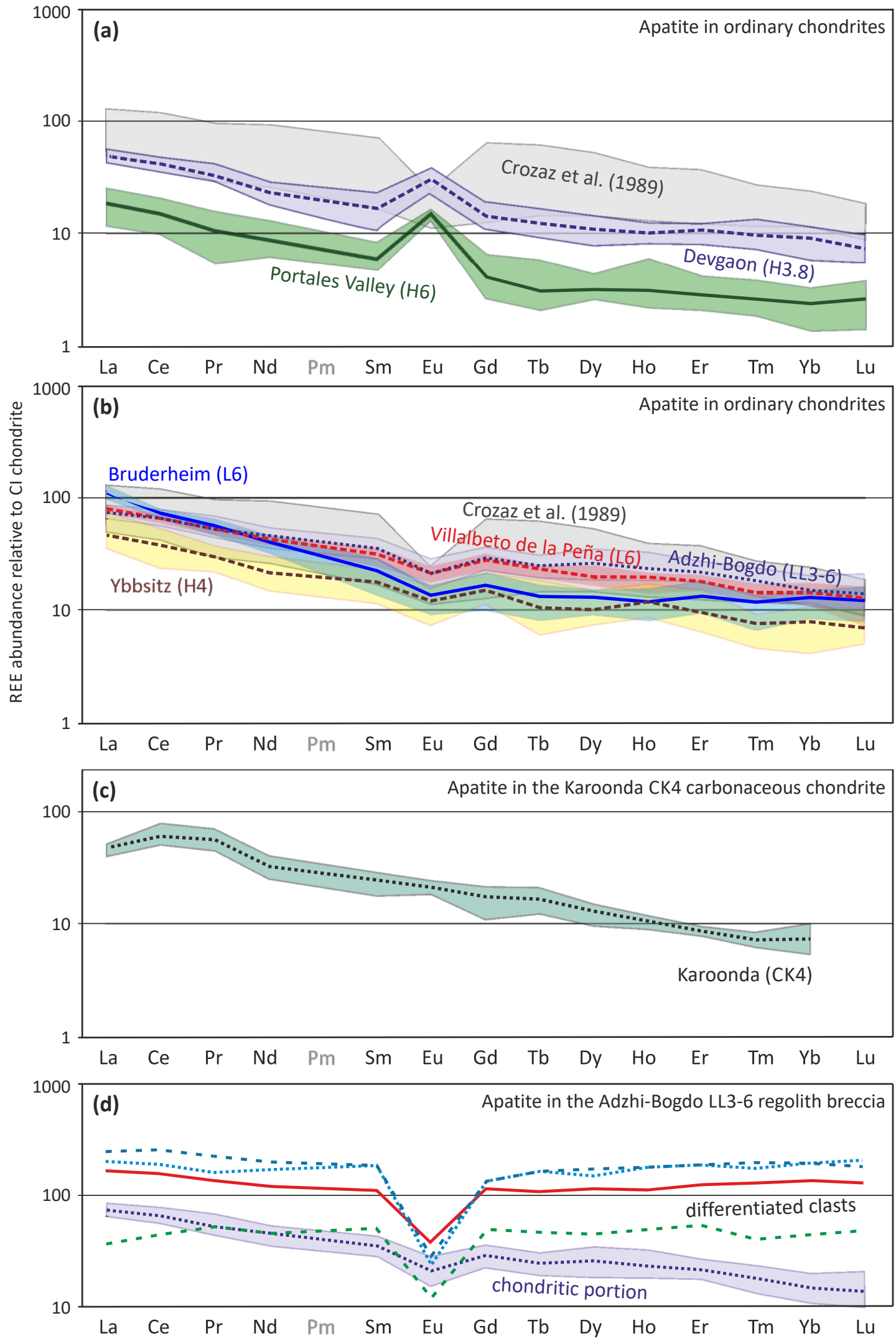
Figure 7
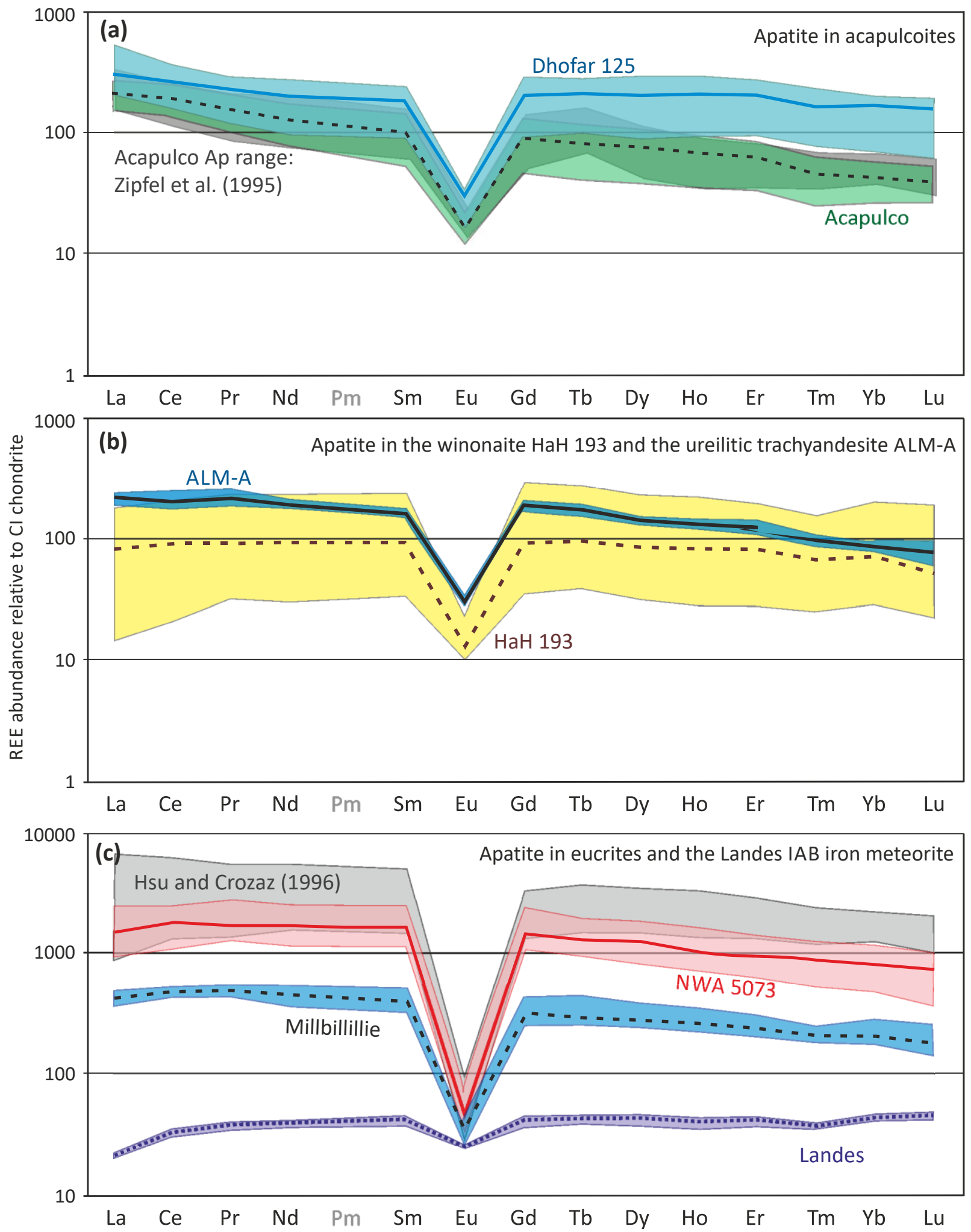
Figure 8
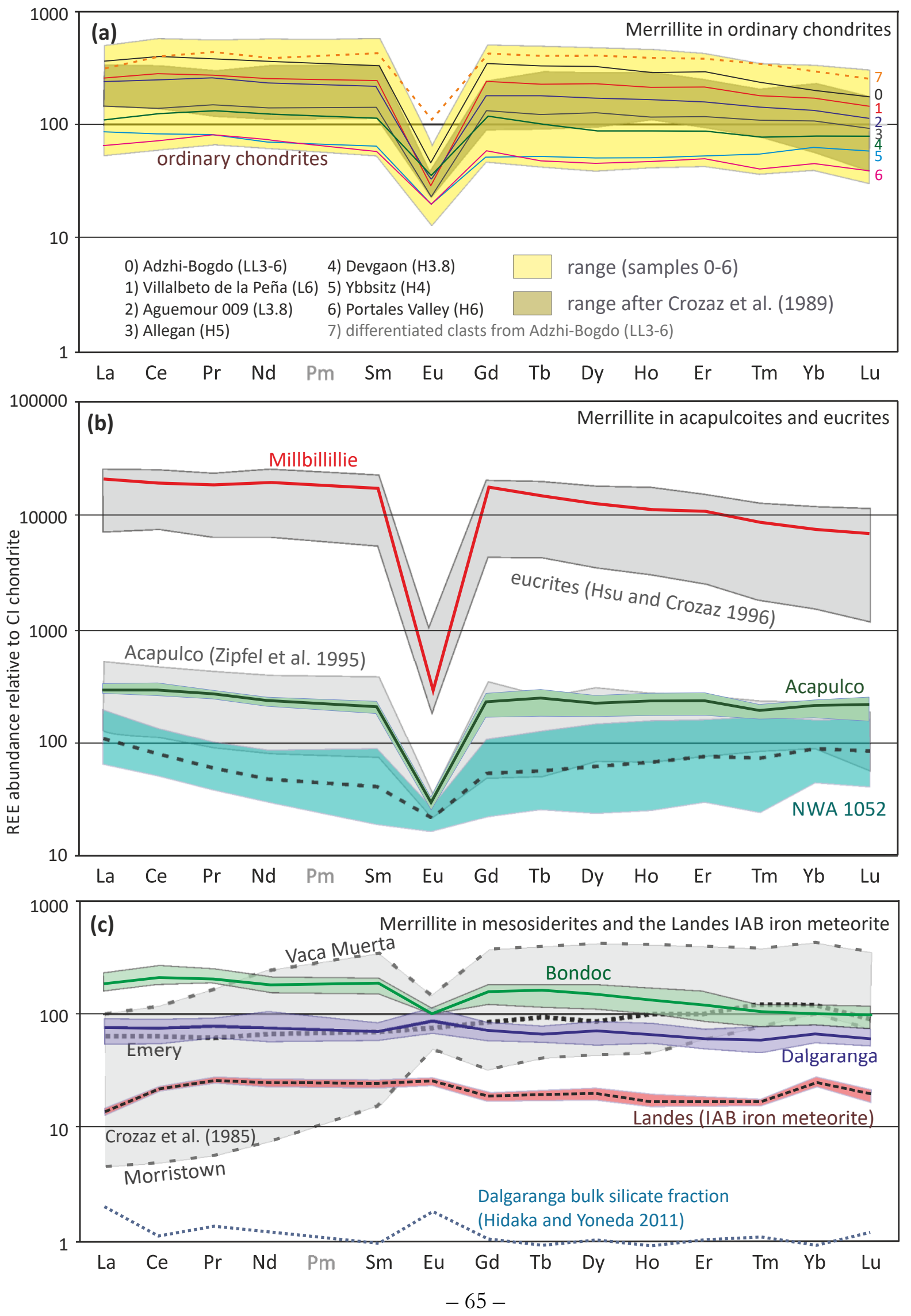
Figure 9

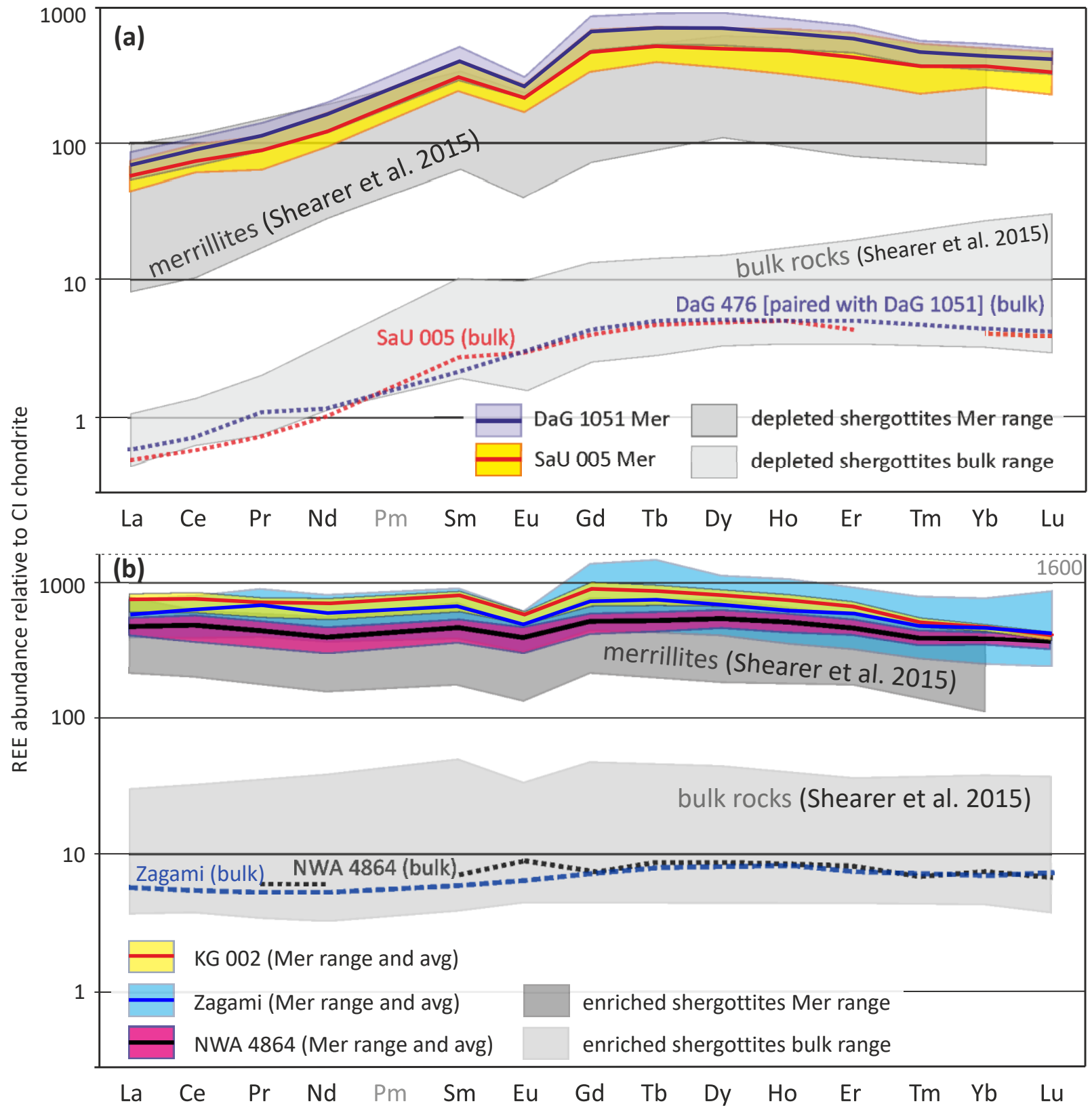


Figure 10

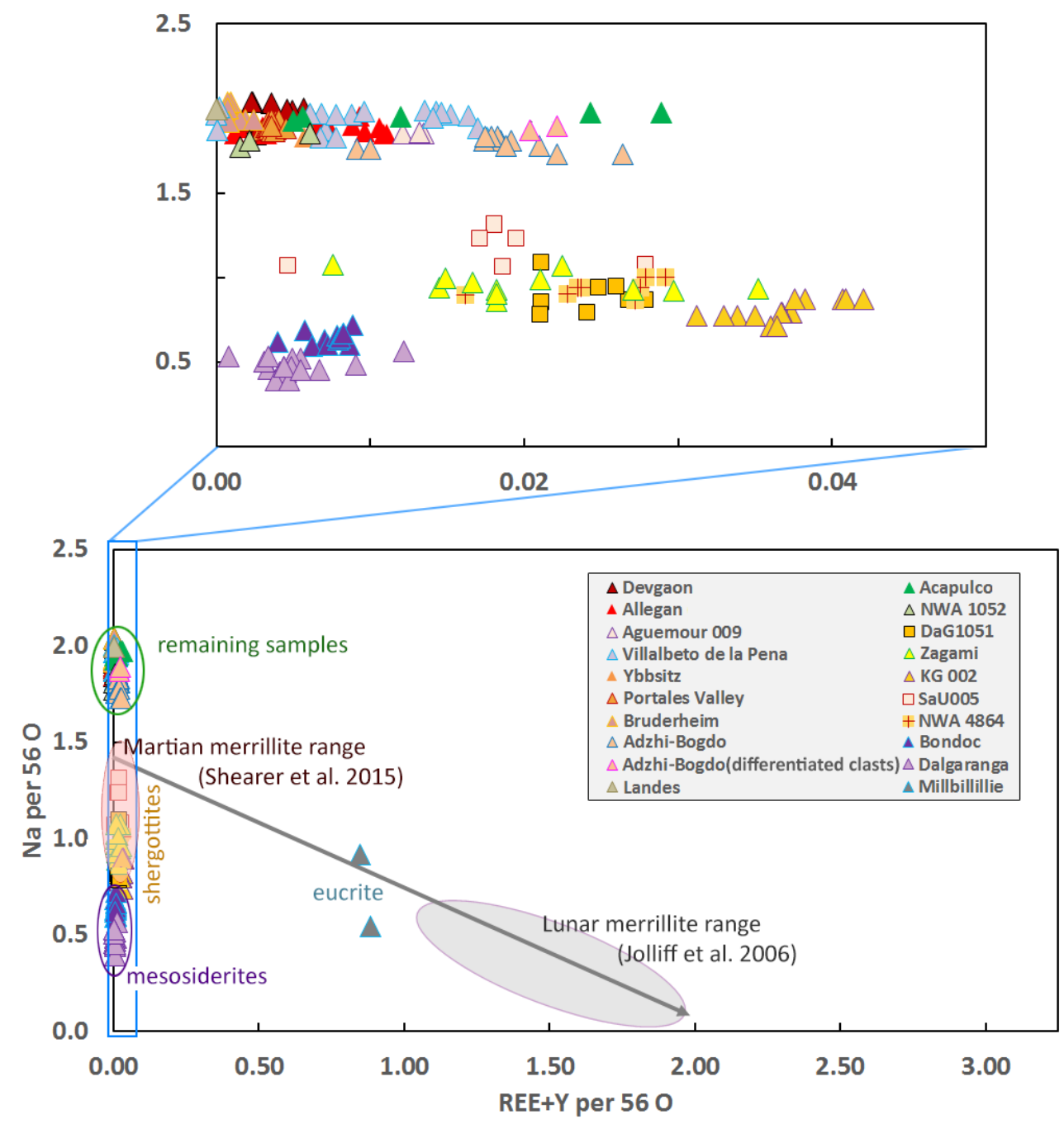

Figure 11

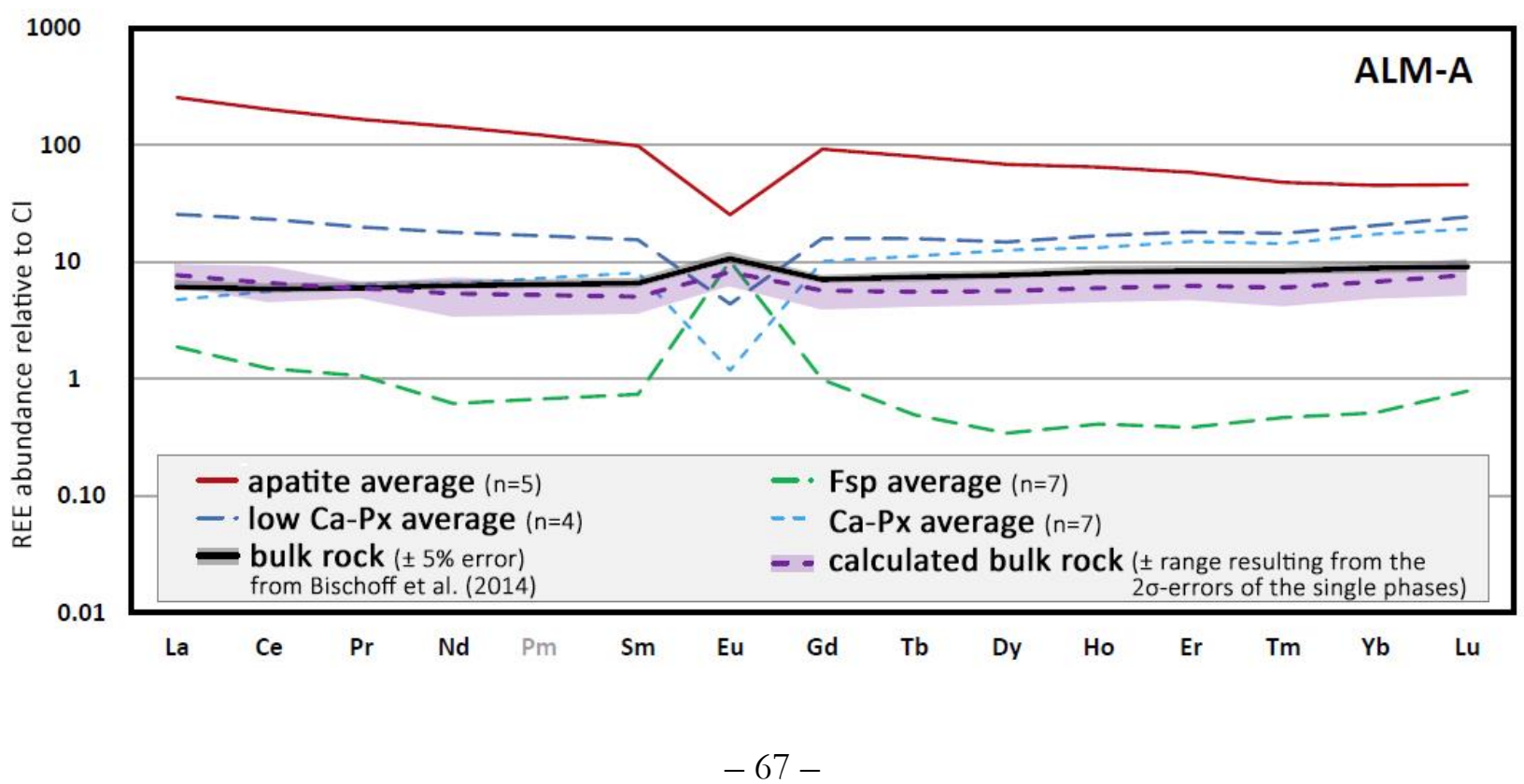


Figure 12

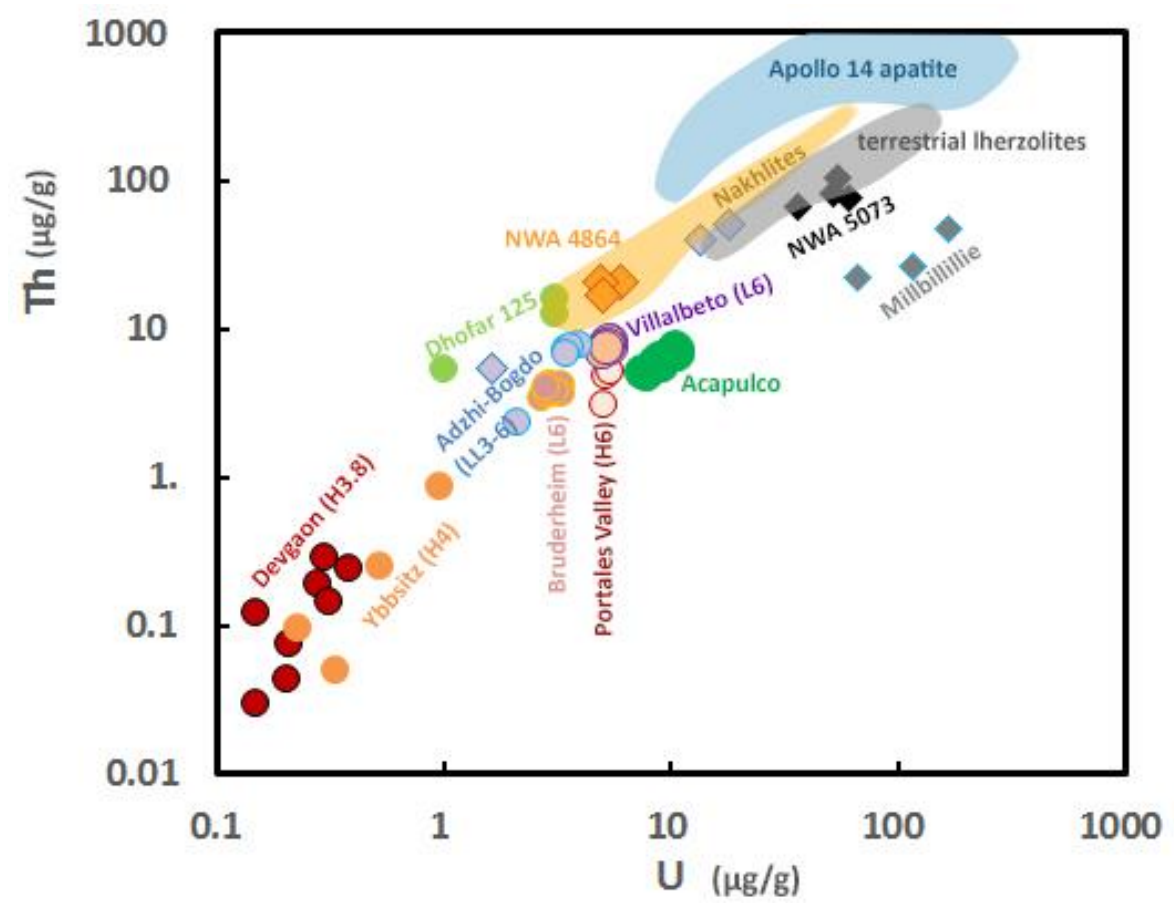

Figure 13
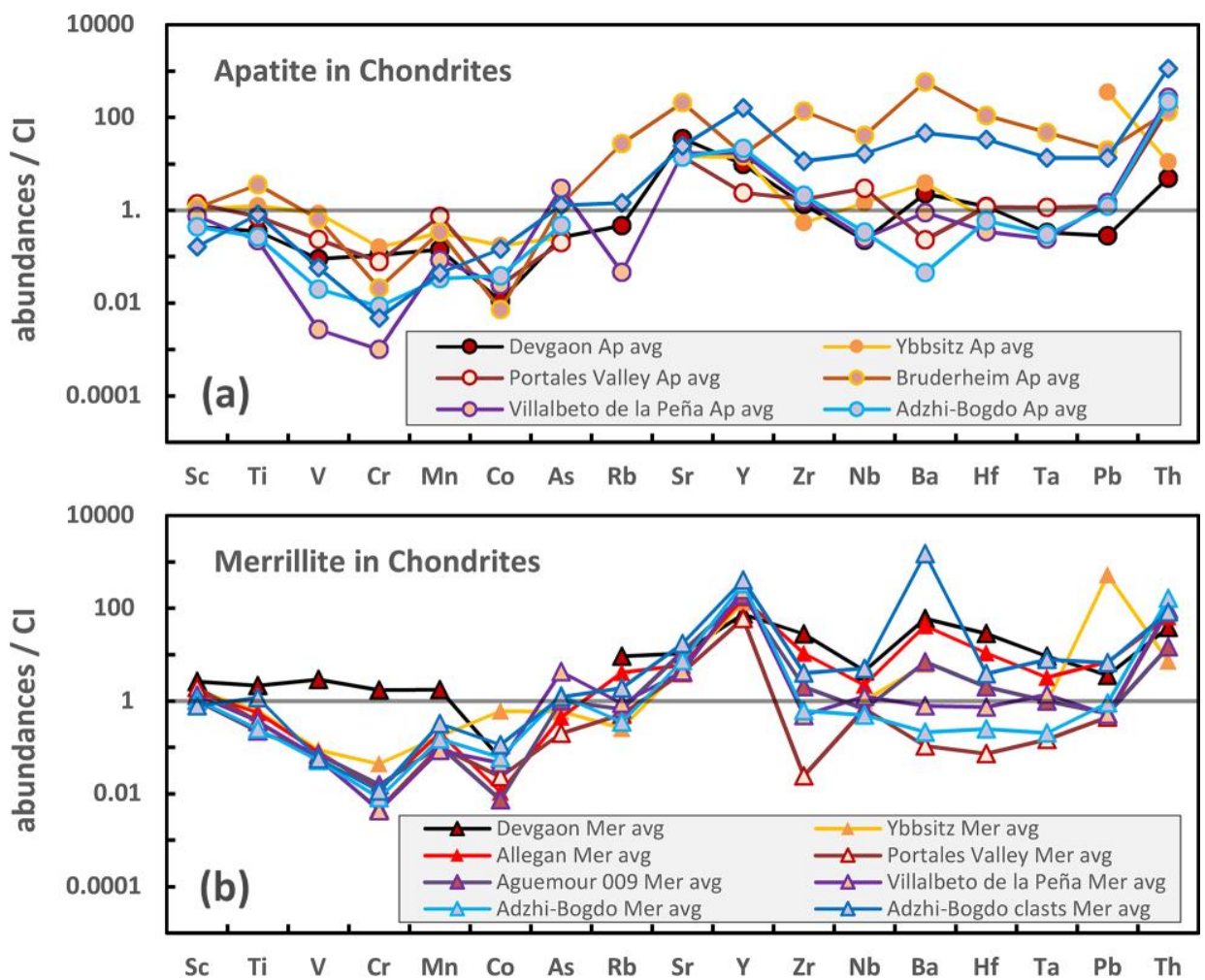
Figure 14
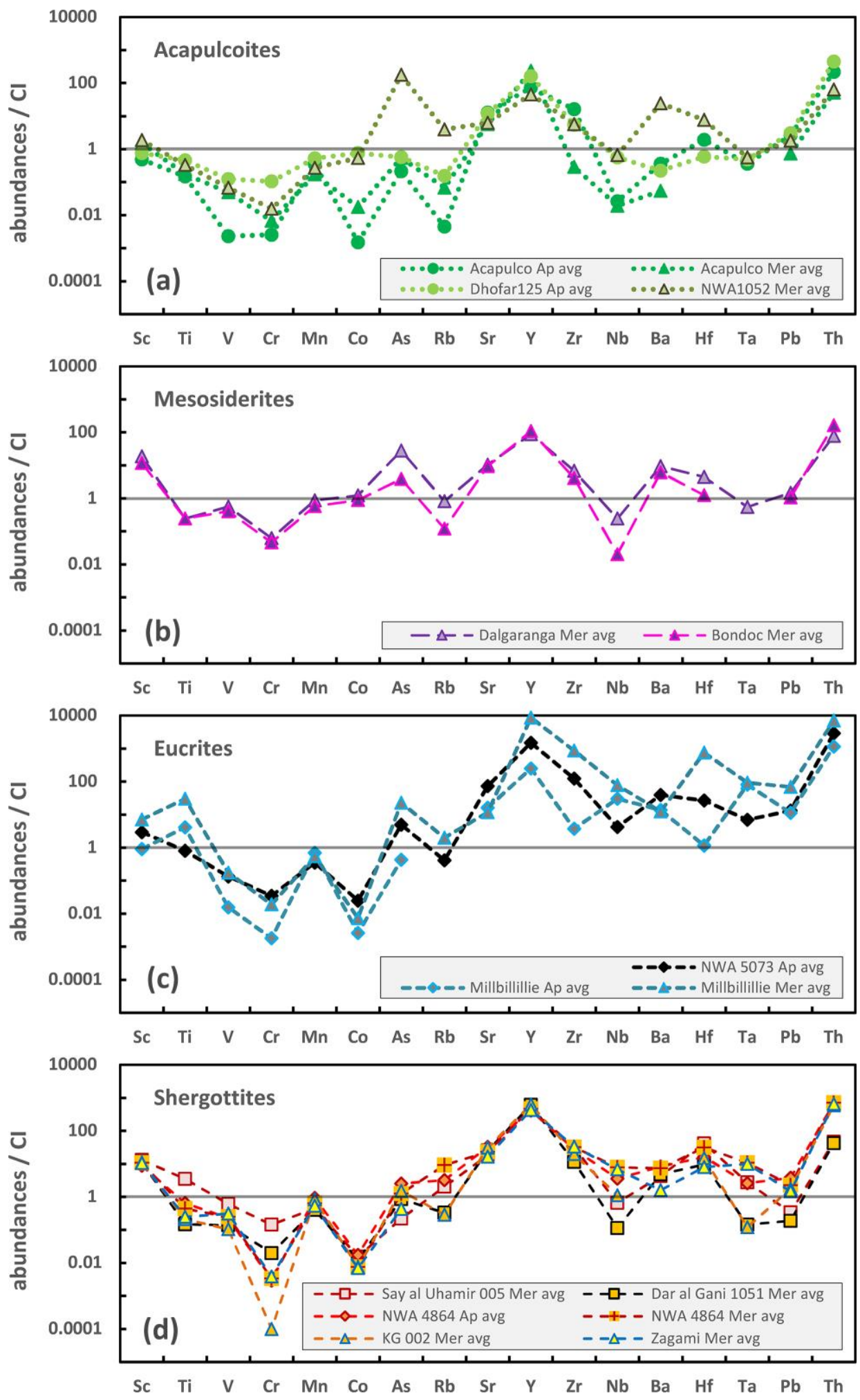